\title{
Exploring West Virginia diabetes educators' perceptions of and experiences with integrating Internet technology in their practice
}

\author{
Elizabeth Quintana \\ West Virginia University
}

Follow this and additional works at: https://researchrepository.wvu.edu/etd

\author{
Recommended Citation \\ Quintana, Elizabeth, "Exploring West Virginia diabetes educators' perceptions of and experiences with \\ integrating Internet technology in their practice" (2008). Graduate Theses, Dissertations, and Problem \\ Reports. 2865. \\ https://researchrepository.wvu.edu/etd/2865
}

This Dissertation is protected by copyright and/or related rights. It has been brought to you by the The Research Repository @ WVU with permission from the rights-holder(s). You are free to use this Dissertation in any way that is permitted by the copyright and related rights legislation that applies to your use. For other uses you must obtain permission from the rights-holder(s) directly, unless additional rights are indicated by a Creative Commons license in the record and/ or on the work itself. This Dissertation has been accepted for inclusion in WVU Graduate Theses, Dissertations, and Problem Reports collection by an authorized administrator of The Research Repository @ WVU. For more information, please contact researchrepository@mail.wvu.edu. 
Exploring West Virginia Diabetes Educators’ Perceptions of and Experiences with Integrating Internet Technology in their Practice

\section{Elizabeth Quintana}

Dissertation submitted to the College of Human Resources and Education at West Virginia University in partial fulfillment of the requirements for the degree of

\section{Doctor of Education}

in

Technology Education

Daniel Hartley, Ed.D.

Richard Iammarino, M.D.

Neal Shambaugh, Ph.D.

Jaci Webb-Dempsey, Ph.D.

Anne H. Nardi, Ph.D., Chair

Department of Technology, Learning, and Culture

Morgantown, West Virginia

2008

Keywords: diabetes education, technology integration, internet, empowerment, professional development

Copyright 2008 Elizabeth Quintana 


\begin{abstract}
Exploring West Virginia Diabetes Educators' Perceptions of and Experiences with Integrating Internet Technology in their Practice
\end{abstract}

Elizabeth Quintana

The purpose of the study was to explore how diabetes educators integrate Internet technology in their medical practice. The study focused on diabetes educators' perceptions and experiences using the Internet to provide diabetes education and how this educational strategy has influenced their diabetes educator-patient relationships.

Employing both quantitative and qualitative research methodologies, the research population of this study involved 41 diabetes educators working in West Virginia. The quantitative research method consisted of a survey with a series of correlational analyses to describe perceptions and use of computer and Internet that diabetes educators employed in their practice. The qualitative case study followed the quantitative design. Using maximum variation sampling strategy, five diabetes educators were purposively sampled. In-depth interviews were conducted at the educators' worksites. Case and cross-case analyses were conducted to answer how educators' perceptions and other factors relate to their integration of Internet technology in their practice.

The results from this research point to the following: educators shared a favorable view of Internet technology, integrated the Internet technology in their practice in a variety of methods, felt that computer use increased their productivity, and viewed their patients bringing information retrieved from the Internet as opportunities for additional education. Diabetes educators are becoming better consumers of online diabetes information. With the use of the Internet to interact with their patients more frequently, educators can extend the reach of counseling.

The study was limited to diabetes educators practicing in West Virginia. Diabetes educators practicing in urban other states may have different perspectives and experiences on how Internet technology could work for diabetes self-management. 


\section{ACKNOWLEDGEMENTS}

I would first like to thank the diabetes educators who participated in the study. Their willingness to share their perspectives and experiences made this study possible. All of the efforts of my committee members are greatly appreciated. Special thanks go out to Dr. Anne Nardi, who stepped in as chairman upon the departure of my previous chairman. Your willingness to take over this project toward the latter part of the endeavor is much appreciated. Thanks to my family for supporting me during the time we missed being together. Your encouragement helped me complete this special journey. 
Table of Contents

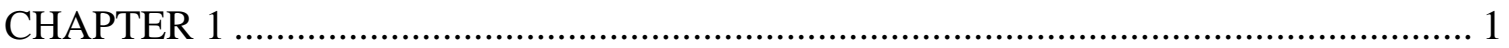

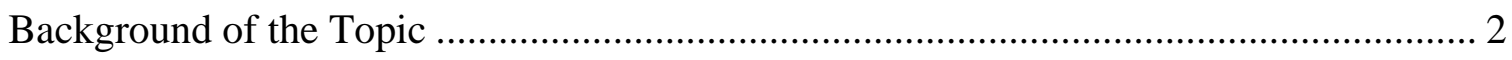

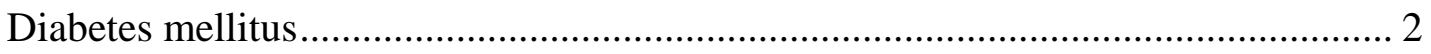

Diabetes self-management education................................................................. 3

Diabetes education in rural communities.......................................................... 6

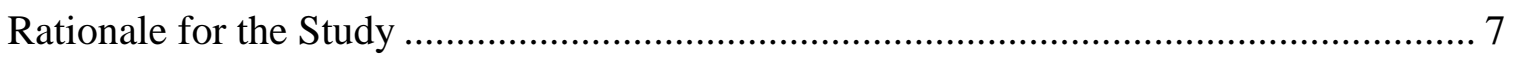

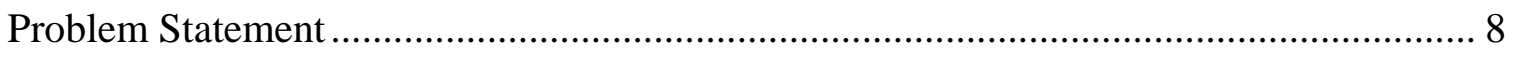

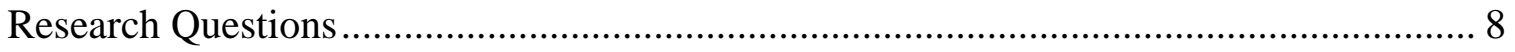

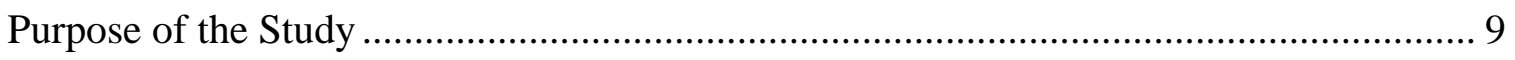

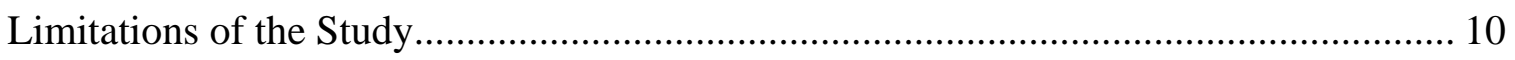

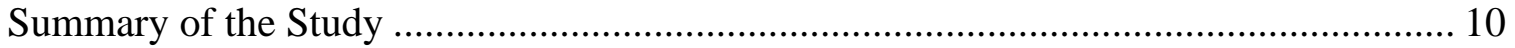

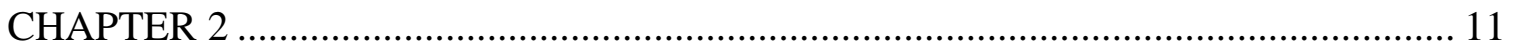

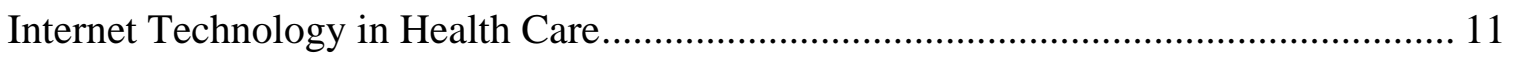

Using Internet Technology for Diabetes Education and Care ...................................... 13

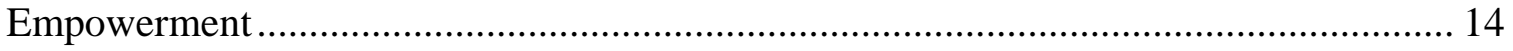

Impact of the Internet on the Educator-Patient Relationship ..................................... 17

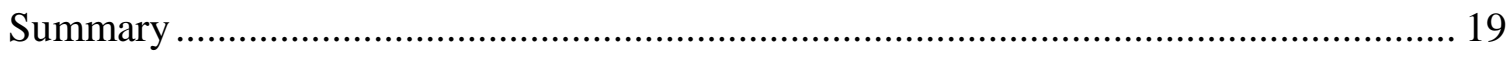

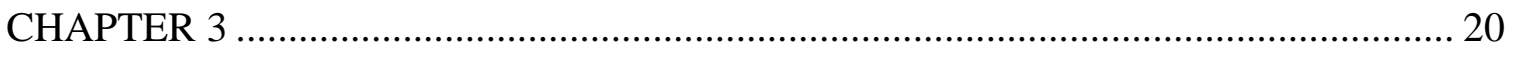

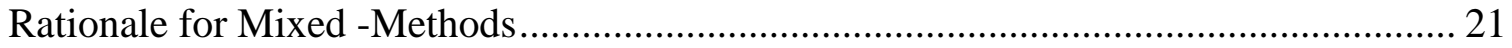

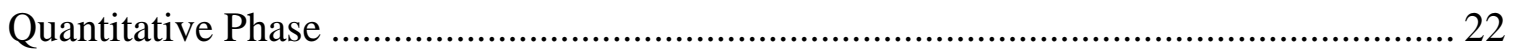

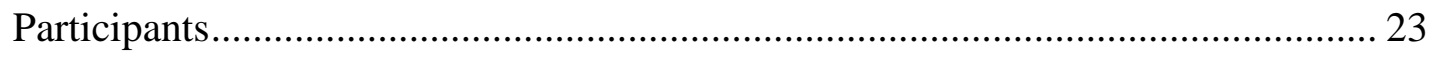

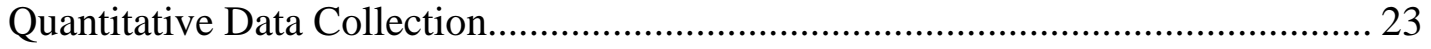

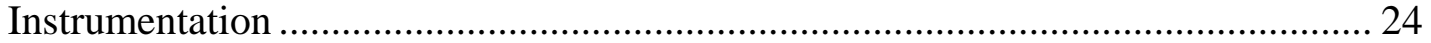

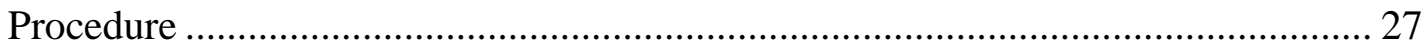

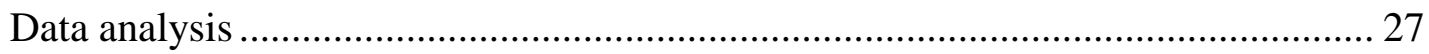




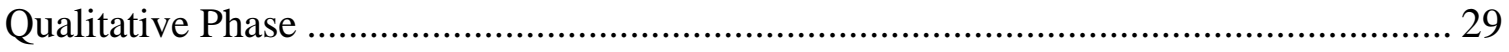

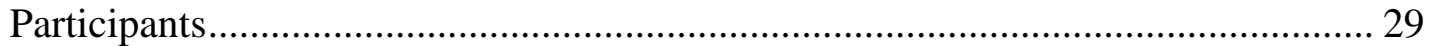

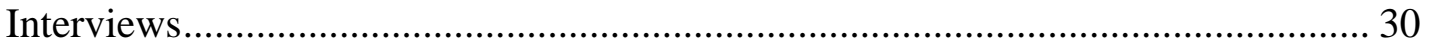

Qualitative Data Collection................................................................................ 30

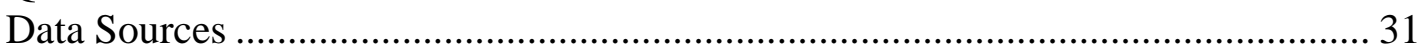

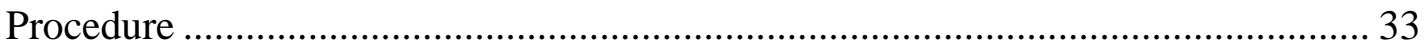

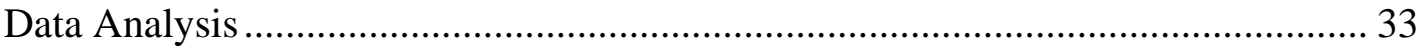

Summary of Research Methods .................................................................................. 34

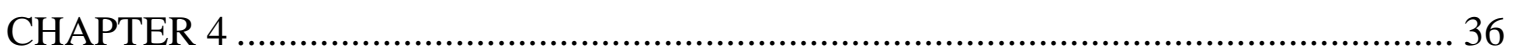

Quantitative Method: Results ................................................................................. 37

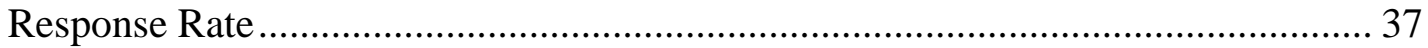

Demographic Data ……………………............................................................ 37

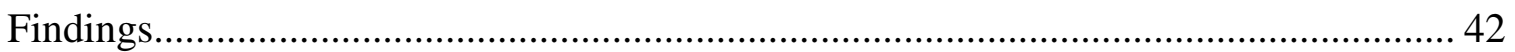

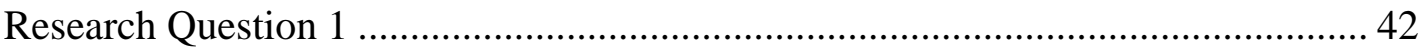

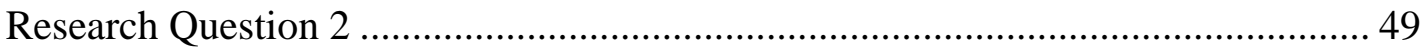

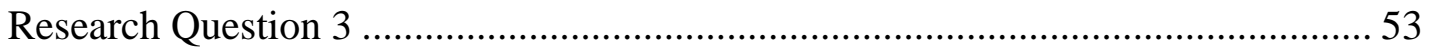

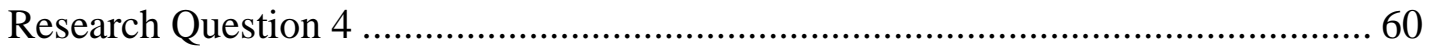

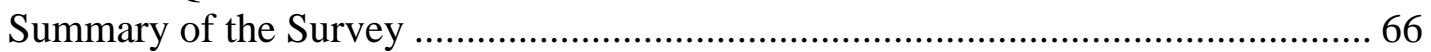

Qualitative Method: Results ........................................................................................ 67

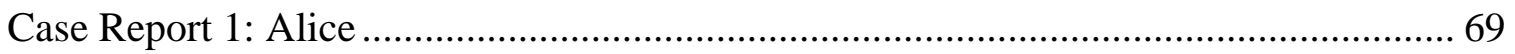

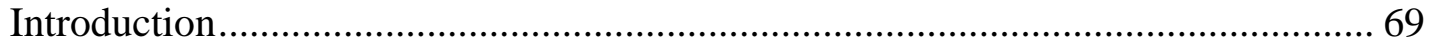

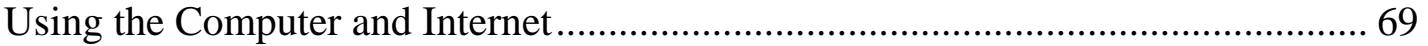

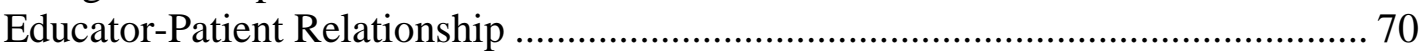

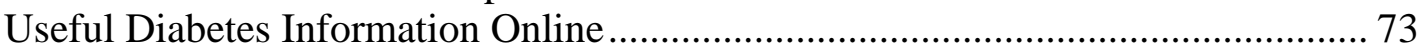

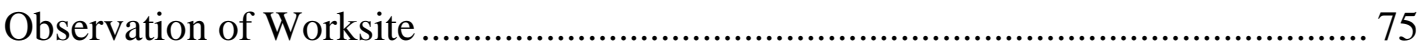

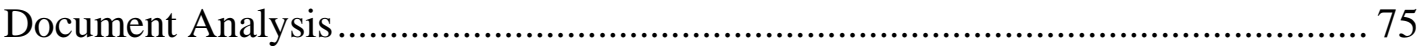

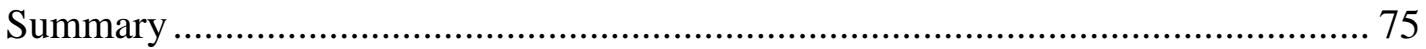

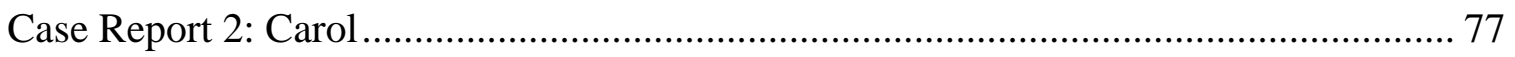

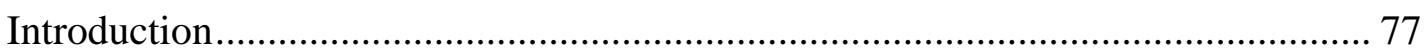

Using the Computer and Internet............................................................................ 77

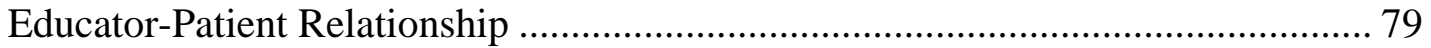

Useful Diabetes Information Online ..................................................................... 81

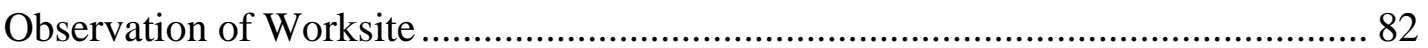

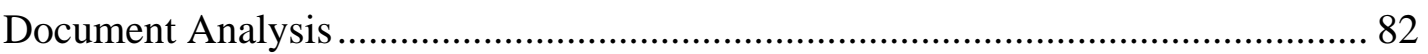

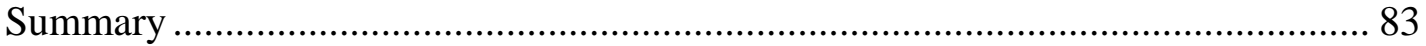




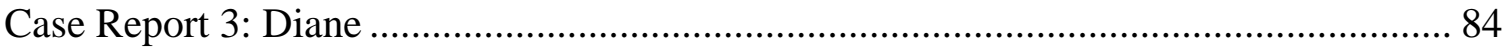

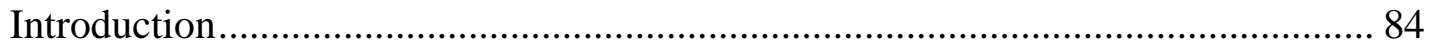

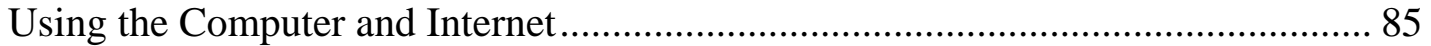

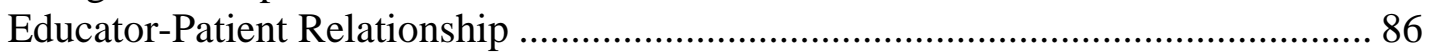

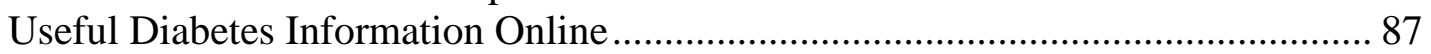

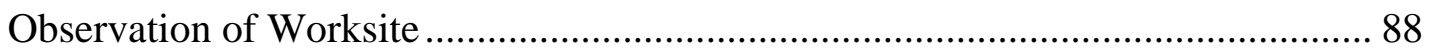

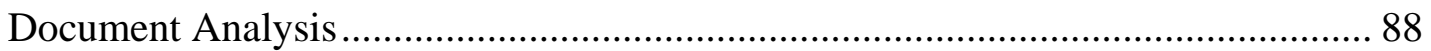

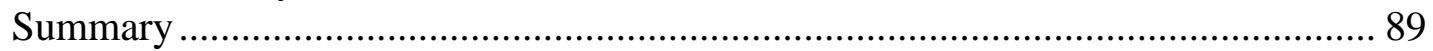

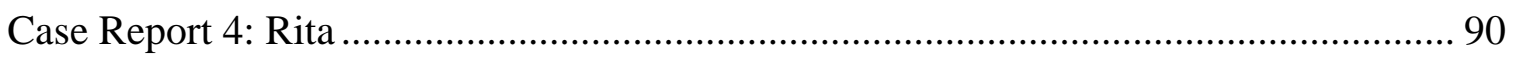

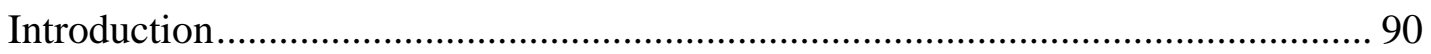

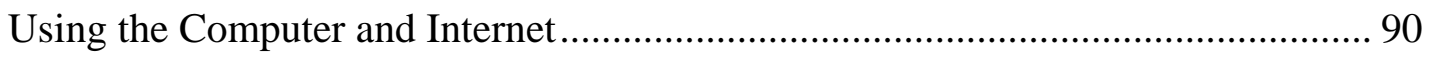

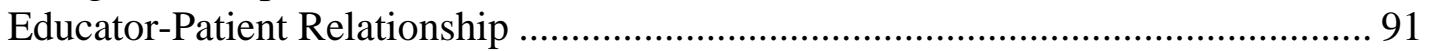

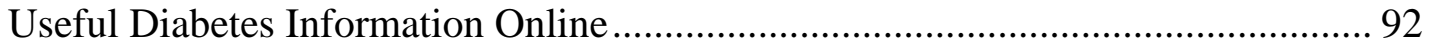

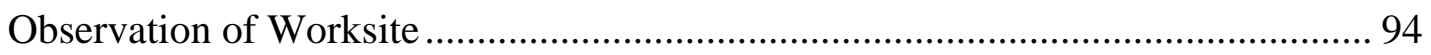

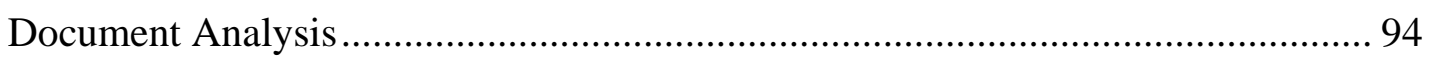

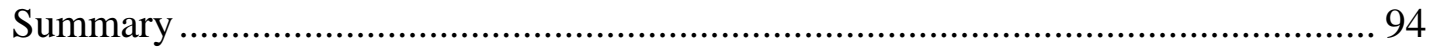

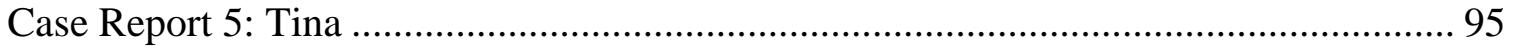

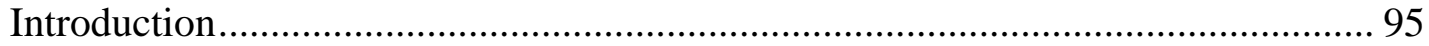

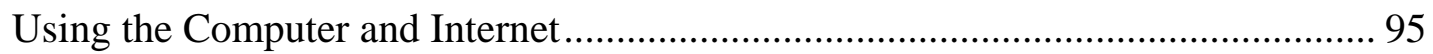

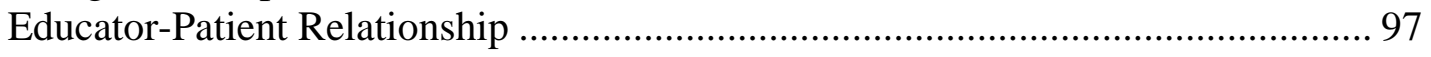

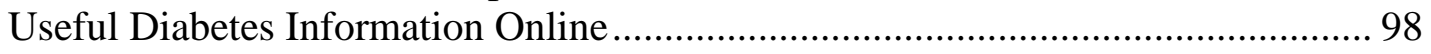

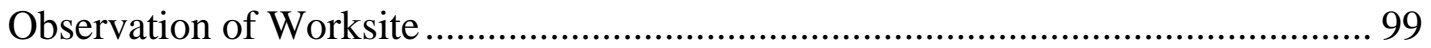

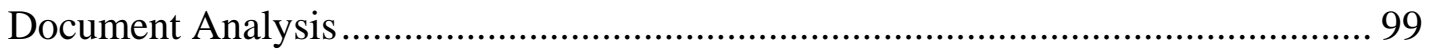

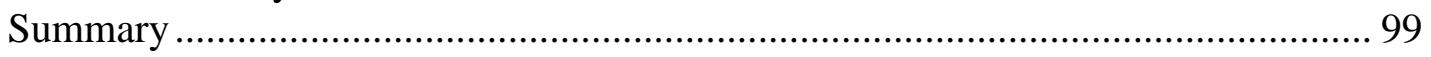

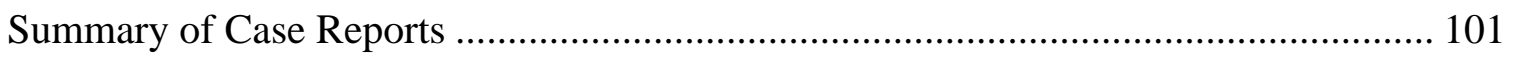

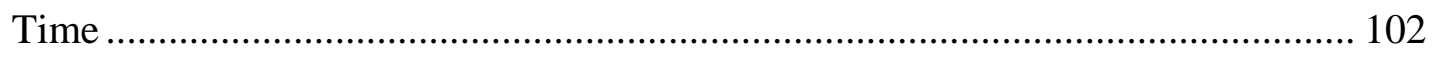

Quality of Diabetes-Related Information on the Internet ................................... 102

Use of the Computer and Internet in their Practice.............................................. 103

Observation of Worksite .............................................................................. 107

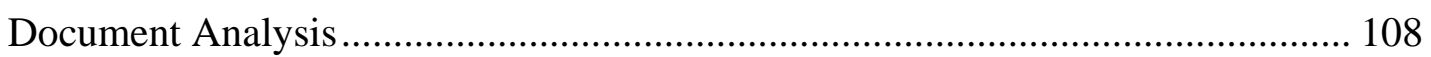

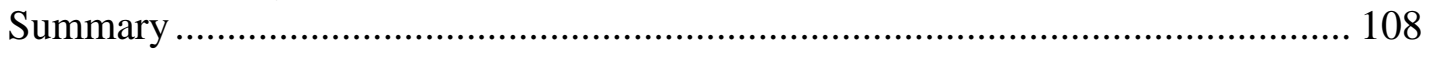

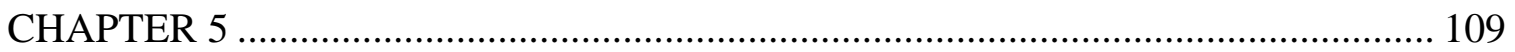

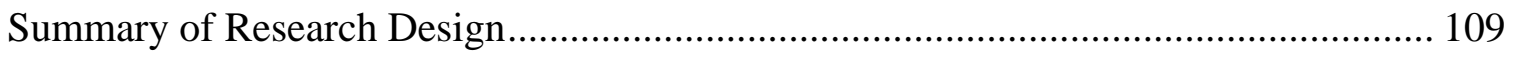

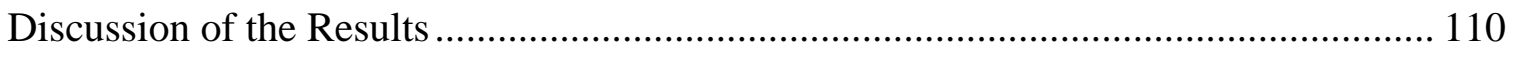

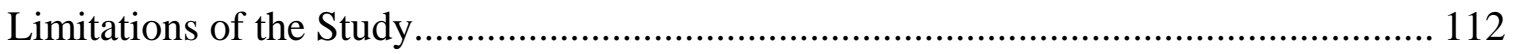

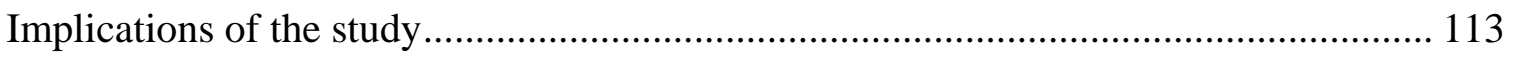

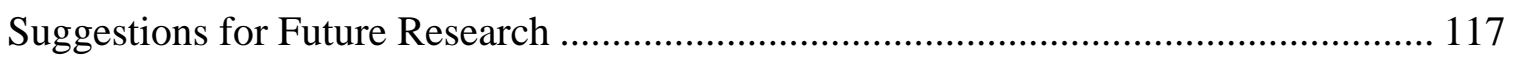


References.

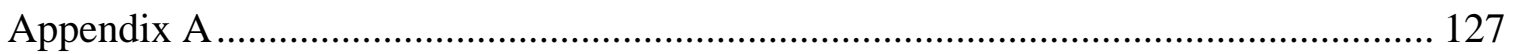

West Virginia University Internal Review Board.................................................. 127

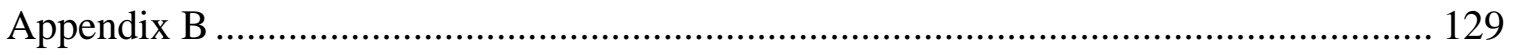

Survey Packet: Cover Letter and Survey ........................................................... 129

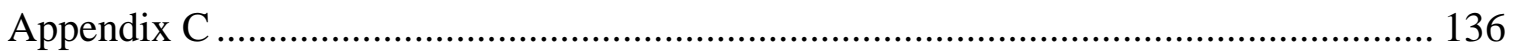

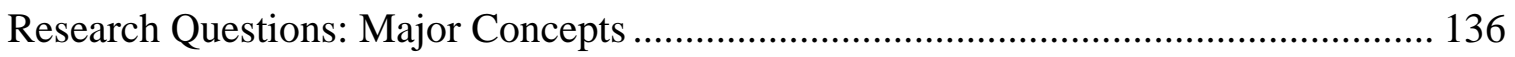

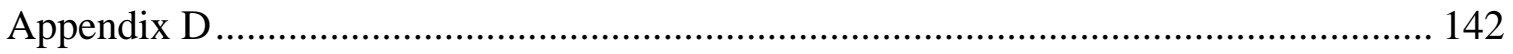

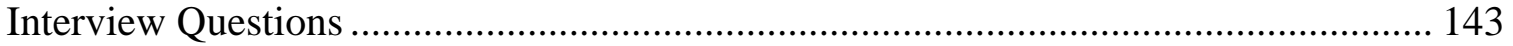

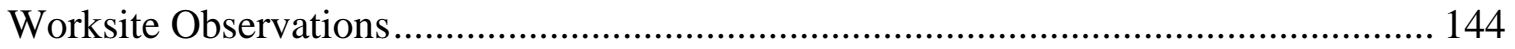

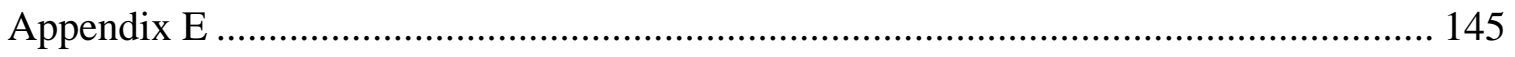

SMOG Readability Calculations for AADE Reviewers ............................................ 145

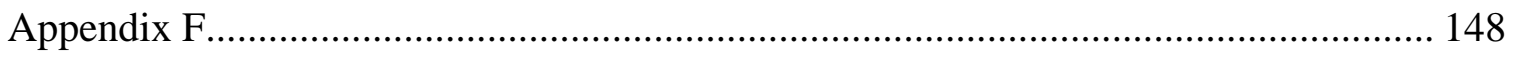

Q4 I have adequate training in using computers.................................................... 148

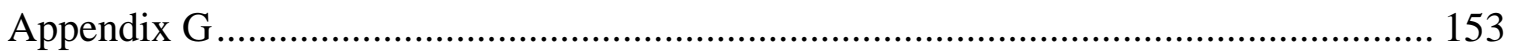

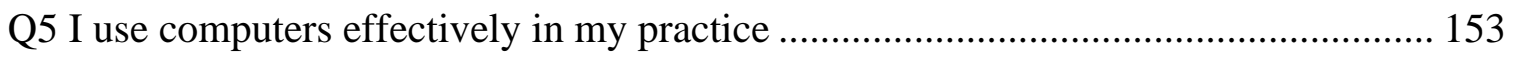

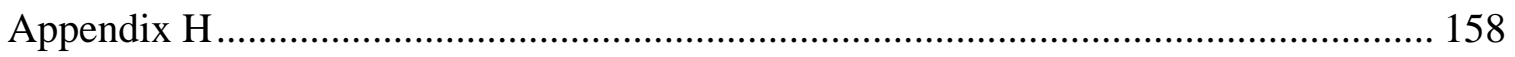

Q18 The quality of diabetes-related information on the Internet for health are

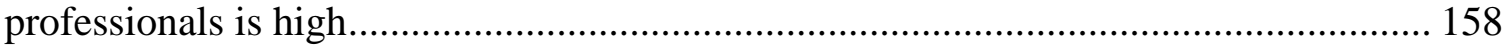

Q19 The quality of diabetes-related information on the Internet for consumers is high 158

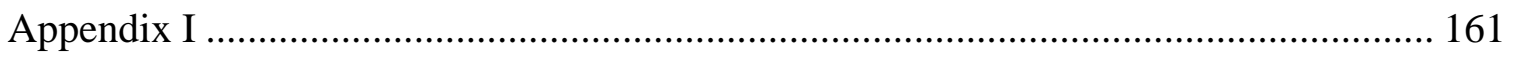

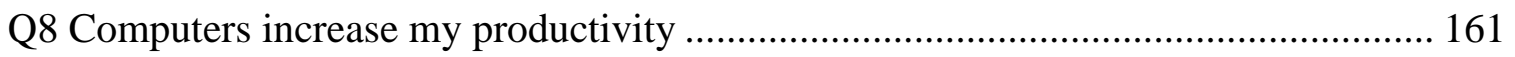

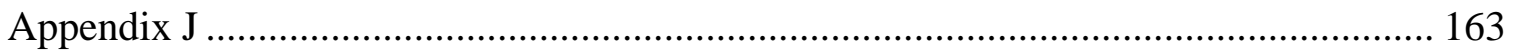

Q11 Learning computers makes high demands on my time........................................ 163

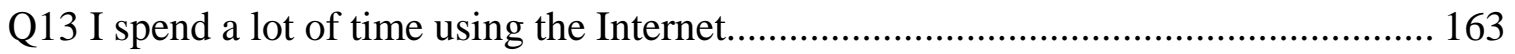

Q15 I have difficulty finding time to search for information online ........................... 163

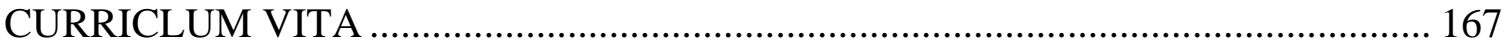


Table of Figures

Figure 1. Visual Model of Seqential Mixed Methods ............................................... 31 


\section{List of Tables}

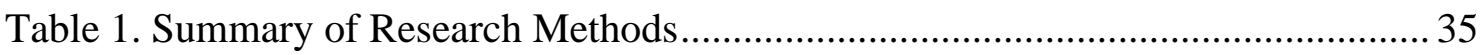

Table 2. Professional Status of Survey Participants ............................................... 38

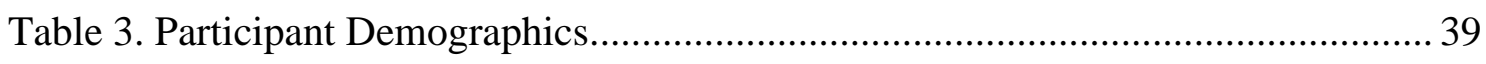

Table 4. Diabetes Education Experience and Worksites ........................................ 41

Table 5. Years Using the Internet for Diabetes Information ..................................... 41

Table 6. Using the Computer and Internet in My Profession ..................................... 44

Table 7. I Use Computers Effectively in My Practice (Q5) ....................................... 46

Table 8. The Internet has Enhanced My Professional Effectiveness (Q16) ................. 48

Table 9. Using the Internet in Your Practice as a Diabetes Educator............................ 51

Table 10. What Information on Diabetes Web Sites Have You Found Useful in Your

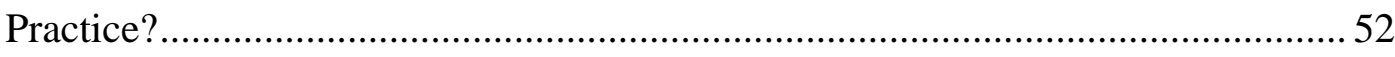

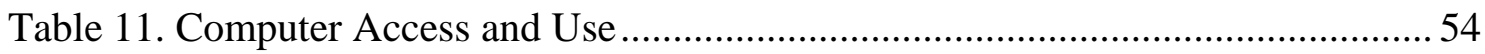

Table 12. I Have Adequate Training in Using Computers (Q4).................................. 55

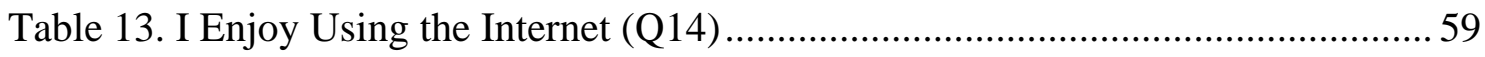

Table 14. Have Patients Ever Approached You with Information that They Got from the

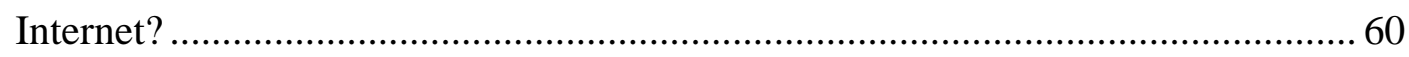

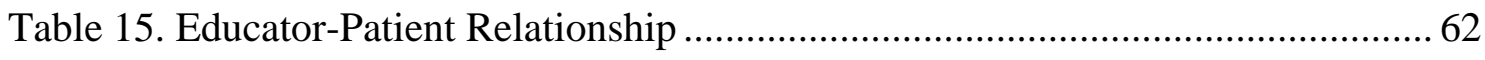

Table 16. I Refer My Patients to Specific Diabetes Web Sites (Q64).......................... 64

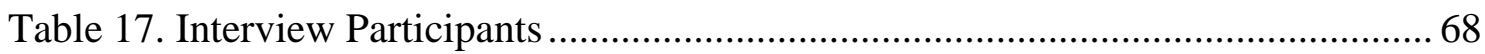




\section{CHAPTER 1}

Introduction

Computers have become an integral part of health care. The most current health care information is readily accessible from the Internet. Health care professionals and clients have become consumers of Internet technology. As the Internet becomes an increasingly important resource for making decisions about health care, it has the potential to improve information dissemination, health care delivery, and clinical outcomes (Baker, Wagner, Singer, \& Bundorf, 2003; Kaiser Family Foundation, 2005).

The rapid development of health care information has a profound impact on the way people think, how they relate to one another, and how they process information. Health care professionals routinely retrieve information from the Internet. Clients often use the information accessed online to supplement their offline care (Madden \& Rainie, 2003; Stoop, van’t Riet, \& Ber, 2004).

Certified Diabetes Educators (CDE) are faced with increasing numbers of patients with diabetes. They must create, process, and disseminate large amounts of information. As more diabetes information and materials become available online, diabetes educators must place a greater reliance on the Internet for educational and informational resources (Fox, Anderson, \& Rainie, 2005; Lewis, 2001; Mazzi, \& Kidd, 2002).

The Internet has also been a useful resource for many of the patients in diabetes self-management programs. Self-management has long been the focus of chronic disease management. The primary purpose of diabetes self-management education is to prepare people with diabetes to make informed decisions about their own diabetes care. 
Anderson and Funnell (2000) feel that effective patient education serves to empower people with diabetes to achieve optimal blood glucose control to avoid and delay the onset of complications. Information found online might help to promote better understanding and application of the diabetes self-management education process.

Anderson and Funnell (2000) feel that diabetes educators are committed to establishing empowering relationships with the patients they serve. Together, they establish individualized education and treatment plans for diabetes care. Franz (2003) agrees that diabetes educators provide information, strategies, and support to help patients make informed decisions and appropriate behavior changes concerning their diabetes care.

Due to limited patient contact time, diabetes educators must look for effective educational strategies to enhance the self-management education process. They can supplement the education process by putting their patients in touch with quality diabetes information available on the Internet. They can play an important role in encouraging patients to gain access to information that would support their efforts in making the necessary lifestyle changes. Diabetes educators’ perception of the usefulness of online diabetes resources can influence their patients’ clinical outcomes.

\section{Diabetes mellitus}

\section{Background of the Topic}

Diabetes mellitus is a complicated, chronic, systemic disease, characterized by elevated blood glucose levels resulting from defects in insulin secretion, insulin action, or both. When left poorly treated, the abnormalities in the metabolism of 
carbohydrates, proteins, fats and insulin may result in damage to various body tissues and organs leading to devastating complications (Franz, 2003).

Patients with diabetes must modify lifestyle behaviors, such as diet modifications and regular physical activity to achieve optimal blood glucose control. They must maintain vigilance to identify symptoms of any emerging health crisis. They are often expected to adhere to frequent blood glucose monitoring and complex medication schedules. Not surprisingly, many patients have difficulty meeting the demands of their illness and experience poor outcomes (Piette, Schillinger, Potter, \& Heisler, 2003).

According to the Centers for Disease Control and Prevention (2008a, 2008b), diabetes is becoming more common in the United States. From 1980 through 2007, the number of Americans diagnosed with diabetes more than tripled (from 5.6 million to 17.9 million). The prevalence is expected to double by the year 2050 .

The Diabetes Prevention Program Research Group (2002) demonstrated that participants (all of whom were at increased risk of developing type 2 diabetes) who made lifestyle changes reduced their risk of developing type 2 diabetes by 58 percent. The lifestyle intervention program, conducted by diabetes educators with 3234 participants at multiple sites, proved to be significantly more effective than medication. Diabetes self-management education

The primary purpose of diabetes self-management education is to prepare people with diabetes to make informed decisions about their own diabetes care. Diabetes selfmanagement education is both science and art in the realms of education and behavioral counseling. Designing a diabetes self-management education program requires the 
selection of appropriate goals and objectives and then determining the level of comprehensiveness. The diabetes educator must decide what materials to include and in what depth (Walker, 1999).

Diabetes educators are health professionals, nurses, dietitians, pharmacists, exercise specialists, physicians, and social workers, who specialize in the education and treatment of people with diabetes. They help people with diabetes learn to live a healthier, more productive life. They work in a variety of settings. They work in hospitals teaching patients in small group classes or may work with patients individually. They also work in doctor's offices, nursing homes, and neighborhood clinics. They may be available when a patient with diabetes is first diagnosed to help the patient to learn new skills (Franz, 2003).

Diabetes educators must have a clear understanding of the pathophysiology of diabetes in order to provide in-depth information about its symptoms and metabolic effects. They must be knowledgeable of the actions of nonpharmacologic and pharmacologic therapies for diabetes in order to provide both information and clinically appropriate care. They must also understand the interactions of food, activity, medications, and blood glucose levels for decision-making and to prepare persons with diabetes for self-management. With the knowledge of the pathogenesis of the complications of diabetes, they teach patients about the modifiable risk factors and symptom recognition for early prevention and treatment (Franz, 2003; American Association of Diabetes Educators, 2005).

How diabetes knowledge and skills are taught can have as much impact on patient outcomes as what is taught. The instructional design of a diabetes self- 
management education program can affect the patient's acquisition of knowledge and skills, their attitudes about diabetes, their motivation to practice appropriate diabetes self-care, their willingness and ability to make behavioral changes, and their degree of psychosocial adjustment to diabetes (Anderson \& Funnell, 2000; Franz, 2003).

Learning is reinforced and retained when it can be applied immediately and repeatedly. Diabetes educators help patients to retain knowledge and skills by providing opportunities for applications and feedback. They reinforce the idea that the patients are persons who can master diabetes self-care skills (Franz, 2003; Walker, 1999).

Diabetes education is a process designed to respond to patients' evolving needs. Diabetes educators help patients to identify obstacles that hinder progress. They train patients to translate and apply relevant medical information in problem solving. These are the skills that people with diabetes will need in order to be successful over the longterm. (Zamudio, 2005).

The vision and skills of diabetes educators are central to the success of the educational and counseling endeavor. Vision speaks of values, purpose, and role definition of the diabetes educator. Theories and methods help educators with the "how" of their work. Before they ask how they accomplish our work, they need to have a vision of "what" they are trying to do. Research in diabetes education can provide the tools to enable diabetes educators to do their work, to help patients make informed selfdirected diabetes management decisions. The diabetes educators' vision, nurtured and deepened by reflective practice, is considered the ever-changing lifelong commitment to learning the art of diabetes education (Anderson \& Funnell, 2000). 


\section{Diabetes education in rural communities}

After surveying Diabetes Control Program Coordinators in all fifty states, Powell et al. (2004) report that health care professionals working in rural areas face many barriers in providing diabetes education services. One of the top perceived barriers to the provision of diabetes self-management education was limited resources. From a 2003 study of medically underserved communities, the Centers for Disease Control and Prevention (CDC) emphasize how rural health providers who pooled their resources are better able to increase the availability of diabetes education services over the long term. Recommendations include encouraging health care providers to use computers for easier access to current information.

The Behavioral Risk Factor Surveillance System reports that the nationwide prevalence of diabetes is estimated at 8.1 percent with West Virginia ranking the third highest (10.8 percent) among the 50 states (the Centers for Disease Control and Prevention, 2008a). In the Diabetes Strategic Plan for 2002-2007, the West Virginia Department of Health and Human Resources (n.d.) emphasizes that West Virginia is the second most rural state in the nation. The state has 64 percent of its population living in communities of fewer than 2,500 people. West Virginia's mountainous regions and limited road infrastructure present challenges associated with geographic distance. Through collaboration with the West Virginia Association of Diabetes Educators, the number of certified diabetes educators in the state has almost doubled. The use of satellite training programs is expected to expand educational opportunities even further (National Center for Chronic Disease Prevention and Health Promotion, 2005). 
In the 2007-2012 Library Services and Technology Act Five Year Plan, the West Virginia Library Commission (n.d.) is mandated to expand access to information technology for citizens of West Virginia. The Statewide Library Network (SLN) is the infrastructure that enables community-based libraries to play a role in providing convenient, reliable access to the Internet to adequately meet the information needs of unserved and underserved residents. The current technology support and maintenance efforts are to be improved by expanding bandwidth and upgrading hardware, subsidizing library automation system upgrades and maintenance, providing regionally based technology support and training, and assuming telecommunications costs for public libraries. Funding from the Electronic Telecommunications Open Infrastructure Act (ETOPIA) would encourage local governments to build the technology infrastructure to develop and strengthen telecommunications and data processing hardware, software and services for both government and private use (Center for Policy Alternatives, 2006). Internet technology may offer new and innovative ways to meet the educational needs of educators and their patients while reducing travel time and cost.

\section{Rationale for the Study}

Working in a rural state, such as West Virginia, diabetes educators face limited access to other diabetes educators and diabetes educational materials. To expand their resources, diabetes educators in West Virginia may benefit from utilizing Internet technology to communicate and collaborate with other health care providers. They can access current relevant diabetes care and education materials available online. 
An in-depth study of diabetes educators’ views and experiences with Internet technology integration in their medical practice would provide insight into how diabetes educators utilize this educational strategy in their medical practice. Although prior studies of diabetes educators document a generally favorable attitude toward computer use for patient education, little data exist regarding the diabetes educators’ perspectives toward integrating Internet technology in the diabetes self-management education process.

\section{Problem Statement}

The purpose of this study is to explore and describe the views and experiences of West Virginia diabetes educators with Internet technology in their medical practice. The study attempts to explore the diabetes educators’ perception and utilization of Internet technology to help provide diabetes education and how this educational strategy has influenced their diabetes educator-patient relationship.

\section{Research Questions}

How do diabetes educators perceive their role as consumers of Internet technology?

The following four associated research questions will help frame the focus of the study:

1. How do diabetes educators perceive using the Internet in their medical practice?

2. How do diabetes educators integrate Internet technology in their medical practice?

3. How do diabetes educators working in rural areas of West Virginia differ from diabetes educators working in larger communities in West Virginia in utilizing Internet technology in their medical practice? 
4. How do diabetes educators perceive the impact of Internet technology on their educator-patient relationship?

\section{Purpose of the Study}

The study is designed to investigate the perspectives and experiences of West Virginia diabetes educators in integrating Internet technology in their practice. Internet technology may enable diabetes educators working in rural areas to gain access to communication and educational materials.

This investigation is to consider the diabetes educators' perceptions, opinions, feelings, knowledge, comfort levels, and experiences as they relate to Internet technology integration in the diabetes self-management education process. Investigating how diabetes educators perceive their role as consumers of Internet technology improves the understanding of how likely they integrate this educational strategy in their medical practice. This study is designed to examine how diabetes educators in more rural areas of West Virginia have benefited from Internet technology. This study also considers the diabetes educators' perception of how Internet technology has impacted their educator-patient relationship.

Results of this study may provide insight into how diabetes educators have applied this educational strategy to accomplish their educational goals to improve their patients' clinical outcomes. This study may have implications for other health care professionals working in rural communities, providers of diabetes-related products and services, and instructional technology designers who are interested in improving the diabetes self-management education process through effective integration of Internet technology. 


\section{Limitations of the Study}

Participants of this study are diabetes educators who practice in West Virginia. Since selected participants come from West Virginia, diabetes educators from other states would be excluded. The results of the study may be only generalized to diabetes educators working in West Virginia or other comparable rural states. Since Internet technology is available in communities of all sizes, it would be expected that part of the results might be applicable to diabetes educators working in other states who integrate Internet technology in their practice. Researcher bias may also influence the results of the study. The investigator of the study is a Certified Diabetes Educator who frequently relies on Internet technology in her practice.

\section{Summary of the Study}

This first chapter explains the relationship of perceptions and experiences of diabetes educators and Internet technology in the diabetes self-management education process. The purpose of the study is to describe the diabetes educators' perspectives and experiences in integrating Internet technology in their medical practice. This study is significant in that its focus on the visions and concerns of diabetes educators working in West Virginia who integrate Internet technology in their diabetes self-management education programs may provide useful information about the use of information technologies in rural areas to enhance medical care. The ways in which diabetes educators utilize the Internet, as well as the influences of technology on the diabetes educator-patient relationship are also explored. 


\section{CHAPTER 2}

\section{Literature Review}

This literature review surveys pertinent studies and perspectives on the use of Internet technology for health care. Initially, an overview of the increasing utilization of Internet technology for health care information is presented. The focus then shifts to the role the Internet plays in chronic disease management for diabetes educators, their patients, and its impact on the educator-patient relationship.

\section{Internet Technology in Health Care}

Anderson, Rainey, and Eysenbach (2003) felt that information technology is changing the focus of medicine from curing disease to prevention of disease and enhancing health status. The researchers estimated that nearly 100 million US adults go online and over half of them reportedly use the World Wide Web to access healthrelated information. The Internet has become one of the most popular and frequently used sources of health care information.

Fox (2005) reported that approximately 80 percent of 537 adults responding to a survey have looked online for health information. This Pew Internet \& American Life Project found Internet users, who looked for health information online, were interested in diet, fitness, drugs, health insurance, and experimental treatments. Fox and Rainie (2002) noted in an earlier Pew Internet Project that more people (about six million Americans) go online for medical advice on any given day than actually visit health professionals. 
Fox, Anderson, and Rainie (2005) concluded that the increasing use of online medical resources could yield substantial improvement in many pervasive problems now facing health care. These concerns included rising health care costs, poor customer service, high prevalence of medical mistakes, malpractice concerns, and lack of access to medical care for many Americans.

In a national survey of 60,000 households, approximately 40 percent of 4,764 respondents with Internet access reported using the Internet to look for advice or information on health or health care (Baker, Wagner, Singer, and Bundorf, 2003). About half of these respondents had at least one chronic disease, specifically heart problems, cancer, diabetes, hypertension, or depression. The respondents indicated that using the Internet improved their understanding of their chronic condition. Among those without any of the five chronic diseases, 67 percent said that the use of the Internet improved their understanding of health care issues.

Approximately 1,980 adults with chronic diseases (heart problems, cancer, diabetes, hypertension, and depression) participated in a health survey (Wagner, Baker, Bundorf, and Singer, 2004). Forty percent of 244 people with diabetes felt that the Internet had improved their ability to manage their condition. The researchers emphasized that certain attributes of the Internet make it particularly appealing for patients with chronic diseases. The cost of distributing information on the Web is low. People in rural areas and those with disabilities can access relevant health information from the Internet.

The 163 subjects who recently registered for access to their health provider's web site responded to a survey on information technology acceptance. Wilson and 
Lankton (2004) noted that patients who are satisfied with their current health care, those who prefer to seek information about their health care, and those who are already dependent on the Internet tend to accept information delivered online. They use the Internet to expand and augment interactions with their health care provider.

\section{Using Internet Technology for Diabetes Education and Care}

Lewis (1994) provided insight regarding diabetes educators’ attitudes toward computer based patient education. The randomly selected 300 certified diabetes educators, who were also American Association of Diabetes Educators (AADE) members, completed the Stages of Concern Questionnaire and reported that they had little experience with computers. Although their primary concerns were informational, their attitude toward computer-based patient education was generally positive. The diabetes educators did not use computer-based patient education. The educators who had access to computers at work or home used them less than two hours per week. The diabetes educators, who were not using computers, expressed interest in how the innovation would impact them personally. They also reported a failure to view patients as adequately prepared to use these applications. The primary implications of Lewis's study were related to the development of intervention strategies for the implementation of computer-based patient education programs.

Although computer-based education has been found to be an effective strategy for transfer of knowledge and skill development for patients, Lewis (2001) found that diabetes educators have been slow to adopt computer-based methods. In this study, Lewis randomly selected 279 certified diabetes educators and members of AADE to complete the Attitudes Toward Patient Education Technology instrument. Descriptive 
findings indicated that most diabetes educators (89.6\%) had access to computers and used them primarily for word processing (43\%). Nearly 30 percent of the participants had never accessed the Internet. Age and gender were not predictors of computer use. Access and organizational issues were the primary barriers to computer use in diabetes education. The potential of computer-based diabetes education to serve as a useful tool would not be realized unless diabetes educators become comfortable with the technology.

Vinicor (2004) promoted broadening the definition of the "office." Given that people with diabetes spend so much more time outside the office or clinic—at home, work, or play—than in direct contact with health professionals, diabetes educators may need to extend their educational and management efforts initially provided in the office into the world of the patient. Internet technology is one of the present efforts to expand the traditional office to bring medical information directly to the patient. Using information from the Internet in this fashion could be considered making a 21st-century house call.

Internet technology allows for more involvement by users. Glasgow and Bull (2001) felt that diabetes educators could direct their patients in selecting useful websites where they can retrieve personalized information tailored for their particular interests and needs. By providing such guidance, diabetes educators would be helping to empower their patients in the diabetes self-management education process.

\section{Empowerment}

The empowerment approach assumes that most people with diabetes are responsible for making important and complex decisions while carrying out the daily 
treatment of their diabetes. According to Franz (2003), more than 99 percent of diabetes care is self-care. The vast majority of diabetes care takes place not two to four times each year in the physician's office or the diabetes center, but literally countless times each and every day in the places where people with diabetes live, work, eat, and play. This approach also assumes that because patients are the ones who experience the consequences of having and treating diabetes, they have both the right and responsibility to be the primary decision maker regarding their own daily diabetes care.

In a randomized controlled trial with 375 patients with diabetes, Anderson and Funnell (1995) found that the patients who participated in a patient empowerment program improved their self-efficacy and attitudes toward diabetes, as well as reduction in blood glucose. When compared with the control group (wait-listed), the participants of diabetes self-management education became empowered when they had enough knowledge to make informed decisions and enough resources to implement these decisions. These patients became informed, equal, active partners in formulating and maintaining their individualized diabetes treatment programs.

Successful diabetes care and education relationships usually begin with a discussion about who is responsible for what in the management of diabetes. Although diabetes educators cannot relieve their patients of this responsibility, Anderson and Funnell (2000) felt that the diabetes educators can teach them skills and supply them with appropriate resources to help them carry out their responsibility. Diabetes educators can provide the diabetes expertise and the knowledge necessary for informed decision-making. They can assist with the development of skills for self care. They can arrange for social and emotional support. They can suggest behavioral change and 
coping strategies. They can provide opportunities for their patients to reflect on their choices and the goals they hope to accomplish.

Empowerment is a patient-centered approach based on respect and compassion. Franz (2003) emphasized that the diabetes educator-patient relationship is based upon shared-responsibilities of both parties. The ultimate goal of this collaborative relationship is for the patients to be able to find their own answers.

Cain, Sarasohn-Kahn, and Wayne (2000) reported that 525 out of 750 consumers retrieving information from the Internet felt that it empowered them to make better choices. It is making it possible for consumers to assume more responsibility for their own health care. Anderson, Rainey, and Eysenbach (2003) favored the development of information and services that assist consumers to assume more responsibility for their own health care and to actively participate in health care decisions.

Schillinger et al. (2003) found that patients would manage their own care if they felt more connected to information about their health. Exit interviews were conducted in a study of 74 patients with diabetes and 38 doctors who treated these patients. The researchers reported that patients forgot up to 80 percent of what the doctor told them during an office visit almost as soon as they walked out the door. Nearly 50 percent of what patients remembered was recalled incorrectly. If patients had access to health information at a web site, and could E-mail follow-up questions, they would be better informed and ultimately healthier. Turner (2004) felt that "people should know what's going on... and if there is something that they don't understand, that's an opportunity for dialogue” (p. 6). 


\section{Impact of the Internet on the Educator-Patient Relationship}

Effective provider-patient communication is important to patient satisfaction, treatment adherence, and health outcomes. The Institute of Medicine (2001) emphasized that patients should receive care whenever they need it and in many forms, not just face-to-face visits. Access to care should be provided over the Internet, by telephone, and by other means. Patients should be given the necessary information and the opportunity to exercise the degree of control they choose over health care decisions that affect them. Patients should have access to clinical knowledge. Clinicians and patients should communicate effectively and share information. The Institute of Medicine (2001) encourages “...making effective use of information technologies to ... make it readily accessible to patients and all members of the care team. An improved information infrastructure is needed to establish effective and timely communication among clinicians and between patients and clinicians” (p. 12).

Fox and Rainie (2002) estimated that about one third of health seekers who find relevant information online bring it to their doctor for a final quality check. Of those who talked to a health care professional, approximately 400 of 500 adults surveyed said their doctor was interested in the information.

Wakefield, Sheeley, Kraus, et al. (n.d.) felt that health care professionals should encourage their patients to seek out information online. Consumers would become proficient in accessing health on the Internet in time. Given training, tools, and access, patients with diabetes would find computers and the Internet to be valuable resources. They would be able to incorporate the information found online into their disease management. Anderson, Rainey, and Eysenbach (2003) agreed that health 
professionals should take the lead in building reliable stairways on the Internet for patient education. They noted the changing ways physicians and patients interact with one another reflect a cultural change in health care.

Merrill (2002) investigated the behaviors and attitudes of twelve primary care physicians and 113 of their patients regarding their use of information from the Internet. What effect did the information brought in have on the encounter with the physician? Most patients who participated in the interviews felt reassured. They expressed that they had a better understanding of the treatment plan established by their physician. Patients who seemed most satisfied with their Internet information were those who had chronic diseases such as diabetes. Those patients who felt included in the health care process were also more likely to be satisfied with their physician's response to their bringing information from the Internet. Many physicians used information brought in by their patients as a teaching tool, to further explain the medical condition or treatment plan. A few physicians used the information to learn more themselves.

Comprehension often leads to compliance and increases motivation. Gerber and Eiser (2001) considered that health care provider-recommended web sites could be thought of as an Internet prescription. Health care providers could take advantage of this unique opportunity to support, reference, and promote awareness of quality electronic sources of medical information. Mikell (2004) explained that providing the names and addresses of these web sites would help reduce confusion involved with Internet searches for useful information. The Internet prescription could help reduce some of the barriers that patients often encounter with using the Internet for obtaining 
health information: time limits, intimidation, embarrassment, low satisfaction, and low literacy.

Studies have been conducted to describe, critically appraise, and analyze consumer health information on the Internet. Eysenbach, Powell, Kuss, and Sa (2002) emphasized that the epidemiology of consumer health information on the Internet is an emerging research discipline where medical informatics intersects with public health. Health care providers could play an important role to help their patients identify trusted web sites. Merrill (2002) felt that patients need safe, authoritative, and user friendly web sites on which to find accurate information in the form of information prescription. An important area of research is identifying methods for guiding patients to quality health care information offered online.

\section{Summary}

The literature review revealed four important reasons for exploring diabetes educators’ perceptions of using Internet technology for diabetes education. First, diabetes educators are likely to use the Internet for diabetes education if they find useful information online. Second, several studies indicate that people in rural areas with limited access to medical care are increasingly relying on the Internet for health information. Third, guidance to useful information on the Internet could help to empower patients in the diabetes self-management education process. Fourth, as diabetes educators guide patients to useful online resources, it may influence the educator-patient relationship. How diabetes educators perceive their role as consumers of Internet technology might influence its integration in the practice of diabetes education and their educator-patient relationship. 


\section{CHAPTER 3}

\section{Method}

The purpose of the study was to explore the perceptions and experiences of diabetes educators who utilize Internet technology and share web-based diabetes information with their patients. The two-phase, sequential mixed methods study included a survey design to obtain statistical, quantitative results from West Virginia diabetes educators' perception of the usefulness of Internet technology in their practice. Followed up in the second phase, the qualitative interview process provided participants the opportunity to directly discuss these issues under investigation in detail. The research questions that this study sought to answer are:

1. How do diabetes educators perceive using the Internet in their medical practice?

2. How do diabetes educators integrate Internet technology in their medical practice?

3. What factors influence the diabetes educator's integration of Internet technology in medical practice?

4. How do diabetes educators perceive the impact of Internet technology on the diabetes educator-patient relationship?

This chapter describes the methods used to conduct the study. Both quantitative and qualitative methods were employed to determine how diabetes educators perceive their role as consumers of Internet technology and the factors that influence its integration in diabetes education and the educator-patient relationship. 
The rationale for the mixed methods study (quantitative and qualitative) is described. The chapter also describes the participants of the study, the data collection method, the instrument design process, and the research design and procedures used in examining the research questions with the two methods. The quantitative phase was framed according to the following: participants, instruments, procedure, and data analysis. The qualitative phase was framed accordingly: participants, research design, data sources, procedure, and data analysis.

\section{Rationale for Mixed -Methods}

The research approach for the study was mixed methods, using both quantitative and qualitative approaches. The combination of mixed methods research techniques was used to gain broader perspectives from the different types of data, strengthen the research design, and add both depth and breadth to the research findings. Using a mixed methods research design was expected to minimize errors that may arise from a single technique and maximize the meaning of data interpretation (Patton, 2002). Quantitative data would enrich the descriptions of the case participants. Qualitative data would be used to describe aspects of the quantitative study that could not be quantified (Tashakkori \& Teddlie, 2003).

Quantitative data served as the basis for collecting and interpreting qualitative data. The quantitative approach to the study employed correlational methods. The qualitative approach to the study was based on the multiple case research method. The qualitative data would add depth, detail, and nuance to the quantitative findings, rendering insights through interviews, observations, and document analysis. 
Triangulation would strengthen the study within the mixed methods strategy (Patton, 2002)

The intent was to explore with a survey of a larger sample in order to test the variables in the quantitative phase, and then to explore in more depth with a few cases during the qualitative phase. The quantitative results were used to guide the purposive sampling of participants in the qualitative phase. The interviews permitted the researcher to examine more deeply into the experiences of the participants. The interviews were used to explore emerging themes in depth and to triangulate the findings (Tashakkori \& Teddlie, 2003).

\section{Quantitative Phase}

The independent variables (predictors) in this study were the following:

1. Diabetes educators' perceptions of the Internet

2. Diabetes educators' perceived comfort level with Internet technology

The dependent variables (criteria) of the study were the following:

1. Reported experience with using the Internet in the practice of diabetes education

2. Reported experience with recommending diabetes information available online To determine how diabetes educators’ perceptions relate to their practices, each dependent variable was compared against the independent variables (within-subjects) using quantitative data analysis methods. In addition to quantitative analyses, qualitative case studies were conducted to describe how diabetes educators’ perceptions of their role as consumers of Internet technology influence its integration in their practice and the educator-patient relationship. 


\section{Participants}

Participants of this study were selected from the American Association of Diabetes Educators (AADE) Member Resource Guide available online. Due to a small number of AADE members in West Virginia, all of the diabetes educators listed in the state were invited to participate in the study. Of the 66 AADE members in West Virginia, 41 were board certified with 32 nurses, 12 dietitians, 10 pharmacists, and 12 without professional designation.

Guidelines for the protection of human participants were followed. The research project was reviewed and approved under the West Virginia University’s Institutional Review Board of Human Subjects (Appendix A) before the diabetes educators were contacted to participate in the study.

Quantitative Data Collection

One of the potential problems for a questionnaire survey would be its low response rate. In order to obtain a higher response rate, the survey was coded to identify if a response was received from the recipient. A packet was sent to potential participants on January 15, 2007 through the postal service or campus mail to office on the Morgantown campus. The packet contained a cover letter and the survey (Appendix B). The cover letter described the purpose of the survey and assured participants confidentiality. The survey consisted of three pages of items and a demographic page.

A follow-up strategy was employed by sending a reminder letter to all nonrespondents on February 1, 2007. The message urged participants to complete the survey. 


\section{Instrumentation}

Upon review of literature, no single reliable and valid survey was available to determine the diabetes educators’ perception of using the Internet. The researcher constructed an Internet Survey for this study. The questions in the survey consisted of three sections: Computer access and use in professional practice, educator-patient relationship, and demographics. The questions on the major concepts appear in Appendix C.

Several procedures were involved in the development of the Internet Survey. The major concepts of computer access and use in professional practice and educatorpatient relationships were identified. Survey questions were developed based on these concepts. Questions were based on findings of an informal pilot study conducted by the researcher on how diabetes educators use the Internet in their practice. Six diabetes educators participated in in-depth interviews. The diabetes educators shared their experiences in utilizing the Internet to obtain patient and professional information on diabetes management. The pilot study was conducted in partial fulfillment of requirements of a graduate course in Qualitative Research Methods and Ethnography in Education (SCFD 615) at West Virginia University College of Human Resources and Education during the fall of 2004.

Wilson and Lankton (2004) reported on their survey of patient acceptance of health information delivered on the Internet. Written permission to modify and use some of their survey questions relating to computer access and experience was granted by Wilson and Lankton. Questions for the survey instrument 
were also inspired by the interviews conducted by Merrill (2002) in her study of the impact of the Internet on doctor-patient relationships.

After the survey questions were initially written, input was elicited from Wilson and Lankton, two diabetes educators, and an instructor in education. These reviewers assessed the survey for content validity and readability of the items in the draft. Changes suggested included rephrasing and adding items to make them more applicable to diabetes educators and Internet use. Questions were rewritten, added, or omitted, based on expert reviewers' comments to the first draft of the survey. A 7-point Likert scale was suggested to obtain greater specificity. Other suggestions addressed survey style, font style and deletion of items. All comments and suggestions were seriously considered and incorporated into the survey when appropriate. The questionnaire was pilot-tested with two diabetes educators for usability of the instrument before data collection. Appropriate suggestions were incorporated into a final revision of the questionnaire.

In an attempt to answer each of the research questions, statements in the survey were written for participants to indicate their level of agreement. Research Question 1: How do diabetes educators perceive using the Internet in their medical practice?

Diabetes educators responded to statements about their perceived effectiveness in using the computer and the Internet in their medical practice and to what degree the Internet improved their professional effectiveness and the quality of the education they deliver. Are they developing expertise in using the Internet? Do they enjoy using the Internet? Do they find the Internet to be a useful tool? The survey also provided open- 
ended questions for diabetes educators to comment on computer access and use in their practice.

Research Question 2: How do diabetes educators integrate Internet technology in their medical practice?

Diabetes educators indicated how they integrate the Internet in their practice. They indicated their participation in computer-based instructions, retrieval of diabetes education materials for patient handouts, and use of the Internet for professional development. Do they communicate with colleagues and patients via the Internet? What information on diabetes web sites have they found useful in their practice? They were also asked to identify what information on diabetes web sites they found useful in their practice.

Research Question 3: What factors influence the diabetes educator's integration of Internet technology in medical practice?

Diabetes educators were asked about access to a computer, and their level of comfort with using the computer and the Internet. Do they feel that they have adequate training in using the computer? Do they feel that they are spending too much time using the Internet? Do they have difficulty finding time to search for information online? How do they feel about the quality of the information they find on the Internet for health care professionals as well as for consumers?

Research Question 4: How do diabetes educators perceive the impact of Internet technology on the diabetes educator-patient relationship?

Diabetes educators indicated how they feel about their patients using the Internet for diabetes information. How do they feel about their patients bringing information 
found online? Do they feel that the information patients bring might be an opportunity to help clarify any misinformation and discuss their concerns? Do they refer patients to specific diabetes web-sites? Diabetes educators were asked to identify web sites they have recommended to their patients. They were also asked to comment on their experiences with patients using the Internet for diabetes information

Diabetes educators had the opportunity to indicate their willingness to participate in an interview to further discuss using the Internet for diabetes education. They were asked to indicate if they wished to receive results of the study upon its conclusion.

Procedure

After exemption was received from West Virginia University’s Institutional Review Board of Human Subjects, the researcher prepared and mailed 66 questionnaire packets based on the sampling strategy described. The packet had a cover letter with the signed stamp of approval addressed to the diabetes educator inviting his/her participation, the Internet Survey, and self-addressed stamped envelop to return the survey. The invitation assured participant confidentiality.

\section{Data analysis}

The quantitative phase of the study used a survey design to investigate diabetes educators' perceptions of their role as consumers of Internet technology and the factors that influence its integration in the diabetes education and the educator-patient relationship. The independent variables examined in this study were diabetes educators’ perceptions of the Internet and their perceived comfort level with Internet technology. The dependent variables in this study were the diabetes educators' 
reported experiences with using the Internet in the practice of diabetes education and they reported experience with recommending diabetes information available online.

The data source for the survey questions is the Likert scale ratings. The scale for each item ranged from 1 (Strongly disagree) to 7 (Strongly Agree). The educators were asked whether they did certain tasks on the computer, e.g. check emails, surf the web, and so on. When each of these answers was a "yes," the sum of the answers was tabulated. Each rated item generated a mean across all participants. This mean indicated their level of agreement with the statement. A total score was generated for each statement. Descriptive means (M) and standard deviations (SD) were used for analysis.

A codebook was assembled for the analysis of data. To assure reliability of the data, a sample of the data was recoded to check for consistency. After the initial coding, the second coding was conducted two weeks later. The codebook lists the variables in the order in which they appear on the survey. The score of 1 is strongly agree and a score of 7 is strongly disagree. Negative statements or reverse-worded statements were recoded for the items to have a common direction. A 1 is scored as if it were a 7, a 2 as if it were a 6, and so on. The data were entered into a spreadsheet.

Nonparametric statistical techniques were used when the assumption of normality could not be met. The Spearman's correlation coefficient for ranking data ( $\left.\mathrm{r}_{\mathrm{s}}\right)$ was used to describe the relationship between variables that are measured on ordinal scales. The Kruskal-Wallis Test, a distribution-free test of analysis of variance between-groups, was used to explore the relationship between ordinal and nominal data. Descriptive statistics were generated using the Statistical Package for the Social 
Sciences (SPSS, version 15.0 (SPSS Inc., Chicago) for analyzing the data. P values less than 0.05 were used to indicate statistically significant differences.

\section{Qualitative Phase}

Patton (2002) emphasized that studying information-rich cases yields insights and in-depth understanding. In qualitative research, participants were selected to represent the phenomenon of interest. Using the maximum variation (heterogeneity) sampling strategy, researchers could capture and describe central themes that cut across variations. Patton suggested that "the common patterns that emerge would be of interest and value in capturing the core experiences and central, shared dimensions of a setting or phenomenon” (p. 235).

\section{Participants}

Purposive sampling was conducted to select five of the responding participants. The selection of extreme cases for this study was intended to yield a detailed description of the diabetes educators' diverse perceptions and experiences with Internet technology for diabetes education. The researcher recruited from the responding diabetes educators who indicated their willingness to participate in the interview process. Diabetes educators were purposively selected on the following criteria: reported use of Internet technology in their practice, health profession, gender, years of experience as diabetes educators, and the types of diabetes education offered at the worksite.

The five diabetes educators selected had access to the Internet. All of the health professions were represented. The health professions included nursing, dietetics, and pharmacy. Both genders were represented. Years of experience as diabetes educators ranged from one year to over 20 years. The diabetes educators selected worked in a 
wide range of settings. They provided inpatient and outpatient diabetes education. They worked in clinics, classrooms, hospitals, and community centers. Interviews

Participants were asked to describe how they feel about using the Internet to obtain diabetes information. How do they decide when to use the Internet for diabetes education? What factors influence their decision? What types of diabetes information do they look for? And, how do they use the information? Participants were also asked about the impact of the Internet on their medical practice. How has sharing of diabetes information from the Internet with their patient influenced the educator-patient relationship? They were asked to identify a web-site on the Internet in response to a hypothetical diabetes question.

The researcher identified the commonalities and differences in their perceptions and experiences. Patton argued that one can learn from participants who are "exemplars of good practice” (p. 234). The researcher explored the factors that promote, as well as hinder, the diabetes educators' successful integration of Internet technology in their medical practice. A small sample of five diabetes educators with diverse views was selected from a total of 24 individuals who indicated their willingness to participate in the interview process. The data collection and analysis yielded detailed descriptions of each case. Shared patterns cut across the cases and derived their significance from having emerged out of the heterogeneity of the cases (Patton, 2002).

\section{Qualitative Data Collection}

Tashakkori and Teddlie (2003) described how the sequential exploratory design is conducted in two phases. The quantitative study was conducted first, followed by a 
qualitative phase. This design type was characterized by the collection and analysis of quantitative data followed by the collection and analysis of qualitative data. Both phases had equal priority. Data from the two phases were interpreted in the integrative phase. The arrow ( $\rightarrow$ ) designated that one form of data collection followed another. The visual model of the sequential mixed methods process was based on the model described by Johnson and Onwuegbuzie (2004), as presented in Figure 1.

Figure 1. Visual Model of Sequential Mixed Methods

\begin{tabular}{|l|l|l|}
\hline $\begin{array}{l}\text { Research } \\
\text { Questions }\end{array}$ & $\begin{array}{l}\text { Purpose of } \\
\text { mixed methods }\end{array} \longrightarrow \begin{array}{l}\text { Selection of } \\
\text { mixed methods }\end{array}$ \\
\cline { 2 - 3 }
\end{tabular}

\begin{tabular}{|l|l|l|}
\hline $\begin{array}{l}\text { QUANTITATIVE } \\
\text { Internet Survey } \\
\text { Data collection } \\
\text { Data analysis }\end{array}$ & $\rightarrow \begin{array}{l}\text { QUALITATIVE } \\
\text { Interviews } \\
\text { Observations } \\
\text { Data collection } \\
\text { Data analysis } \\
\text { Document analysis }\end{array}$ \\
\cline { 3 - 4 }
\end{tabular}

\section{Data Sources}

Open-ended interviews, reflections, and worksite visit observations of Internet technology utilization and web-based documents were employed as data sources to conduct the multiple case reports. Permission from the diabetes educators was requested to audiotape the interviews. Interview questions focused on perceptions and experiences of using the Internet in diabetes education. The open-ended interview questions were centered on the diabetes educators' perceptions and experiences with 
using Internet technology in their practice. Interview questions are found in Appendix D.

A visit to the participant's worksite was an opportunity for direct observation. Yin (2003) suggested that some relevant behaviors or environmental conditions might be available for observation. Since the study was about using the Internet in the practice of diabetes education, observations of this technology at work was invaluable for understanding its actual uses or potential problems being encountered. The interviews were conducted at locations where the diabetes educators primarily work with their patients.

During the interview at the worksite, the researcher made note of the environment in which the diabetes education is routinely provided: physical setting, access to the Internet, and availability of computer printout of diabetes education materials from the Internet. Diabetes educators were asked to present two diabetes education materials they retrieved online for patient education. A document analysis was conducted on these diabetes education materials from the Internet. The analysis included the source, purpose, content, reading level, frequency of distribution, perceived usefulness, reading level, and whether the materials were edited prior to distribution. The SMOG (Simple Measure of Gobbledygook) readability calculations for Association of American Diabetes Educators (AADE) educational materials reviewers were used to determine the grade level of the patient education materials the educators retrieved from the Internet. SMOG formula and procedures and document charts are presented in Appendix E. Observation checklists were used to record information gathered during the work-site visit (Appendix F). 


\section{Procedure}

Case study participants were purposively selected from those participants who indicated on the survey their willingness to discuss their use of the Internet for diabetes education based on criteria presented as noted earlier. When these participants were contacted, they received an explanation about the interviews. The interviews were scheduled at a time most convenient to the participants lasted approximately 30-45 minutes. Permission was requested from the participants to audiotape the interviews. Following the interviews, audio recordings were transcribed verbatim. Observations of key points included in the field notes. Participant identification was protected by using a pseudonym for each participant.

\section{Data Analysis}

Upon completion of the interviews, all sources of case study data were analyzed for case descriptions. The initial analysis was reflection on the data to uncover emerging themes. Emerging themes were organized and coded. Data from the interviews and field notes from observations were assigned words or phrases to describe and assign meaning to the data and convey interpretation. Assigning codes to data allowed the researcher to dissect data in a meaningful way. The open coding process included reviewing all responses from the participants, highlighting words or phrases with high frequencies. A code book was maintained to make transparent where the codes emerged and what they represented. Through the axial coding process, the codes were compared on the basis of similarities and differences, and sorted into categories and subcategories (Harry, Sturges, \& Klingner 2005; Tashakkori \& Teddlie, 2003). Yin (2003) suggested making a matrix of categories and placing the evidence within the 
categories. Creating data displays, such as flowcharts, was helpful for examining the data.

Integration of the two types of data occurred during data collection, data analysis, and interpretation. The researcher "mixed" the data. That meant that all sources of evidence were reviewed and analyzed together. In data collection, openended questions on the survey were combined with close-ended questions. Mixing at the state of data analysis and interpretation involved transforming qualitative themes or codes into quantitative results in the integrative phase of the study. This procedure enabled the researcher to compare quantitative results with qualitative data. The findings were based on the convergence of information from the different sources, both quantitative and qualitative (Yin, 2003).

As a measure of quality control, all interview transcriptions were independently reviewed by a certified diabetes educator and a doctoral student, who were not associated with the study. The emerging themes were also reviewed by the same certified diabetes educator to identify any additional themes.

\section{Summary of Research Methods}

A mixed methods study was used to explore the perceptions and experiences of West Virginia diabetes educators with integrating Internet technology in their medical practice. Table 1 summarizes the procedures used in the study. 
Table 1.

Summary of Research Methods

Quantitative Method

Procedures

Analyses

Surveys were sent to all 66 members of the American Association of Diabetes Educators listed under West Virginia.

Two surveys were returned undeliverable.

41 completed surveys were returned.
Multiple correlational analyses were completed on 41 surveys, comparing diabetes educators' perspectives on using computers and the Internet, integration of Internet technology in practice, and their perception of Internet technology on the educator-patient relationship.

\section{Qualitative Method}

Five educators with varied work experiences in diabetes education were selected for the interviews.

The interviews were conducted at the educators’ worksites.

Document analyses were conducted on diabetes education materials used by the educators.
Multiple case study analyses were conducted to compare five diabetes educators' perspectives on using computers and the Internet, integration of Internet technology in practice, and their perception of Internet technology on the educator-patient relationship. 


\section{CHAPTER 4}

Results

This chapter presents and analyzes the data collected from the survey and interviews. Forty-one West Virginia diabetes educators holding membership in the American Association of Diabetes Educators were surveyed to determine their perspectives and experiences with using Internet technology for diabetes education. Five educators were selected to participate in in-depth interviews of their perceptions and experiences in integrating this technology in their practice. The interviews were conducted at their place of work. During the interviews, observations were made of the environment in which the diabetes educators worked. Subsequent to the interviews, a document analysis was conducted on samples of the patient educational materials the diabetes educators obtained from the Internet.

The research questions that this study sought to answer are:

1. How do diabetes educators perceive using the Internet in their medical practice?

2. How do diabetes educators integrate Internet technology in their medical practice?

3. What factors influence the diabetes educator's integration of Internet technology in medical practice?

4. How do diabetes educators perceive the impact of Internet technology on the diabetes educator-patient relationship?

Both quantitative and qualitative research methods were employed to answer how diabetes educators' perceptions and experiences relate to their use of Internet 
technology for diabetes education. A detailed demographic description of the participants is followed by the findings in relation to the research questions. SPSS statistical analysis was used for the analysis and data manipulation. The quantitative statistical findings will be reported first for the research questions followed by the qualitative findings.

\section{Quantitative Method: Results}

This section will begin with an overview of the research design in terms of the demographics of the participants, response rate, scoring instruments, and the analysis of the research questions. Findings of each question will be discussed, followed by the intercorrelations of the variables used in this research.

\section{Response Rate}

Surveys were sent to all 66 American Association of Diabetes Educators members in West Virginia. Forty-one diabetes educators responded to the survey. Two surveys were returned as undeliverable. The response rate of the survey was calculated as the number of surveys returned divided by the number of surveys sent out and not returned as undeliverable. The response rate for this survey was $64.06 \%$.

\section{Demographic Data}

The majority of the diabetes educators were female ( $N=37,90 \%)$, while only 4 were male. All 41 respondents indicated that their ethnicity/race as white, nonHispanic. The majority of the educators were nurses $(\mathrm{N}=27,65.85 \%)$. The remainder were dietitians and pharmacists ( $\mathrm{N}=7$ each or $17.07 \%)$ for a total of $34.14 \%$. The percentage of respondents by profession was comparable to the representation of professions in the full membership, as shown on Table 2. 
Table 2.

Professional Status of Survey Participants

\begin{tabular}{lcccc}
\hline & \multicolumn{2}{c}{ Surveys Sent } & \multicolumn{2}{c}{ Surveys Returned } \\
\hline & $\mathrm{N}^{*}$ & $\%$ & $\mathrm{~N}$ & $\%$ \\
\hline Nurses & 32 & 59 & 27 & 66 \\
Dietitians & 12 & 22 & 7 & 17 \\
Pharmacists & 10 & 19 & 7 & 17 \\
\hline
\end{tabular}

* 12 educators did not declare their health profession

Diabetes educators who responded to the survey were well educated. Relative to the highest degree earned, seven (17\%) completed a doctoral degree, 16 (39\%) completed a master's degree, 12 (30\%) completed a baccalaureate degree, three (7.3\%) completed an associate degree, and three (7.3\%) completed a diploma in nursing.

The range of years of diabetes education experience varied. Over half of the participants ( $\mathrm{N}=23$ or $56 \%$ ) had ten or fewer years in diabetes education. Whereas, 15 (37\%) had 11 to 20 years, and three (7\%) had 21 to 25 years of diabetes education experience. The mean was 11.04 years.

The majority of the diabetes educators in West Virginia who responded to the survey were Certified Diabetes Educators ( $\mathrm{N}=31$ or $73 \%)$. Two of these educators were also Board Certified in Advanced Diabetes Management (BC-ADM). Of the 10 not certified in diabetes education, eight educators indicated that they plan to take the certification examination. The demographics are presented in Table 3. 
Table 3.

Participant Demographics

Participant Demographics

\begin{tabular}{|c|c|c|c|}
\hline & & $\mathrm{N}$ & $\%$ \\
\hline \multirow[t]{2}{*}{ Gender } & Male & 4 & 9.76 \\
\hline & Female & 37 & 90.24 \\
\hline \multirow[t]{3}{*}{ Profession } & Nurses & 27 & 65.85 \\
\hline & Dietitians & 7 & 17.07 \\
\hline & Pharmacists & 7 & 17.07 \\
\hline \multirow[t]{5}{*}{ Education } & Doctorate & 7 & 17.07 \\
\hline & Masters & 16 & 39.02 \\
\hline & Baccalaureate & 12 & 29.27 \\
\hline & Associate & 3 & 7.32 \\
\hline & Diploma in nursing & 3 & 7.32 \\
\hline \multirow{5}{*}{$\begin{array}{l}\text { Total years of experience in } \\
\text { diabetes education } \\
(\mathrm{M}=11.04, \mathrm{SD}=6.53)\end{array}$} & & & \\
\hline & 5 or fewer & 11 & 26.83 \\
\hline & $6-10$ & 12 & 29.27 \\
\hline & $11-15$ & 9 & 21.95 \\
\hline & $16-25$ & 9 & 21.95 \\
\hline \multirow[t]{2}{*}{ Certified Diabetes Educators } & Yes & 31 & 75.61 \\
\hline & No & 10 & 24.39 \\
\hline \multirow[t]{2}{*}{ Plan to certify } & Yes & 8 & 80.00 \\
\hline & No & 2 & 20.00 \\
\hline Total years certified & 0 & 10 & 24.39 \\
\hline \multirow[t]{4}{*}{$(\mathrm{M}=7.98, \mathrm{SD}=7.38)$} & $1-5$ & 6 & 14.63 \\
\hline & $6-10$ & 10 & 24.39 \\
\hline & $11-15$ & 8 & 19.51 \\
\hline & $16-22$ & 7 & 17.07 \\
\hline \multirow{2}{*}{$\begin{array}{l}\text { Board Certified in Advanced } \\
\text { Diabetes Management } \\
\text { (BC-ADM) }\end{array}$} & Yes & 2 & 4.88 \\
\hline & No & 39 & 95.12 \\
\hline
\end{tabular}


Diabetes educators provided education for patients with diabetes in a variety of health care settings. On the average, they reported seeing almost 50 patients each month. One educator estimated seeing a monthly average of 230 patients. When identifying worksites, 17 (41\%) educators indicated that they see patients in two or more health care settings. Most of them delivered diabetes education in outpatient clinics ( $\mathrm{N}=33$ or $81 \%)$. Over half $(\mathrm{N}=18$ or $55 \%)$ of the educators provided diabetes education for patients in hospitals. Educators conducted individual counseling $(\mathrm{N}=27$ or $66 \%)$ as well as group classes $(\mathrm{N}=24$ or $58 \%)$. Educators indicated that they also provided patient education in other settings: home health, diabetes support group, community education, health fairs, cooking schools, and the West Virginia University Extension Service Dining with Diabetes Program. Details of the diabetes educators' experience and worksites are summarized in Table 4.

The number of years that the diabetes educators used the Internet for diabetes information ranged from zero to 17 years, with a mean of 5.17 years and SD 3.81. Six educators (14.6\%) indicated that they did not use the Internet for diabetes information. Of the 35 educators who indicated using the Internet for diabetes education, over half of the diabetes educators ( $\mathrm{N}=20$ or $57 \%$ ) indicated that they had been using the Internet for diabetes information for at least five years. Over a third of the educators $(\mathrm{N}=13$ or 37\%) had been using the Internet between six and ten years. Table 5 summarizes the years educators used the Internet for diabetes information. 
Table 4.

Diabetes Education Experience and Worksites

\begin{tabular}{llrr}
\hline & & $\mathrm{N}$ & $\%$ \\
\hline $\mathbf{M}=$ 48.54, SD = 52.91) & & 10 & 24.39 \\
& 10 or fewer & 9 & 21.95 \\
& $11-25$ & 10 & 24.39 \\
& $26-50$ & 10 & 24.39 \\
& $51-100$ & 4 & 9.76 \\
& $101-200$ & 1 & 2.44 \\
\hline \multirow{3}{*}{ Diabetes Education* } & $201-230$ & & \\
& & 33 & 80.48 \\
& Outpatient & 18 & 43.90 \\
& Inpatient & & \\
& & 27 & 65.85 \\
& Individual counseling & 24 & 58.54 \\
\hline \multirow{3}{*}{ Group sessions } & & \\
& & 32 & 78.05 \\
& Clinic & 5 & 12.20 \\
& Physician office & 3 & 7.32 \\
& Public health & 4.76 \\
& Private consultant & 4 & 2.44 \\
& Home health & 1 & 2.44 \\
& Diabetes support group & 1 & 2.44 \\
& Community education & 1 & 2.44 \\
& Health fairs & 1 & 2.44 \\
& Cooking schools & 1 & 2.44 \\
\hline Dining with Diabetes & 1 & $100 \%$.
\end{tabular}

* Participants could select more than one answer. The percentages do not total $100 \%$.

Table 5.

Years Using the Internet for Diabetes Information*

\begin{tabular}{ccc}
\hline Years & $\mathrm{N}$ & $\%$ \\
\hline 0 & 6 & 14.6 \\
1 to 5 & 20 & 48.78 \\
6 to 10 & 13 & 31.71 \\
15 & 1 & 2.4 \\
17 & 1 & 2.4 \\
\hline
\end{tabular}

$* \mathrm{M}=5.17, \mathrm{SD}=3.81$ 


\section{Findings}

Research Question 1

How do diabetes educators perceive using the Internet in their medical practice? Diabetes educators' self-reported perceptions of how they used the Internet in their medical practice were determined by computation of the means and standard deviations of the survey questions relating to the research question. Educators indicated their level of agreement using to a Likert scale $(1=$ strongly agree, $4=$ not sure, $7=$ strongly disagree) for each statement. Spearman’s correlation coefficient for ranking data $\left(\mathrm{r}_{\mathrm{s}}\right)$ was used to calculate correlations on diabetes educators' perspectives on using computers effectively in their practice (Q5) and how they perceived the Internet in enhancing their professional effectiveness (Q16) with other perspectives in using computers and the Internet in their practice.

West Virginia diabetes educators surveyed generally viewed using computers and the Internet favorably. The educators agreed that the computer is a good communications tool and found the Internet to be useful. They agreed that computer skills will help them professionally, as well as increase their productivity. They reported that they enjoyed using the Internet and they were developing expertise in using the Internet in their practice. Educators indicated that they participate in computer-based instructions. They felt comfortable using the computer and thought that they used computers effectively in their practice. They agreed that the Internet had enhanced their professional effectiveness, as well as improved the quality of education they deliver. As for the quality of diabetes-related information on the Internet, educators rated the information for professionals higher than for consumers. 
Diabetes educators reported a wide range of agreement with the adequacy of training in using computers and in the time spent at the computer. Educators presented similar responses to questions relating to time demanded for learning computers and having difficulty finding time to search for information online. Table 6 presents a general view of how the educators perceived using computers and the Internet in their practice. 
Table 6.

Using the Computer and Internet in My Profession

\begin{tabular}{|c|c|c|c|}
\hline & $\mathrm{N}$ & M & $\mathrm{SD}$ \\
\hline Q4 I have adequate training in using computers & 41 & 3.34 & 1.682 \\
\hline Q5 I use computers effectively in my practice & 41 & 2.78 & 1.492 \\
\hline Q6 I am comfortable using the computer & 41 & 2.61 & 1.394 \\
\hline Q7 Computer skills will help me as a professional & 41 & 1.34 & .617 \\
\hline Q8 Computers increase my productivity & 41 & 1.85 & 1.195 \\
\hline Q9 I participate in computer-based instructions & 36 & 2.50 & 1.483 \\
\hline Q10 Computer is a good communications tool & 41 & 1.71 & 1.078 \\
\hline Q11 Learning computers makes high demands on my time ${ }^{(a)}$ & 40 & 3.80 & 1.800 \\
\hline Q12 I am developing expertise in using Internet in my practice & 40 & 2.58 & 1.412 \\
\hline Q13 I spend a lot of time using the Internet ${ }^{(\mathrm{a})}$ & 40 & 3.33 & 1.670 \\
\hline Q14 I enjoy using the Internet & 41 & 2.32 & 1.422 \\
\hline Q15 I have difficulty finding time to search for information online ${ }^{(a)}$ & 41 & 3.80 & 2.040 \\
\hline Q16 The Internet has enhanced my professional effectiveness & 41 & 2.59 & 1.449 \\
\hline Q17 The Internet has improved the quality of education I deliver & 41 & 2.80 & 1.436 \\
\hline $\begin{array}{l}\text { Q18 The quality of diabetes-related information on the Internet for } \\
\text { health care professionals is high }\end{array}$ & 41 & 2.51 & 1.075 \\
\hline $\begin{array}{l}\text { Q19 The quality of diabetes-related information on the Internet for } \\
\text { consumers is high }\end{array}$ & 41 & 2.95 & 1.396 \\
\hline Q20 The Internet is a useful tool & 41 & 1.80 & .641 \\
\hline
\end{tabular}

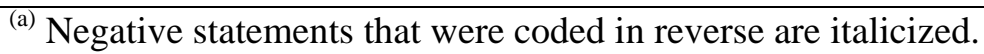


Using computers effectively in their practice (Q5). Spearman's correlation coefficient for ranking data $\left(\mathrm{r}_{\mathrm{s}}\right)$ was used to compute correlations on diabetes educators' perspectives on using computers effectively in their practice (Q5) with other perspectives in using computers and the Internet. Table 7 presents details of the educators' perspectives on using computers effectively. The strongest correlation of perceived effectiveness in computer use (Q5) was perceived comfort in using this technology (Q6). Of the diabetes educators reporting that they used computers effectively in their practice, there were significant correlations with adequate training in computer use (Q4) and computers contributing to increased educator productivity (Q8). Participation in computer-based instructions (Q9) correlated to perceived effectiveness in using computers. Significant correlations were also found with developing expertise in using the Internet in their practice (Q12), feeling that the Internet enhanced their professional effectiveness (Q16), and improved the quality of education they delivered (Q17).

There was a negative, but significant correlation with diabetes educators' perceived effectiveness in using the computers in their practice (Q5) and not spending a lot of time using the Internet (Q13). The negative relationship might indicate that the educators, who reported perceived effectiveness in computer use, reported perceived spending a lot of time using the Internet. 
Table 7.

I Use Computers Effectively in My Practice (Q5)

$r_{S}$

Q4 I have adequate training in using computers

$.809 * *$

Q6 I am comfortable using the computer

$.874 * *$

Q7 Computer skills will help me as a professional

Q8 Computers increase my productivity

$.376 *$

Q9 I participate in computer-based instructions

$.707 * *$

Q10 Computer is a good communications tool

.251

Q11 Learning computers makes high demands on my time ${ }^{(\mathrm{a})}$

.112

Q12 I am developing expertise in using Internet in my practice $.697 * *$

Q13 I spend a lot of time using the Internet ${ }^{(\mathrm{a})}$

$-.391 *$

Q14 I enjoy using the Internet

$.378 *$

Q15 I have difficulty finding time to search for information online ${ }^{(a)}$

$.328 *$

Q16 The Internet has enhanced my professional effectiveness

$.512 * *$

Q17 The Internet has improved the quality of education I deliver

$.472^{* *}$

Q18 The quality of diabetes-related information on the Internet for health care professionals is high

Q19 The quality of diabetes-related information on the Internet for consumers is high

Q20 The Internet is a useful tool

(a) Negative statements that were coded in reverse are italicized.

* Correlation is significant at the 0.05 level (2-tailed).

** Correlation is significant at the 0.01 level (2-tailed). 
The Internet has enhanced my professional effectiveness (Q16). Spearman's correlation coefficient for ranking data $\left(\mathrm{r}_{\mathrm{s}}\right)$ was used to conduct correlations on how diabetes educators perceived the Internet in enhancing their professional effectiveness (Q16) with other perspectives in using computers and the Internet. Table 8 presents details of how diabetes educators perceived the Internet in enhancing their professional effectiveness. Developing expertise in using the Internet (Q12) was the strongest correlation of diabetes educators' perception of the Internet's role in enhancing their professional effectiveness. There was a significant correlation between diabetes educators' statement that the Internet enhanced their professional effectiveness and the Internet improving the quality of education delivered (Q17). Professional effectiveness was also positively correlated with enjoy using the Internet (Q14) and feeling that the quality of diabetes-related information on the Internet for health care professionals was high (Q18).

While not having difficulty finding time to search for information online (Q15) was positively correlated with the Internet enhancing professional effectiveness, not spending a lot of time using the Internet (Q13) was negatively correlated with this perspective. The contrasting correlations might indicate that diabetes educators who perceived that the Internet was effective in enhancing them professionally found or made time to conduct searches on the Internet, but they perceived that they spent a lot of time using this technology. 
Table 8.

The Internet has Enhanced My Professional Effectiveness (Q16)

$\mathrm{r}_{\mathrm{S}}$

Q4 I have adequate training in using computers

$.427 * *$

Q5 I use computers effectively in my practice

$.512 * *$

Q6 I am comfortable using the computer

$.460 * *$

Q7 Computer skills will help me as a professional

.022

Q8 Computers increase my productivity

Q9 I participate in computer-based instructions

$.536 * *$

Q10 Computer is a good communications tool

Q11 Learning computers makes high demands on my time ${ }^{(\mathrm{a})}$

.257

Q12 I am developing expertise in using Internet in my practice

$.785^{* *}$

Q13 I spend a lot of time using the Internet ${ }^{(\mathrm{a})}$

$-.628 * *$

Q14 I enjoy using the Internet

$.650 * *$

Q15 I have difficulty finding time to search for information online ${ }^{(a)}$

Q17 The Internet has improved the quality of education I deliver

Q18 The quality of diabetes-related information on the Internet for health care professionals is high

Q19 The quality of diabetes-related information on the Internet for consumers is high

Q20 The Internet is a useful tool

(a) Negative statements that were coded in reverse are italicized.

* Correlation is significant at the 0.05 level (2-tailed).

** Correlation is significant at the 0.01 level (2-tailed). 


\section{Research Question 2}

How do diabetes educators integrate Internet technology in their medical practice? Methods by which diabetes educators integrated Internet technology in their medical practice are detailed in Table 9. Diabetes educators indicated using items available on the Internet by checking $(\checkmark)$ the items on the survey.

Educators were interested in professional development opportunities available on the Internet. Out of the 41 respondents, 38 diabetes educators (92.68\%) reported that they seek diabetes-related news posted on the Internet. Educators ( $\mathrm{N}=32$ or $78.05 \%)$ participated in computer-based instructions, while as many as 29 (70.73\%) obtained their continuing education credits in diabetes online. Educators $(\mathrm{N}=31$ or $75.61 \%)$ performed medical searches for diabetes-related problems, whereas slightly fewer educators ( $\mathrm{N}=28$ or $68.29 \%$ ) surfed the web for general diabetes information.

The Internet was reported to be a source of information as well as educational materials and supplies. To support their patient education program, diabetes educators ( $\mathrm{N}=25$ or $60.98 \%$ ) reported that they seek hand-outs available online for their patients. Twenty educators (48.78\%) reported interest in diabetes products posted on the Internet. Diabetes educators ( $\mathrm{N}=19$ or $46.34 \%$ ) looked to the internet for diabetes educational materials and reported purchasing diabetes educational materials and supplies through the Internet.

Diabetes educators used the interactive features available on the Internet. A majority of the educators ( $\mathrm{N}=24$ or $58.54 \%$ ) reported sharing web-based diabetes information with their colleagues. Few educators obtained messages from professional 
listservs, checked messages on the forum or message board, and participated in diabetes-related chat rooms.

Nearly half of the diabetes educators ( $\mathrm{N}=20$ or $48.78 \%)$ reported receiving email messages from their patients. In contrast, slightly fewer educators ( $\mathrm{N}=15$ or $36.59 \%$ ) reported emailing diabetes information to their patients. Other features on the Internet were used less. Seven (17.07\%) of the educators' worksites had a web page for communicating with their patients. Only three educators (7.32\%) had their own professional webpage. 
Table 9.

Using the Internet in Your Practice as a Diabetes Educator

$\begin{array}{lll}2 & \mathrm{~N} & \mathrm{M}\end{array}$

Q21 I surf the web for general diabetes information

68.29

Q22 I read diabetes-related news

$38 \quad 92.68$

Q23 I perform medical searches for diabetes-related problems

$31 \quad 75.61$

Q24 I search for patient handouts

$25 \quad 60.98$

Q25 I locate diabetes products

$25 \quad 60.98$

Q26 I purchase diabetes educational materials and products

$20 \quad 48.78$

Q27 I obtain messages from professional Listserv

$19 \quad 46.34$

Q28 I check messages on the forum or message board

$9 \quad 21.95$

Q29 I participate in diabetes-related chat room

Q30 I share web-based diabetes information with colleagues

$3 \quad 7.32$

$24 \quad 58.54$

Q31 I receive email from patients

$20 \quad 48.78$

Q32 I email diabetes information to patients

$15 \quad 36.59$

Q33 I obtain continuing education credits in diabetes

$29 \quad 70.73$

Q34 I have my own professional web page

$3 \quad 7.32$

Q35 My office has a web page for communication with Patients

Diabetes educators reported finding useful diabetes information online that can directly support their medical practice. Thirty-two educators (78.05\%) identified special links for health professional (Q46). High on the list of useful information for educators ( $\mathrm{N}=30$ or 73.17\%) were medication (Q38) and product information (Q40). 
Twenty-nine educators (70.73\%) reported that clinical guidelines (Q37) and diabetes research (Q39) were also useful. Both patient handouts $(\mathrm{Q} 41)$ and recipes $(\mathrm{Q} 43)$ were identified by 28 educators (68.29\%). Diabetes educators ( $\mathrm{N}=27$ or $65.85 \%)$ reported nutrition facts (Q42), while 24 educators (58.54\%) reported physical activity tips (Q44) and links for additional diabetes information to be useful. Few educators selected special links for consumers (Q47), support group (Q48), and message board (Q49).

Table 10.

What Information on Diabetes Web Sites Have You Found Useful in Your Practice?

\begin{tabular}{lcc}
\hline & $\mathrm{N}$ & $\mathrm{M}$ \\
\hline Q37 Clinical guidelines & 29 & 70.73 \\
Q38 Diabetes medication & 30 & 73.17 \\
Q39 Diabetes research & 29 & 71.00 \\
Q40 Diabetes product information & 30 & 73.17 \\
Q41 Patient education handouts & 28 & 68.29 \\
Q42 Nutrition facts & 27 & 65.85 \\
Q43 Recipes & 28 & 68.29 \\
Q44 Physical activity tips & 24 & 58.54 \\
Q45 Link for additional diabetes information & 24 & 58.54 \\
Q46 Special links for health professionals & 32 & 78.05 \\
Q47 Special links for consumers & 10 & 24.39 \\
Q48 Support group & 9 & 21.95 \\
Q49 Message board & 5 & 12.20 \\
\hline
\end{tabular}




\section{Research Question 3}

What factors are influencing the diabetes educator's integration of Internet technology in medical practice? Diabetes educators reported integrating Internet technology in their medical practice. The factors reported to influence educators’ integration of the technology in their practice were access and use of computers and the Internet, perceived adequacy in training on the use of computers, and perceived effectiveness in computer use in practice. Other factors included educators’ perceived quality of diabetes information on the Internet, perceived productivity with computer use, time demands with using the Internet, as well as enjoyment in using the Internet.

Computer access and use. All 41 of the diabetes educators reported that they had access and used the computer. Although all of the respondents had access to the computer at work, 34 of the educators (82.93\%) also had access to a computer at home. The same number of educators reported that they used the computer at least five times a day.

Training in computer use. Diabetes educators reported that they acquired their computer skills through multiple methods. Most of the educators acquired these skills through informal education. Over half of the educators reported that they gained their skills through one or more of these sources: in-service training, workshops, colleagues, friends, and family. A similar number of educators acquired their skill through selfstudy. Only 20 percent of the educators indicated that they received training on using computers during their formal education (undergraduate and graduate education). Table 11 summarizes the diabetes educators' computer access and use. 
Table 11.

Computer Access and Use

\begin{tabular}{lrr}
\hline \multicolumn{1}{c}{ Access to a computer } & $\mathrm{N}$ & $\%$ \\
\hline Location & 34 & 82.93 \\
At home & 41 & 100.00 \\
At work & & \\
Acquisition of computer skills* & 9 & 21.95 \\
Classes: undergraduate & 8 & 19.51 \\
Classes: graduate & 21 & 51.22 \\
In-service/workshops & 27 & 65.85 \\
Colleagues, family & 17 & 41.46 \\
Self-study & & 82.93 \\
& & 14.63 \\
Frequency of computer use & 34 & 2.44 \\
More than 5 times/day & 6 & 0 \\
Daily, less than 5 times & 1 & \\
Once a week & 0 & \\
Never use it & & \\
&
\end{tabular}

*Participants could select more than one answer. The percentages do not total $100 \%$.

Diabetes educators indicated their level of agreement using to a Likert scale to the adequacy of their training in using computers (Q4). Their view of the adequacy of their training varied considerably ( $M=3.34, \mathrm{SD} 1.68)$. Spearman’s correlation coefficient for ranking data $\left(\mathrm{r}_{\mathrm{s}}\right)$ was used to conduct correlations on diabetes educators' perspectives on adequate training in using computers (Q4) to other perspectives on computer and Internet use. The strongest correlation of diabetes educators’ perception of adequate training in computer use was with their perception that they used computers effectively in their practice (Q5). Adequacy in computer use training was also positively correlated with these variables: comfort in using the computer (Q6), computers increasing their productivity (Q8), computers increasing their professional 
effectiveness (Q16), developing expertise in using the Internet in practice (Q12), not having difficulty finding time to search for information online (Q15), and improvement in the quality of education delivered (Q17).

Table 12.

I Have Adequate Training in Using Computers (Q4)

$r_{S}$

Q5 I use computers effectively in my practice $.809 * *$

Q6 I am comfortable using the computer $.725^{* *}$

Q7 Computer skills will help me as a professional $-.042$

Q8 Computers increase my productivity $.366^{*}$

Q9 I participate in computer-based instructions $.641^{* *}$

Q10 Computer is a good communications tool .064

Q11 Learning computers makes high demands on my time ${ }^{(\mathrm{a})}$ .188

Q12 I am developing expertise in using Internet in my practice $.534 * *$

Q13 I spend a lot of time using the Internet ${ }^{(\mathrm{a})}$

Q14 I enjoy using the Internet

Q15 I have difficulty finding time to search for information online $e^{(a)}$

$.414^{* *}$

Q16 The Internet has enhanced my professional effectiveness

$.427 * *$

Q17 The Internet has improved the quality of education I deliver

$.416^{* *}$

Q18 The quality of diabetes-related information on the Internet for health care professionals is high

Q19 The quality of diabetes-related information on the Internet for consumers is high

Q20 The Internet is a useful tool

(a) Negative statements that were coded in reverse are italicized.

* Correlation is significant at the 0.05 level (2-tailed).

** Correlation is significant at the 0.01 level (2-tailed). 
Diabetes educators who reported having adequate training in using computers indicated that they integrated computer and Internet technology in their practice. There were significant correlations of adequacy in training with participation in computerbased instructions (Q9), obtaining messages from professional listservs (Q27), checking for messages on the forum or message board (Q28), as well as finding useful information on both diabetes medication (Q38), and special links for consumers (Q47). Educators who perceived having adequate training in computers also felt that there is useful diabetes-related information for patients online (Q63). Details of how the diabetes educators’ perceived adequacy in training (Q4) correlated with other perceived variables are found in Appendix F.

Using computers effectively (Q5.) Diabetes educators ( $\mathrm{M}=2.78, \mathrm{SD}=1.492)$ agreed that they were using computers effectively in their practice (Q5). Obtaining messages from professional listservs had the strongest correlation with effective use of the computer (Q27). Statistical analysis also indicated significant correlations with educators who reported using computers effectively and performing medical searches for diabetes related problems (Q23) and receiving email from their patients (Q31). Details of how diabetes educators' perceived effective use of computers correlated with other perceived variables are found in Appendix G.

Quality of diabetes information on the Internet (Q18, Q19.) Diabetes educators responding to the survey agreed that the quality of the diabetes-related information on the Internet was high for professionals $(\mathrm{M}=2.51, \mathrm{SD}=1.08)$ as well as for consumers $(\mathrm{M}=2.95, \mathrm{SD}=1.40)$. Of the educators who agreed with the high quality of online diabetes information for professionals, there was a significant correlation with their 
perceived adequacy in computer training (Q4), increased productivity with computer use(Q8), Internet enhancing educators’ professional effectiveness (Q16), improved quality of education they deliver (Q17). Details of how diabetes educators’ perceived quality of diabetes-related information on the Internet correlated to other perceived variables are found in Appendix $\mathrm{H}$.

Increased productivity (Q8). Of the diabetes educators who agreed that computers increased their productivity, there was a significant correlation with their perception of the usefulness of the tool (Q20). They also reported that they use the computer effectively in their practice (Q5) and are comfortable using the computer (Q6). They perceived that the quality of diabetes-related information on the Internet to be high. The perception that computers increased productivity strongly correlated with the perception that computer is a good communications tool (Q20). Details of how diabetes educators’ perceived productivity correlated to other perceived variables are found in Appendix I.

Time for using the computer. The amount time spent using the computer varied among the respondents. Diabetes educators' $(M=3.33, \mathrm{SD}=1.67)$ perception of the time spent using the Internet varied (Q13). Respondents $(\mathrm{M}=3.8, \mathrm{SD}=1.8))$ also had mixed feelings with the demand on their time for learning how to use computers (Q11). For many of the educators $(\mathrm{M}=3.80, \mathrm{SD}=2.04)$, finding time for online information search posed a challenge (Q15). Details of how diabetes educators’ perceived the time commitment in using computers and the Internet correlated to other perceived variables in Appendix J. 
Enjoy using the Internet (Q14). Diabetes educators who indicated that they enjoyed using the Internet had found the Internet to be a useful tool (Q20). There were significant correlations with enjoyment in using the Internet and feeling comfortable using the computer (Q6) and using the computers effectively in their practice (Q5). Diabetes educators who enjoyed using the Internet participated in computer-based instructions (Q9). They also reported that the Internet improved the quality of the education they deliver (Q17). The strongest correlation of educators’ enjoyment in using the Internet was the development of expertise in using the Internet in their practice (Q12).

Statistical analysis did not indicate a significant correlation between enjoyment in using Internet and adequate training in using computers (Q4). The absence of relationship might indicate that adequate training may not be a factor for educators to enjoy using the technology. Statistical analysis resulted in a significant, but negative correlation between enjoyment in using the Internet and not having difficulty finding time to search for diabetes information online (Q15). The negative relationship might indicate that for diabetes educators who enjoy using the Internet, finding time to search for information online might be less of a challenge. Table 13 summarizes how diabetes educators’ enjoyment with using the Internet correlated with other perceived variables. 
Table 13.

I Enjoy Using the Internet (Q14)

$r_{S}$

Q4 I have adequate training in using computers

.282

Q5 I use computers effectively in my practice

$.378 *$

Q6 I am comfortable using the computer

$.388 *$

Q7 Computer skills will help me as a professional

.190

Q8 Computers increase my productivity

.126

Q9 I participate in computer-based instructions

$.482^{* *}$

Q10 Computer is a good communications tool

Q11 Learning computers makes high demands on my time ${ }^{(\mathrm{a})}$

Q12 I am developing expertise in using Internet in my practice

Q13 I spend a lot of time using the Internet ${ }^{(\mathrm{a})}$

$-.485 * *$

Q15 I have difficulty finding time to search for information online ${ }^{(a)}$

$.330 *$

Q16 The Internet has enhanced my professional effectiveness

$.650 * *$

Q17 The Internet has improved the quality of education I deliver

$.544 * *$

Q18 The quality of diabetes-related information on the Internet for health

.192 care professionals is high

Q19 The quality of diabetes-related information on the Internet for consumers is high

Q20 The Internet is a useful tool

(a) Negative statements that were coded in reverse are italicized.

* Correlation is significant at the 0.05 level (2-tailed).

** Correlation is significant at the 0.01 level (2-tailed). 


\section{Research Question 4}

How do diabetes educators perceive the impact of Internet technology on the diabetes educator-patient relationship? Diabetes educators provide diabetes care and education for their patients in a variety of settings. They see their patients in individual counseling or in group settings. The group encounters may be diabetes classes or support groups. During these group encounters, educators may provide formal lectures with power point slides, product demonstrations, cooking school, or grocery tours.

Thirty-six diabetes educators (92.3\%) reported that their patients approached them with information found on the Internet. Two educators did not respond to this question. Almost half of the educators ( $\mathrm{N}=19,49 \%)$ reported patients bringing information from the Internet at least once a month. Three educators (8\%) responded that patients did not bring any information from the Internet to their attention. Table 14 summarizes the frequency patients approached diabetes educators with information from the Internet.

Table 14.

Have Patients Ever Approached You with Information that They Got from the Internet?

\begin{tabular}{lcr}
\hline & $\mathrm{N}$ & $\%$ \\
\hline No, it's never happened & 3 & 7.60 \\
Yes, but only once or twice & 17 & 43.59 \\
Yes, it has happened as often as once a month & 15 & 38.46 \\
Yes, it happens nearly every week & 4 & 10.26 \\
Total answering & 39 & 100.00 \\
No response & 2 & \\
\hline
\end{tabular}


Impact of the Internet on the educator-patient relationship. How diabetes educators perceived the impact of the Internet on the educator-patient relationship is summarized on Table 15. Negative statements were recoded in reversed order $(1=7$, $2=6,3=5$, etc.) to produce a common direction. Diabetes educators agreed that the Internet is a useful tool and that there is useful diabetes-related information for patients online. When patients bring diabetes information from the Internet, diabetes educators considered it an opportunity to discuss their concerns about the diabetes information found online. They agreed that it was helpful to know what the patients are thinking about. The educators felt that they learned from the information patients bring in. Some educators agreed that it's so easy for patients to get the wrong information, and it is difficult to reverse the misconceptions.

Although most diabetes educators agreed that the Internet is a good teaching tool, some reported they prefer that patients rely on the information they receive from the educators. They felt that it might depend on which patients are bringing the information in. Educators were divided at almost an even split on patients using the Internet to take better care of themselves.

Diabetes educators reported that searching for diabetes information on the Internet was not time-consuming with little to be gained. They reported that it is not a big waste of everyone's time. They disagreed with the statements about feeling tense when patients bring information found online. Educators reported that they do not avoid discussing Internet-based information with their patients. 
Table 15.

Educator-Patient Relationship

M SD

Q52 It's so easy for patients to get the wrong information, and it's difficult to reverse the misconceptions ${ }^{\text {(a) }}$

$4.54 \quad 1.804$

Q53 It can be time-consuming with little to be gained

$3.53 \quad 1.370$

Q54 I feel tense when they bring information found online

$2.70 \quad 1.175$

Q55 I prefer patients rely on the information they receive from us

$4.29 \quad 1.523$

Q56 I avoid discussing Internet-based information

$2.22 \quad .917$

Q57 In my opinion, it's a big waste of everyone's time

$1.76 \quad .683$

Q58 It depends on which patients are bringing the information in

$4.79 \quad 1.647$

Q59 It's helpful to know what the patients are thinking about

$2.11 \quad .727$

Q60 Sometimes I learn from the information patients bring in

$2.38 \quad .893$

Q61 I can help to clarify any misinformation they may have

$1.92 \quad .580$

Q62 It's a good teaching tool

$2.38 \quad .782$

Q63 There is useful diabetes-related information for patients

$2.08 \quad .739$

online

Q64 I refer my patients to specific diabetes web sites

$2.08 \quad .1 .140$

Q65 Patients use the Internet to take better care of themselves

$3.00 \quad 1.277$

Q66 They trust my opinion on diabetes information found online

$2.42 \quad .858$

Q67 We can discuss their concerns about diabetes information

$2.13 \quad 1.361$ found online

Q68 Reputable websites help to reinforce diabetes self-

$1.82 \quad .556$ management

(a) Negative statements that were coded in reverse are italicized. 
Referring patients to specific diabetes web site (Q64). Spearman's correlation coefficient for ranking data $\left(\mathrm{r}_{\mathrm{s}}\right)$ was used to conduct correlations on diabetes educators' perspectives on referring patients to specific diabetes web sites and on using the Internet for diabetes education. There were significant correlations between referring patients to diabetes web-sites and their agreement that there is useful diabetes-related information for patients (Q63), that online reputable websites can help to reinforce diabetes selfmanagement. (Q68), and that patients trusted their opinion on diabetes information found online (Q66). Significant correlations were also found on referring specific diabetes web site and the opportunity to discuss Internet-based information (Q61), to discuss their concerns about diabetes information found online (Q67), and to help clarify any misinformation their patients might have (Q61). Table 16 summarizes diabetes educators' perspectives on referring patients to specific diabetes websites. 
Table 16.

I Refer My Patients to Specific Diabetes Web Sites (Q64)

$\Gamma_{\mathrm{S}}$

Q52 It's so easy for patients to get the wrong information, and it's $-.062$ difficult to reverse the misconceptions ${ }^{\text {(a) }}$

Q53 It can be time-consuming with little to be gained

Q54 I feel tense when they bring information found online .108

Q55 I prefer patients rely on the information they receive from us

Q56 I avoid discussing Internet-based information $.340 *$

Q57 In my opinion, it's a big waste of everyone's time

Q58 It depends on which patients are bringing the information in

Q59 It's helpful to know what the patients are thinking about

Q60 Sometimes I learn from the information patients bring in

Q61 I can help to clarify any misinformation they may have

Q62 It's a good teaching tool

Q63 There is useful diabetes-related information for patients online

Q65 Patients use the Internet to take better care of themselves

Q66 They trust my opinion on diabetes information found online

Q67 We can discuss their concerns about diabetes information found online

Q68 Reputable websites help to reinforce diabetes self-management

(a) Negative statements that were coded in reverse are italicized.

* Correlation is significant at the 0.05 level (2-tailed).

** Correlation is significant at the 0.01 level (2-tailed). 
Written comments from the diabetes educators. In an open-ended question, diabetes educators were asked to comment on their experiences with patients who used the Internet for diabetes information. When patients bring diabetes information from the Internet, a diabetes educator felt that, "it shows that they are interested in learning more information and many times reinforces what we have discussed.” Another educator reported that," most [patients] found good information on the Internet. Most information has either supported existing information or encouraged discussion of usefulness in their care.”

Diabetes educators voiced their concerns with misinformation on the Internet and with websites that are not are considered "reputable." Several commented on their patients’ interest in complementary and alternative medicine to manage diabetes. "Many times they come in with misinformation; foods that 'cure' diabetes and dietary supplements,” an educators reported. “Most patients bring me information they have found regarding: herbs, wanting to use these rather than meds. It is difficult to convince patients that the herbals may not be the 'cure all,' though many do have some benefits.” Another educator encouraged patients with diabetes to exercise caution, "I try to urge patients to be careful of chat rooms, especially those that are clearly against standards of diabetes care, such as severely limiting carbohydrates or other harmful behavior.” Concerns about artificial sweeteners and their safety were mentioned by several educators.

A diabetes educator noted, “They learn from the Internet, but may not fully understand. It is a good feeling when they come to a CDE to clarify their understanding.” Several educators commented on the opportunity for discussion and to 
“weed” out information patients found confusing. One educator felt that, “Any information received by internet, mail, books, friends, and family opens the door for discussion, clarification, and verification. [It] is a helpful learning tool and resource for patients.” Another educator commented on the usefulness of the Internet, “The internet augments the diabetes educator's resource toolbox.”

Summary of the Survey

Diabetes educators were able to integrate Internet technology in their practice. Four factors influenced diabetes educators' integration of the technology in their practice. These factors included (1) access and use of computers and the Internet, (2) educators’ perceived adequacy in training on the use of computers, (3) educators’ perceived effectiveness in computer use in practice, and (4) educators' perceived quality of diabetes information on the Internet.

Diabetes educators who reported having adequate training indicated having a high comfort level with using the computer. They perceived the quality of diabetes information on the Internet to be high and that the Internet increased their productivity and improved the quality of education they deliver. Educators who perceived that they were using computers effectively in their practice reported using the internet for professional development and communicating with their patients. Finding time for online information search posed a challenge for many of the educators.

Diabetes educators felt that frequent communication with their patients promotes self-management and enhances the educator-patient relationship. Educators had mixed feelings about the quality of the diabetes information found online. They referred their patients to Internet-based diabetes information, discussed their concerns 
about web-based diabetes information, and helped clarify any misinformation their patients might have.

\section{Qualitative Method: Results}

To gain a greater understanding of the diabetes educators’ perspectives and experiences in utilizing Internet technology, personal interviews were conducted at the educators' worksite. From the 24 responding educators who indicated on the survey their willingness to participate in the interviews, the maximum variation approach used to select the five educators. Considerations included variety in experience as well as the years of diabetes education experience. Both genders and all three health professions (nursing, dietetics, and pharmacy) were represented. Educators provided formal and informal education for inpatients, outpatients, and consumers. All five of the educators reported using the computer more than five times a day. Characteristics of the participants in the interview process are summarized in Table 17.

The case reports focused on the diabetes educators' perspectives and experiences using the computer and Internet in their medical practice. Case reports were described individually for each participant under the subheading: (1) Using the computer and Internet, (2) educator-patient relationship, (3) useful diabetes information online, (4) observation of worksite, (5) document analysis, and (6) summary. Pseudonyms were used to protect the identity of the diabetes educators.

At the end of description of individual cases, a summary of case reports presented the most important characteristics across the cases. Case comparisons were conducted to portray how diabetes educators with similar perspectives integrated computer and Internet technology in their medical practice. 
Table 17.

Interview Participants

\begin{tabular}{|c|c|c|c|c|c|}
\hline & Alice & Carol & Diane & Rita & Tina \\
\hline $\begin{array}{l}\text { Diabetes } \\
\text { Education } \\
\text { (Years) }\end{array}$ & 25 & 10 & 4 & 10 & 9 \\
\hline $\begin{array}{l}\text { CDE } \\
\text { (Years) }\end{array}$ & 20 & 9 & 1 & 7 & 1 \\
\hline $\begin{array}{l}\text { Patients per } \\
\text { month }\end{array}$ & 80 & 6 & 120 & 30 & 60 \\
\hline Methods & Individual & $\begin{array}{l}\text { Individual } \\
\text { Support } \\
\text { group } \\
\text { Community } \\
\text { education } \\
\end{array}$ & Individual & $\begin{array}{l}\text { Individual } \\
\text { Group }\end{array}$ & $\begin{array}{l}\text { Individual } \\
\text { Group }\end{array}$ \\
\hline Worksites & $\begin{array}{c}\text { Outpatient } \\
\text { Inpatient } \\
\text { Clinic } \\
\text { Hospital } \\
\text { Dr.'s Office }\end{array}$ & $\begin{array}{l}\text { Outpatient } \\
\text { Dr.'s office }\end{array}$ & $\begin{array}{c}\text { Outpatient } \\
\text { Hospital }\end{array}$ & $\begin{array}{c}\text { Outpatient } \\
\text { Hospital }\end{array}$ & $\begin{array}{l}\text { Outpatient } \\
\text { Clinic }\end{array}$ \\
\hline $\begin{array}{l}\text { Patients } \\
\text { bring info } \\
\text { from the } \\
\text { Internet }\end{array}$ & $\begin{array}{l}\text { Nearly } \\
\text { every week }\end{array}$ & $\begin{array}{l}\text { Once a } \\
\text { month }\end{array}$ & $\begin{array}{l}\text { Once a } \\
\text { month }\end{array}$ & $\begin{array}{l}\text { Nearly } \\
\text { every week }\end{array}$ & $\begin{array}{l}\text { Once a } \\
\text { month }\end{array}$ \\
\hline
\end{tabular}

*Gender, profession, and location of worksite were omitted to maintain anonymity. 
Case Report 1: Alice

\section{Introduction}

Alice has over 20 years experience in diabetes education. In addition to being a certified diabetes educator (CDE), she has a master's degree in her health profession. Alice works at four different sites during the week. In addition to her office and classroom at a community hospital, Alice cares for patients in clinics in three surrounding counties.

\section{Using the Computer and Internet}

Alice had learned to use the computer primarily through self-study, on-line tutorials, and self-help books. Although she had not received any formal training in using computers, she felt that she had been using computers effectively in her practice. Learning to use the computer made high demands on her time. She felt that her computer skills had helped her professionally and that she had been developing expertise in using the Internet in her practice. She used the computer to communicate with her patients throughout the day. Finding time to search for diabetes information online remained a challenge for Alice.

When asked about her feeling about using computers, Alice readily related her enthusiasm, "I love working with the computer. It is so much easier than books. I still have a lot of books as you can tell. It is so much easier. Each of the clinics I work at, it is set up with Internet. I don’t have to take anything with me when I go. I just show up and retrieve it wherever I am.”

As for her feelings about information from the Internet, Alice shared, "The internet gives me quick, convenient, on-the-spot information.” She had been utilizing 
the Internet to keep abreast of diabetes-related news. She sought "scientific-based information with references of how data was concluded.”

Alice voiced concerns about new diabetes medications on the market. She presented an example of an oral diabetes medication with cardiovascular adverse side effects that made recent newspaper headlines as to its safety. She stated that, “...if you have been watching the FDA [Food and Drug Administration] site, that's been going on for a while. It's nothing new.”

\section{Educator-Patient Relationship}

Alice felt that the Internet is a good communications tool. Her diabetes education program had a special e-mail account created for the patients to regularly submit their blood glucose readings. She shared, "When they open it up, they have a little graph. All they have to do is to plug the numbers in. We go into it couple of times a day and print it off. We can make comments back. We can write our notes right here. This goes in the chart. It is real clear what we e-mail back to the patients. We also find that our patients will write us notes, too. We simply print this, answer them back, and jot our answer down. It’s all in one place. People who are computer savvy love it.” Her patients also have the capability of faxing their blood sugars to a specific phone line designated for blood sugar only. For people who are not comfortable with the computer, Alice included a third option. These patients could call in to a voice-mail line that is dedicated for blood sugar readings.

Alice noted the reduction in time and the increased accuracy in communicating with her patients associated with integrating computer and Internet technology in her practice. She felt that managing blood glucose levels among pregnant patients with 
diabetes could be especially challenging, when blood glucose must be maintained within a very narrow range. Since these patients must be more intensively monitored in order to achieve optimal outcome, regular communications with detailed instructions would be essential. Alice reported that, "most of the young girls are really computer savvy. They love it. I check it twice a day and answer them. It's very quick and efficient. If I need to call them for something, I call them. Most of the time, I don't have to. Everything is concrete. We have all the pre- and post- [blood sugar readings], carbs, and what time it was. It is really convenient for us. We were taking multiple phone calls.” She added, "When I make a change, very next day they write the answer back to me.”

In updating information for diabetes classes, Alice had been using the Internet to look up new drugs and their mode of action. She added new information to the medication component of the Power Point presentations that she used in diabetes classes. She stated, "I am a firm believer that if you explain to them very specifically what the drug is doing in their body, why it needs to be taken when it's taken, and show that to them in some kind of concrete form ....pictures, diagram of some sort that connects with that person, then the compliance of taking the medicine and the fear of taking the medicine is significantly reduced. The compliance is better. The fear is less.” Alice felt that by explaining the rationale of the treatment process, she would be better able to promote adherence among her patients, "I actually give a demonstration of this is what's happening in your body with your glucose and your insulin. This is what's happening now, the normal process. When I plug this drug in, this is what it 
does. I find that it's like light bulbs going off. The patient says, oh, I understand now! I understand why I have to take this now and not later.”

When asked about referring patients to specific web-sites, Alice noted that, "When I am doing the assessment of the patient, I determine how computer savvy they are. If there is someone who is extremely interested in the computer, then I give them resources. Because, they are going to do it. Number 1, they want the information. Number 2, they like using the computer.”

To better manage some of her patient appointment times, Alice had been referring patients to a specific website on the Internet. She had been able to address requests from patients for instruction on how to take a certain diabetes medication that required frequent injections. She would send the patients to the product website first before scheduling an appointment for an office visit or a class meeting. She stated, "I had a few family practices starting the patient [on the medication] just by giving them a prescription. The patients would call and want to know what to do. We try to get them in as quickly as we can. Obviously we cannot accommodate everybody at the same time. So, we have them go to that site and look at it. Try it. Call us back. Let us know how you are doing. We just have a few that we have to bring in. The rest have done really well on following those instructions. We always get them in to assess how well they did understand it. So far, everyone has done pretty well.” She added, “There is a very nice....step one...step two...for those who want to do one step at a time. They can pause. I've found that most of the patients I have worked with haven't had any problems with it. When they go there, they probably have half of their questions answered, whether they are a good candidate and whether this is the medicine for 
them." She asked her patients to "make me a list of questions. When you come in and we'll go from there. She felt that, “They are very knowledgeable about it when they go to that site. I even told a few people who don't have computers to go over to the library. This is how you get on. They come in and [have] done it [properly injected the medication]! ”

\section{Useful Diabetes Information Online}

Alice shared some special web-sites that she frequently uses for diabetes education: Food and Drug Administration (FDA), American Association of Diabetes Educators (AADE), American Diabetes Association (ADA), American Association of Clinical Endocrinologists (AACE), National Institutes of Health (NIH), and Family Practice (FP) websites. She also mentioned several diabetes medication websites that she frequently used and shared with patients: Byetta.com and Januvia.com. When doing online research, Alice said she might search by the names of experts in diabetes management field. She found articles that detail their research findings that could be incorporated in her class presentations.

When asked about the ideal website for the diabetes educator, Alice already had a wish list. The list started a "favorites" list of helpful links for quick retrieval. She also included a hospital-based web-site that would be accessible from any computer connected to the Internet. She became animated as she shared her dreams, "I would like to develop a computer program that when a patient is in the hospital, they can go to the computer. The computer would be in their room. Go to the computer as they are feeling as they are able to do it. They can get survival skills on that computer. I want you to eat like this. I want you to test your blood sugars this way. This is how you take 
an injection. And then number 4, call this number and get an outpatient diabetes education program. That's my dream that they develop that here.” She emphasized the benefits of starting patients with their diabetes education in the hospital, "It will help people be able to get what they need right now, until they get out of the hospital. It will help them know what to do until they can get back in here. We can get them started when they are feeling better." She added, "If you go to give them that information oneto-one, they don't remember it. At least with a website, they can say... 'I look at it in the hospital, but I don't remember what she said about eating.' So they can go back to the website when they get home. They can pull it up. They look at it again...right when they want to know the information” She acknowledged that, "when you try to be an inpatient educator and make rounds on all the folks, you can't get to everybody right at the time they're ready. If you have a website, when they are ready, they can go to it. The only hindrance to that is not all of our population is computer savvy yet. I can see that in the future that would be less and less of a problem.”

Alice would like to have more diabetes care manuals available electronically so they can be retrieved online. She felt that the information can be readily updated and available from any computer with an Internet connection. Ideally it would have a single point of entry, one URL. She could locate information targeted for the diabetes educator as well as those for patients. She would be able to print-out the most relevant diabetes patient education hand-outs for patients to take home and review. From this single source, she suggested a link to a companion site specifically designated for patients to retrieve additional diabetes education information and materials. 


\section{Observation of Worksite}

Alice had access to a computer with Internet connection and printer at her office. Her classroom was adjacent to her office. It was equipped with an LCD projector and she had an extensive library of diabetes education books and journals in both rooms. She also kept a supply of diabetes management booklets produced by pharmaceutical manufacturers for consumers. Most of these booklets could be ordered directly from the Internet. The whiteboard in her office still had a faint outline of an algorithm used in determining diabetes treatment plans. The walls held colorful posters that helped to translate glycosylated hemoglobin into average blood glucose levels and diagrams illustrating how the complications of diabetes affected the various systems of the body. Document Analysis

Alice shared a copy of the form on which her patients entered their blood glucose readings. Instructions included detailed information on how to email, fax, or call their blood glucose in weekly to her office. She acknowledged that, "I have a few patients who don't like this format. They make up their own.”

\section{Summary}

Alice appeared to have fully embraced many of the benefits that the communication and research features that computer and Internet technology offered the diabetes educator. A frequent user of this technology, she readily voiced her appreciation of its accessibility from the various worksites she sees patients. She had been using the resource to keep up-to-date on the latest diabetes information, which could be readily incorporated in providing diabetes care and education. 
The technology allowed Alice the flexibility to communicate with her patients in a timely fashion. She was able to obtain blood glucose readings and provide a speedy response to her patients. By referring her patients to a specific website, her patients arrive at their scheduled appointments better prepared. Alice provided follow-up to determine their success. She had identified multiple situations in which computer and Internet technology can be integrated in her medical practice. 


\section{Case Report 2: Carol}

\section{Introduction}

Carol had over ten years of diabetes education experience. A certified diabetes educator since 1998, she has been involved primarily with out-patient diabetes education in a physician's office setting. She also conducts two diabetes support groups (adult and juvenile), and community diabetes education. Working in a growing community, her patient load had increased dramatically over the years.

Without any formal training on using computers, Carol learned to use the computers from colleagues, friends, and family. She also relied on online tutorials and self-help manuals. She had been using the computer several times each day to communicate with her patients and to search for diabetes information.

Using the Computer and Internet

When asked how she feels about using the computer, Carol replied, "I think it opened up a world of knowledge to me... where I could contact people. I could contact you. Say, hey this is what happened to me. Do you know anything? Can you help me?” She recalled what it was like before the availability of computers and the Internet, "I’m trying to remember before and after. Before we had the Internet.... and then after we had the internet.” In addition to increasing her communications with other people, Carol stated that the Internet had been a very useful tool. It had helped her professionally and increased her productivity.

As for using the Internet for diabetes information, Carol replied, "If I need it very quickly....if I need some information very quickly. I don’t have time to go to a 
textbook. I will go to the internet. There are so many things that have been coming out the last few years that have revolutionized the care of diabetes. It's hard to keep up.”

Carol felt that the Internet had been a very good resource. She recalled going to the Internet to research a highly concentrated form of insulin to be used with an unfamiliar diagnosis. "We will get [a] patient who uses insulin U-500. She is very resistant. It was this diagnosis that I never heard of. Lipodystrophy.” Carol acknowledged that the Internet had been a valuable resource. She quickly added with a chuckle, "So we can talk to a patient and act like we know sort of what we are doing."

Carol voiced her concerns with misinformation on the Internet as well. She had been relying primarily on Google or MSN to help find diabetes information. With online searches, she would type in the word and get thousands of hits. To determine whether the information is useful, she would "look at the bottom. Oh, that looks like a reliable resource, something that I would believe.”

The ability to review information had been very helpful for Carol. She shared, “Let me see that again. That's a feature I like about those types of things. I get distracted. Your mind goes away. What was that? You go back and look at [again].” The opportunity to order educational literature online was a feature that Carol found helpful. She felt that it was easier than faxing. She mentioned, "You can go through and mark what you want.” Due to the lack of storage space, Carol was particularly appreciative of the ability to print out patient information sheets as needed. She could not always accurately predict what hand-outs would be required before the patient visits. 


\section{Educator-Patient Relationship}

Carol shared a situation with a patient whose employment may be jeopardized by his need to use insulin to control his blood glucose. She posted a note on the American Diabetes Association (ADA) web site advocacy forum requesting information from other diabetes educators on how to help her patient. From the responses, she was better able to advise her patient on the best treatment plan.

A good communication tool, Carol noted that the computer had been very helpful. She noted that, "instead of having to call on the phone and get a voicemail, can you call me back? I can email patients. They can email back their blood sugars. I have better contact with them.... when they do it. I have better contact with them. I feel that I have a better relationship or handle on what they are doing.” Carol said she felt that the outpatient clinic setting allowed her the flexibility in using Internet technology to develop a better relationship with her patients.

Carol was adamant about, “These chat rooms... I don’t depend on them.” She would remind her patients when they have been looking on the internet, "I say that I hope that you are using reputable sources....like the ADA (American Diabetes Association), AADE (American Association of Diabetes Educators), or the American Dietetic Association, that you are getting good information and reliable information. Because I have nightmares where a patient who say, 'Oh yeah, I went on a chat room and I told them that I was eating 60 grams of carbs at a meal and they say, oh my god...you shouldn’t be eating over 15 grams a day.' I don’t know where they got that information but you should not listen to them.” 
Carol shared a scenario about an educated woman who was diagnosed with gestational diabetes. The patient went online and found what she thought the blood sugar should be for gestational diabetes. Carol said that the patient informed her that she did not need to be seen, "She didn’t need us. She already read about it. We said, 'well, number one, you need to meet with us so that we can follow you. Number two, we don't use the same value as the American Diabetes Association does. For gestational diabetes, we use lower values in this office. That's where we like to keep our pregnant women. We find that it decreases the birth weight and [we] have less complication....if we use these numbers. A lot of literature will say that this is the recommended, but research found that [if we] keep them even lower [it may] decrease those problems.' She came to see us. She was reluctant, but came to see us. She may be very knowledgeable in one area, but not in diabetes.”

Carol mentioned how she appreciated "the pump school” that allowed visitors "go right in and push button and see what they do. I think that's nice." She made a sheet with the different insulin pumps and their websites for her patients to go and research. She found that by referring patients to specific diabetes web-sites, she saved everyone time. That would be time the patients took to search for the information, as well as the time for the educator to dispel any myths that the patients might inadvertently found during their search. Carol added, “As we talk and go through, that there are areas that they find that they had missed. I didn’t know that!” Scheduling patient appointments following website visits allowed Carol the opportunity to emphasize particular areas of concern. 
Technology had been helpful in maintaining contact with patients. She related, “People feel that when they can’t get hold of the doctor, they can shoot me an email. I tell them that I might get your email right when you send it.” Carol admitted to checking email and voice messages more regularly, "to try to keep in contact. I find myself using it more and more. Send me your blood sugars. Let me see them on a weekly basis...or every two day basis or whatever. Let me look them over so that we can keep on this, so we don’t let three months go by.”

Carol felt that technology had contributed to better patient follow-up. "I feel better when I know. I don't like to get that slap in the face when you are feeling that you are doing OK and then you don't see them for three months. They come back and their A1c is worst than before.”

\section{Useful Diabetes Information Online}

Carol found useful information on the national diabetes-related sites, such as the American Diabetes Association (diabetes.org) and the American Association of Diabetes Educators (diabeteseducator.org). In addition, she found the National Institutes of Health website (nih.gov) to be a useful source of diabetes information.

As for an ideal website for diabetes, Carol started with links with information about the diabetes center. She would like to have "What we do and what we offer. Contact information." She would include links to ADA and AADE for patients to find. Professional links for herself, but also for another professional. Carol recalled, “A nurse who was trying to get information about diabetes. She can go to that link too.” Carol felt that the professional links would be faster than email. She would also like to have the ability [for] colleagues or professionals or even patients to be able talk to her, 
"Have a question and talk to me. Like a little chat room. I have no idea how to do a chat room, but I know that they are out there. I don’t know how to do it.”

"What's New" would be another feature that Carol considered to be on the website. When a patient inquired about patients bringing in unfamiliar information, she confessed, “I got over being embarrassed. They'd say, 'what do you think about the some trial about this drug my dad is on?”

\section{Observation of Worksite}

Carol's office was equipped with a computer with access to the Internet and printer. She had on-hand various booklets targeted for patients produced by pharmaceutical and diabetes supply companies. Although her office had glass windows on two sides, she had colorful posters on the other two walls. These posters reminded patients the need to monitor their “ABC’s” - A1c, blood glucose, and cholesterol. Document Analysis

An important component of diabetes education is providing support for patients. Carol had been coordinating two diabetes support groups, one for adults and another for children. She was in the process of designing a postcard reminder. She showed the graphics she found on the Internet to highlight the various themes for the monthly meetings. She emphasized the importance bringing people with diabetes together. She recognized that, “adults like to socialize but they want information. Children want to talk amongst themselves.” By making the postcards more attractive, Carol hoped that they would encourage her patients to participate. 
Summary

Carol represented diabetes educators who did not receive formal training in using computers. She found assistance from colleagues, family, friends, and online tutorials. She was particularly concerned with misinformation found on the Internet. In promoting advocacy for patients with diabetes, Carol was able to locate online sources. Internet technology allowed Carol to readily share diabetes information with patients and colleagues. She also used graphics from the Internet to spark her patients' interest in becoming more involved in diabetes self-management. 


\section{Case Report 3: Diane}

\section{Introduction}

Although Diane became certified as a diabetes educator for only one year, she has been a practicing health professional for many years. Working in a small community, she had multiple responsibilities in multiple worksites during the course of her work day. The interview was conducted in her main office where diabetes education routinely occurred. Due to the small patient population requesting diabetes education, Diane would typically see patients individually in her office. She had been coordinating several diabetes support groups each month in multiple locations. These sessions were held in community centers to accommodate large groups of participants. Typically during these sessions, family members or support persons would also participate.

Training on using computers for Diane occurred in the early 1990's when Diane was first introduced to Lotus 1-2-3. She also took a class at a Vo-tech center that covered the basic mechanics of computers. Since the course was not consumerfriendly, Diane did not find the course useful at the time. She shared a historical perspective, "When they first put out computers that people could afford to buy, you had to type out the commands. Some of them didn't have disk drives. You had to do everything on your own to get anything out of it. Floppy was a floppy then. Now the flash drive, I love those things!” 


\section{Using the Computer and Internet}

Diane reported that computer skills had helped her professionally and increased her productivity. She had been developing expertise in using the Internet in her practice. She shared that "any time I'm around somebody that is around the computer or I am interested in it...I will say, how do you do that? I always feel really open about it...getting information. If I know something, I'll try to help someone else out.” Although Diane confessed that she spent a lot of time using the Internet, she felt that it is a useful tool and enjoyed using it.

When conducting online searches, Diane had been using several different search engines, Yahoo, Google, and MSN. She found that, "some search engines go to certain areas, while others don’t. Sometimes you have to pick a couple of different search engines if you are looking for different things.” She noted that, “Some people just like to Google everything.”

Diane found the websites featuring diabetes medications to be particularly helpful. She felt that, "It's hard to keep up with it. You can't get enough of it [new information]...by waiting for the new PDR [Physician’s Desk Reference]. Sometimes you get some information in the mail. Sometimes it's best if you know that there is a new medicine coming out, to look it up from their website. You can just write in the name and it will give all the information you need about it.”

Having to teach a patient how to properly dose a new diabetes medication, Diane recalled how helpful the website was for patient education. Although she attended a group session sponsored by the pharmaceutical company on the medication, she relied on the medication website for review. She shared, "When I did have my first 
educational session for a patient, I went to that website and reviewed what was on there for them. I watch myself first to be sure that it was something that I could use. It was a very good session for them [patients]. They didn’t have access to the computer. I actually sat down with them in front of the computer so they [could] watch the session themselves. It would be demonstrated to them on the computer itself.”

For both the diabetes program and support groups, Diane would order supplies directly from the Internet. With the ability to print patient hand-outs as needed, Diane appreciated not having to store printed materials.

\section{Educator-Patient Relationship}

Diane felt that some of her patients "are afraid of the Internet.” She continued, "But once you sit down with them and you show them some simple things, then they are really interested in what's going on. It really helps them to see a little better. It's a lot easier to show them than it is to try to describe something, even to the point where you can use some type of 3-D images. It's a lot better than if you just show them on paper.” Diane was convinced that using the Internet piqued her patients' interest. She discovered that for several of her patients, it was their first experience using the Internet. Although family members, particularly grandchildren, would be users of the Internet, these patients never had the opportunity. Her patient would comment, "Oh!

Oh, I’m looking at the computer! Oh, I’m looking at the internet!” Diane felt that, “A lot of people are still in awe of that media. It does help to get their attention. It keeps their attention.”

Diane was appreciative of the variety of diabetes information available online. The variety allowed her to individualize the diabetes education she delivers. Diane 
remarked, "You have some choices too. When you have some low literacy people or you are speaking with college-educated people. It makes a lot of difference that you have some choices on the Internet. It's nice that you can choose what they understand at the time.” She felt that managing diabetes often poses a challenge to newly diagnosed patients, “I don't want to confuse them. It's already bad enough. They already had a shock. It is pretty overwhelming."

In contrast, Diane’s diabetes support groups included many people with a long history of diabetes. She stated, "My support groups like to hear about the different organs that it affects. How to watch for those problems and how to manage what level that it involves...the eyes, how circulation is involved, nerves, the kidneys, nerves. They are concern about complications. Some of them are already dealing with them. Some of them are trying to prevent them.”

Diane noted her patients’ concerns with herbal medicines from England. She remarked, "It is supposed to be a diet pill. I went on the internet to find about it." She felt that sites with either dot.org, dot.gov, or dot.edu would be appropriate. They would be research-based. As for the dot.com sites, Diane felt that, "Most of the time they're mostly commercializing their own products. Sometimes you have to get that, but then you don’t stay with one web-site.” She emphasized the importance of visiting “other websites to see if there is any opposing information.”

\section{Useful Diabetes Information Online}

Some of Diane’s favorite websites are saved on her computer for easy access.. They included frequently used medication websites, the Center for Disease Control and Translations (CDC), and the National Institute for Diabetes, Digestive and Kidney 
Disease (NIDDK). For low literacy diabetes education materials, she added the Joslin website to her list of favorites.

As for an ideal website for diabetes information, Diane requested the basics of diabetes self-management. In addition, she would like, "How to get in touch with me? If you are not there, there should be some way to leave messages.” She felt that the site should also be attractive and colorful. She was interested in having links for educators to access resources, such as the American Diabetes Association or to graphics that would not be copyrighted.

\section{Observation of Worksite}

Although Diane had a small space in which to educate her patients, her arrangement of a small round table surrounded by colorful display of diabetes supplies and posters made the education area quite cozy. She had booklets distributed from pharmaceutical and blood glucose meter companies displayed. She posted reminders on routine foot care. She also had a variety of product samples to share with her patients. Document Analysis

Diane would assemble a packet of basic diabetes information that she routinely used for educating patients newly diagnosed with diabetes. The packet included educational materials ordered from the Internet. Booklets contained large fonts, 12 points or higher. Diane felt that, “It helps to visualize what's going on. I'm not trying to sell you anything. I'm trying to get you the information. I find that they are easier to read. It helps them get the information.” Diane encouraged her patients to send for a free diabetes book from the CDC. Over 100 pages, it could be downloaded from the 
Internet. She felt that, “As long as they'll send it to my patients free, I give them one of these forms to send out."

Based on the individual patient's need, Diane would include the most appropriate literature. She would include an identification card in the packet. She commented, “It’s something for their wallet until they get their medical alert bracelets or necklace.” She would review the proper procedure to dispose sharps, such as lancets, needles, and syringes. Since her patients with diabetes routinely monitor their blood glucose, she felt that they need to safely dispose the used lancets. She printed in colored paper “The Household Guide for Proper Disposal of Syringes and Sharps” hand-out from the West Virginia Department of Health and Human Resources website. The SMOG readability level for this document was at the eighth grade level.

Summary

When the computer was in its infancy, Diane had an unsatisfactory and brief exposure. More recently as a diabetes educator, she discovered the new improved modern day version of the computer. Her experiences using the computer had improved and increased dramatically. She learned to access diabetes information and materials from the Internet. When there was a need, she felt comfortable asking for assistance. She enjoyed sharing diabetes information from the Internet with her patients and colleagues. She found useful web-based information with which to individualize her patients' diabetes education. Diane had been successfully integrating technology in her practice. 


\section{Case Report 4: Rita}

Introduction

Rita has been certified in diabetes education for seven years. Her patient load averaged 30 each month in an outpatient hospital setting. Typically she sees patients individually as well as in group classes. Without formal training in using computers, Rita acquired her computer skills from colleagues, friends, and family. She reported using the computer more than five times each day.

Using the Computer and Internet

Rita strongly agreed that computers increased her productivity and helped her professionally. She had been using the internet for various different resources. Being a frequent user of the computer, she participated in computer-based instructions. She searched the web for patient handouts and diabetes products. She felt comfortable using this technology. She thought the quality of diabetes-related information was high for health professionals as well as for consumers. She had not experienced any difficulty in finding time to search for information online. Rita admitted, "I like to use the internet a lot. I have the Dow Jones report on the internet between patients to check on investments.”

With unfamiliar or new topics, Rita would perform a “Google” search. Occasionally the topic might be a supplement or food that she had not used previously. She would look for websites that she felt were credible. She would also check on the latest news that the government issued. She noted, "I really like to confirm any information that I see....to see what their sources are.” 
Rita voiced some concerns with some listservs and websites. She felt that there might be some misinformation that came through that she might be tempted to utilize. However, the information was not properly referenced. She admitted, "I am pretty selective about the sites I go to get information. Just like email. We get a lot of things through the email. There's all this email about all kinds of medication. A lot of spam. That's the concern.”

\section{Educator-Patient Relationship}

Before responding to individual patient inquiry, Rita would frequently go to the Internet for diabetes information. She shared, “If I don’t have a journal present with me, or don’t have any kind of reference, I’ll use the Internet to try finding something quickly. I go to a site that is credible to use that information.” To meet the individual patient's need, she would copy the diabetes information from a website and paste it on a word document. She would perhaps change a few things, such as enlarge the font size, to meet the patient's particular need. Or, what she felt the patient needed based upon her expertise.

Rita would encourage patients to bring diabetes information to class. The information could be from newspaper articles or anything they get off the internet to share. Rita felt that, “This fast paced environment that we are in, it's very possible that somebody can pick something up, something from the news, something on the internet that I've not even seen yet from the journal. I am not offended if somebody tells me that. That's fine.” She thought that sometimes the patient would be utilizing a nonreferenced resource in getting the diabetes information. She viewed patient sharing web-based information provided an opportunity to clarify any misinformation. 
In group classes, Rita found that delivering information to the patients about the different websites available on the Internet had been helpful for the patients. The list would be in addition to the hand-outs that she would give her patients and the practical experience that they would receive during the diabetes education classes. Rita included a variety of websites for the patients. The websites included fast foods, restaurants, and the United State Department of Agriculture (USDA). During class discussions, she would highlight the special features of each website on the list and its usefulness to her patients.

Rita frequently received email from her patients. She would have the answers to her patients' questions ready at the next class. She felt that information from reputable websites could help to reinforce diabetes self-management. She strongly agreed that the internet is a good teaching tool. However, Rita indicated on the survey that she disagreed with the statement, "Patients use the Internet to take better care of themselves.” During the interview, the researcher pointed out the inconsistency in her responses to similar statements about the benefits of the Internet for patient education and care. Rita took the opportunity to clarify her responses. She emphasized her concern for her patients' ability to identify reputable diabetes websites. In an effort to promote a product or service, she felt that some websites might present incorrect information.

\section{Useful Diabetes Information Online}

To address health issues relating to specific nutrients, Rita would go to the USDA website. Information sought could be on potassium, phosphorus, or some of the 
nutrients that might have been limited. Information on these nutrients would not be on the food label. She admitted to having a long list of favorite websites.

For an ideal website for diabetes education, Rita would like to see information that addresses hypoglycemia. She stated, "When they are first interviewed, patients use all sorts of bizarre foods to treat low blood sugar that are not appropriate.” She included patient oriented information on complications of diabetes. She felt that, "It is challenging to give them something we understand. The average consumer gets lost sometimes with all that detail.” She felt that the information they could read would be on a $6^{\text {th }}$ grade level. She shared, “This reading level would apply to anybody, whether they are educated or not.” She also included a food database on the website that the patient could access the information on the nutrients and portion sizes of various foods. She mentioned that many websites already have links or access to videos that might show how to measure food properly, do this stretching before physical activity, or proper injection sites for their medications.

Rita felt that "Taking things that would be demonstrated in a classroom that could actually be put in a film version on the website would be very helpful.” She shared a scenario of a possible webcast, "Patients tell me that they are too busy to eat lunch. They just really have to go to fast food to get their lunch. I say to them, how can you say that? You have a refrigerator in your office, you have a microwave oven. Sometimes, I go to the refrigerator and bring my food out. This is what I have for my lunch and in addition to maybe providing that something that they can take home. They can see that in their mind. If a dietitian could plan healthful meals and looked healthy, the patient would feel 'Maybe it's good for me too.'” 


\section{Observation of Worksite}

Rita’s office adjoined a large classroom. She typically used a laptop and LCD projector to show the Power Point slides presentations. Posters on diabetes care were displayed throughout the room. Rita prepared three-ring notebooks for each of her patients. The notebooks were filled with lessons, booklets, and handouts for the diabetes education classes. Many of the handouts were prepared from information found on the Internet.

Document Analysis

Rita was eager to share several documents that she printed out from the Internet. They included a patient factsheet from the American Academy of Periodontology on periodontal disease and diabetes mellitus, nutrient contents of some fast food selections, diabetes support groups in West Virginia, and patient diabetes resources which listed websites with a short description of the offerings on the sites.

\section{Summary}

Although she did not have any formal training on using computers, Rita fully utilized the computer and Internet technology for diabetes education. She used the Internet for personal information as well. She felt that the Internet is a useful tool. She readily shared educational materials from the Internet with her patients. She envisioned various educational methods in which the Internet can help patients learn new information, as well as to review this information outside of class. By referring her patients to specific diabetes websites, she would be certain that they would obtain the correct information. 
Case Report 5: Tina

Introduction

Tina had been teaching patients with diabetes in the diabetes center for nine years. She had been certified in diabetes education for only one year. She also serviced other programs in her hospital and clinic facility.

Not having had formal training with using the computer, Tina gained her computer skills through in-service workshops and online tutorials. She accessed the computer only at work and used it more than five times each day.

Using the Computer and Internet

Although Tina somewhat agreed that she had adequate training in using computers and that she was comfortable using the computer, she strongly agreed that computer skills would help her professionally.

While Tina was developing increased expertise in using the Internet, she was not sure that the Internet had improved the quality of education she delivered. When asked about her ability to use the Internet, Tina voiced her frustration with locating information quickly. She felt less confident about her computer knowledge when comparing her computer information retrieval skills with younger adults, "My level of expertise [pause], seriously, sometimes I am not as successful at finding things as younger people who do it all the time. Sometimes when I do journal searches, even though I put in the criteria I am looking for, I'll get minimal hits. Other people will find 40 - 50 articles that are relevant.” When Tina went to the Internet, she did locate the new information she sought. She also used the Internet for needed information not 
immediately available, such as blood glucose recording forms or patient education handouts.

Although Tina agreed that the quality of diabetes-related information on the Internet was high for health professionals and consumers, she encountered consumer oriented information, even if she clicked on professional links. She experienced difficulty finding time to search for information. Compared to today's Internet technology, Tina felt that she was more successful doing searches with "old technology.” She used a disk to perform literature search of the databases of the National Library of Medicine. She admitted that, "It's that I have to work at it. I am getting better at finding things.”

Tina noted that learning to use computers had made high demands on her time and she spent a lot of time using the Internet. She found a couple of educator sites that have slides. She shared, "I sign on a couple of times. Then I always get pulled away. I never have a chance to sit down and browse those sites. I'm sure that there is wonderful information there.”

Using Microsoft Office SharePoint, Tina had been able to collaborate with team members in various part of the country. She noted that, "We can all get on the site at the same time. The head of the group sets up an agenda. You can organize your meeting. Post documents that you are working on. We all have 'read and write' [capabilities on the website]. We can get in and update documents. It's fascinating! We meet every week online.” She emphasized, “That’s the new wave of the future!” 


\section{Educator-Patient Relationship}

Tina filled two roles during diabetes classes. She provided diabetes education as part of the diabetes education team. She also provided therapy and wellness assessment. She would review patient medications, their control, and make recommendations for interventions.

During diabetes classes, Tina would have to serve a large number of patients at one time. When patients needed specific information, she would have to look up the information later and call them back. She would get the medication-related questions and pathophysiology. Occasionally, she would get an herbal question. She noted that, "I do know that when I do follow-up with the patients that they are very appreciative. We get a whole range of feed-back. The ones that I am usually following with are highly motivated. They're the ones who really do want to make some change. My follow-up is not so much as a diabetes educator, but just a clinician.”

Tina would follow-up with patients when their blood glucose levels were not well controlled. She would review the blood glucose logs. She had the authority to make adjustments to their insulin regimen. At that point, Tina noted that that her patients would ask a lot of questions or state that, “I don’t know why I am here. I don’t have diabetes." She would have to sit down with the patients and explain to them how diabetes is diagnosed. She would give them the encouragement. She would explain, “That doesn't mean that you have to take insulin. It might happen somewhere down the road, but that could be many years down the road. You might be able to control it with diet and exercise if you start working on that. Then many of them will accept it.” For the pre-diabetes, Tina would say, "You don't have diabetes yet. You are not processing 
sugars normally. So, we want to take care of this now to keep your sugars controlled. So, it's longer down the road before you get to diabetes. Maybe you won’t get there.” Tina agreed that there are reputable websites that help to reinforce diabetes selfmanagement and she frequently referred her patients to specific diabetes websites.

Tina shared, “If it’s really a complicated patient, I often run it by the provider just to say this is what I think we ought to do. What do you think?” She would make a point to get back to her patients. She felt that, "Patients are almost always glad that you get back to them with something they want to know.” She felt that she sometimes learned from the information patients bring in and that it would be helpful to know what the patients are thinking about.

\section{Useful Diabetes Information Online}

For diabetes teaching materials, Tina would usually go to the American Diabetes Association website. If she needed the most recent news article on a medication or supplement, she would go to the Internet and "Google" the key words and "see what pops up.”

As for an ideal website for diabetes information, Tina quickly mentioned the standards of care, "test your knowledge” quizzes, diabetes in the news, and a link to specifically to insulin pump with catalogs and descriptions of supplies. Since she relied heavily on the Internet for information on insulin pumps, she would like detailed information that would enable her to determine which insulin pumps to recommend for her patients. She declared, "Just good general information when you want to know more about pumps. When you click on that site, it just brings up the picture of the pumps, 
each of the products that would be used with the pump, catalog number, and maybe the price.”

Tina included, “Maybe on my favorite website, if you are looking for information on DKA (diabetic ketoacidosis), these are some suggested sites with good information. Maybe frequently asked questions, chat boxes, leave messages, input or ask a question and then add dialogue underneath.”

\section{Observation of Worksite}

Tina had a computer with Internet connection in her office. In the diabetes classes, she used a laptop computer. She did not have access to the Internet. Although wireless, the signal was lost in the classroom. She experienced difficulty completing notes and orders. At the time of the interview, researcher met with Tina in her office. The patient information packet was assembled by another diabetes educator. Tina contributed handouts for the diabetes education program

\section{Document Analysis}

Tina printed patient hand-outs on specific diabetes medications off the Internet from the drug manufacturer's website. The information included the brand name, generic name, dosages, mode of action, side effects, and interactions with other drugs and food. Tina used this information to help her patients gain a better understanding of their medication as well as to help promote adherence to their medications.

\section{Summary}

Although Tina was not formally trained in using the computer, she appeared to be using the technology extensively. She expressed her frustration in the time required to complete Internet searches and the limited access to the Internet during group classes. 
She enjoyed sharing diabetes information from the Internet as well as referring her patients to specific diabetes websites. By collaborating in a virtual community, Tina was able to complete projects with other health care professionals from other parts of the country. 


\section{Summary of Case Reports}

An examination across the five cases was conducted to describe the similarities and differences in how diabetes educators perceive their role as consumers of Internet technology. The interview process provided opportunities for educators to elaborate on their perspectives and experiences with using the Internet in their practice. They also clarified some discrepancies found in their responses to the survey.

The diabetes educators in the study provided diabetes care and education for their patients in a variety of settings. They saw their patients in individual counseling or in group settings. The group encounters were either in diabetes classes or support groups, or both.

\section{Training}

All the five of the diabetes educators indicated on the survey that they had no formal education during their undergraduate or graduate education in using computers. The diabetes educators learned to use the computer from workshops, tutorials, colleagues, friends, and family on an "as needed” basis. Diane noted during the personal interview that she did have some early training in a Vo-tech center in using the computer. She stated that she did not find it to be very useful.

Although the diabetes educators interviewed mostly learned to use computers on-the-job, how they viewed the adequacy of their training varied greatly. Rita strongly agreed that her training was adequate, whereas Carol strongly disagreed. Both Carol and Tina expressed their concern with their lack of knowledge on using this technology more efficiently. Tina voiced similar frustrations with her lack of formal training. Carol, Tina, and Diane compared themselves with the younger generations who grew up 
with greater exposure to computers and Internet technology. Carol shared that, "I have children that come here [who] know more about it than I do.” She indicated that she was able to use the Internet extensively in her practice, selecting 10 out of 15 uses of the Internet listed on the survey. The other four educators averaged only seven uses of the Internet in their practice. Limited training did not appear to prevent these diabetes educators from using the computer and Internet in their practice.

Time

All five of the diabetes educators interviewed agreed that learning to use the computer made high demands on their time. They spent a lot of time using the Internet. Alice had multiple responsibilities at several worksites at different counties in West Virginia. Although she was not able to spend much time using the Internet, she reported having access to the Internet at all her worksites. She was able to quickly download diabetes education materials off the Internet as needed. Working on several projects in different facilities within the same institution, Tina also reported difficulty in finding time to search for information online. She stated that not all the rooms and offices in which she worked had Internet connectivity. For Alice, Diane, and Tina, it was important to note that diabetes education and care was one of many assignments in their workload. Nevertheless, these educators were able to carve out enough time in their busy work schedule to utilize the Internet for diabetes education and care.

\section{Quality of Diabetes-Related Information on the Internet}

The vast array of websites makes it challenging for diabetes educators to know to what content their patients have been exposed. Diabetes educators expressed mixed feelings about the general quality of the diabetes-related information on the Internet for 
both health professionals and consumers. Although Rita felt the quality was high for both categories, the other four educators reported being unsure about the quality of diabetes-related information on the Internet. This ambivalence expressed by the four educators might result from their concern for patients retrieving incorrect or incomplete information from the Internet.

\section{Use of the Computer and Internet in their Practice}

All five diabetes educators interviewed agreed that the computer is a good communications tool and that the Internet is a useful tool. They all strongly agreed that computer skills would help them professionally. Educators also felt that computers increased their productivity and that they were developing expertise in using the Internet in their practice. The diabetes educators agreed that the Internet improved the quality of education they deliver.

While four diabetes educators agreed that they used the computer effectively in their practice, Carol expressed concerns about her effectiveness. Without formal training, she learned to use the computer from colleagues and family. She felt that she would be able to use the computer and Internet better if she had a better knowledge of the technology and its available resources, rather than by accidental discovery.

The diabetes educators reported that they used the Internet in a variety of ways for patient education. The Internet was helpful for keeping up-to-date with new diabetes information and products. With increasing developments in diabetes care, educators were particularly interested in obtaining current information on diabetes medications, products, and devices for their patients. Juggling seven different classes of oral diabetes medicines, multiple combinations of insulin, and a variety of diabetes 
products and devices (glucose meters, insulin pumps, and continuous glucose monitoring systems), diabetes educators frequently relied on manufacturers' websites for detailed information on their products.

Diabetes educators had specific websites they relied on for diabetes-related information. Many of these diabetes-related websites included links for both consumers and health professionals. Educators said that they would review the information for appropriateness and completeness, prior to making any referrals. They found helpful webcasts that contained animations with an audio feature presenting step-by-step procedures on how to properly utilize medications or devices. These videos available online were particularly useful for patient education, review, and reinforcing diabetes self-management training. After viewing a product website together, Diane would "walk" her patients through the process of properly injecting a new diabetes medication. When given the website, most of Alice's patients were able to access the Internet on their own. To assist her patients with injecting the same diabetes medication, Alice would first send her patients to the website to view the procedures on their own. After the viewing, patients would make a follow-up phone call or office visit as needed. For comparing various features in insulin pumps, Carol relied on the insulin pump manufacturers' websites. Her patients would practice pushing the buttons on virtual insulin pumps prior to the actual initiation and insertion training.

Diabetes educators sought patient education handouts from the Internet. They found some handouts ready to download and use, whereas others had to be modified prior to copy and distribution. Rita said that she would first copy and paste patient education information on a text file, and then edited the information to meet the specific 
needs of individual patients. Diane found Spanish language patient handouts online to be helpful for reinforcing the education her patients received during their visits. To promote adherence, Alice sought information on the pathophysiology to explain how the diabetes medications actually functioned in the body.

Diabetes educators conducted medical searches, purchased diabetes materials, and obtained continuing education credits online. With many of the medical journals available electronically, educators utilized this resource for conducting online medical searches. They also directly ordered diabetes educational materials and products from the manufacturers online. To maintain their credentials, diabetes educators must complete continuing education requirements. They were able to achieve part of their requirements through computer-based instructional programs.

The Internet provided a means for communicating with patients via email messaging, with other providers on professional listserv, and with colleagues in sharing of information from the Internet. Alice, Carol, and Rita reported receiving email messages from their patients. However, only Alice and Carol reported sending emails to their patients. Depending on the frequency of diabetes classes meeting or follow-up appointments, responses to patients' email messages could be discussed directly with patients during the next class meeting or appointment. By participating in different professional listservs, Rita and Tina were able to communicate with other diabetes health providers. Carol and Tina frequently shared web-based information with their colleagues. The educators interviewed did not participate in any diabetes-related chat rooms. They did not have their own professional web-pages for patient communications. Alice's diabetes education program had a special email account 
created for their patients to submit their blood glucose reading on a regular basis.

Carol's department had a webpage that presented general information on the diabetes education program with contact information.

The diabetes educators interviewed found online information useful in their practice. All five of the educators found useful information on product information and links for additional diabetes information. They all relied on professional diabetes websites, such as the American Diabetes Association, the American Association of Diabetes Educators, the Centers for Disease Control and Prevention, and National Institutes of Health, for information on diabetes education and care.

\section{Educator-Patient Relationship}

Although diabetes educators expressed concern with the amount of misinformation about diabetes on the Internet, they felt that the Internet was a good teaching tool. While they agreed that using the Internet can be time-consuming, they did not agree that the time was wasted.

All five educators agreed that it is easy for patients to get the wrong information and it would be difficult to reverse misconceptions. All the educators interviewed voiced concern with misinformation found on the Internet, such dietary supplements, herbs, and "the cure” for diabetes, which patients frequently sought. Educators felt that some patients might not be able to distinguish between useful information and product promotions. Since patients sometimes experience difficulty discerning objective from subjective, and reliable from unreliable information on the Internet, educators felt that patients need to exercise caution when identifying reputable sites. Carol was particularly concerned with the "missed" information, when her patients found only a 
portion of the information or found information that did not apply to their particular situation. Incomplete information could be misleading for patients who were not yet well-educated about their disease and treatment goals.

All the diabetes educators interviewed received an inquiry from their patients about diabetes-related information from the web at least once a month. Alice and Rita reported receiving inquiries as frequently as once a week. All the educators felt that the Internet is a good teaching tool with useful information for patients with diabetes. They agreed that the reputable websites can help to reinforce diabetes self-management. They all referred patients to specific diabetes-related websites. As part of the diabetes education notebook, Rita offered a list of quality websites for her patients to visit. By providing reputable sources of diabetes information available online, diabetes educators encouraged their patients to seek additional information to support diabetes selfmanagement education. Their patients became familiar with examples of what might be valuable in advancing their diabetes management.

Diabetes educators viewed these inquiries as opportunities to discuss patients' concerns, and to clarify any misinformation their patients might have. They felt that it was helpful to know what concerns their patients have. Educators were pleased that their patients trusted their opinions. In fact, they agreed that they sometimes learned from the information their patients brought in.

\section{Observation of Worksite}

Visits to the educators' worksites provided another dimension to the study. The researcher was immersed in the environment in which the educators worked and interacted with their patients. Observations of the availability of the educators' 
resources included access to computers, printers, and the Internet, displays of information retrieved from the Internet, and the physical arrangement of the classroom/office of the diabetes educators.

Document Analysis

Diabetes educators retrieved a variety of different information from the Internet for use in their diabetes education program. Educators found useful information on the Internet for their patients. They would download and directly print out the information as it appeared. Educators would also modify the information to meet the specific needs of their patients.

Summary

Personal interviews provided deeper insight into how diabetes educators utilized Internet technology in their practice. The researcher attempted to capture the diabetes educators' perspectives on utilizing the technology in greater depths in the case reports. Without formal training in computer use during their undergraduate or graduate education, the diabetes educators were successful in using this technology. The educators had developed expertise in using the Internet for patient education as well as for professional development. They were able to integrate Internet technology with a variety of strategies to support diabetes education and care for their patients. Educators, who reported multiple uses of the Internet, also reported greater comfort with and enjoyment in using his technology. 


\section{CHAPTER 5}

\section{Discussion}

This chapter includes four sections. These sections provide the following: (1) a summary of research design, (2) discussion of the results, (3) limitations of the study, (4) implications of the study, and (5) suggestions for future research.

\section{Summary of Research Design}

The main purpose of this study was to explore and describe the views and experiences of West Virginia diabetes educators with Internet technology in their medical practice. The study surveyed only educators who were listed as American Association of Diabetes Educators members in West Virginia. In-depth interviews were conducted with five of the educators who indicated on the survey their willingness to participate. In order to better describe the perspectives and experiences of diabetes educators in using the Internet in their practice, the study employed mixed methods.

For the quantitative method, the researcher developed a questionnaire titled, “Internet Use among Diabetes Educators Survey.” The instrument was based on findings of an informal pilot study. After the questionnaire was reviewed by an expert panel for content validity and readability, suggestions were incorporated into the questionnaire. The questionnaire was pilot-tested for usability of the instrument before data collection. A total of 41 diabetes educators self-reported their views and experiences with using the Internet with the survey. The questions were designed to gather data pertaining to diabetes educators' use of the computer and Internet in their 
practice, information on diabetes web sites educators found to be useful, and how they perceived the impact of the Internet on the educator-patient relationship.

Following the quantitative part of the study, five case studies were conducted to bring more in-depth descriptions of how diabetes educators integrated the Internet in their practice and how they perceived the impact of the technology on the educatorpatient relationship. The researcher recruited educators who indicated their willingness to participate in the interviews. Diabetes educators were purposively selected on the following criteria: reported use of Internet technology in their practice, health profession, gender, years of experience as diabetes educators, and the types of diabetes education offered at the worksite. Observations of worksite were noted. A document analysis was conducted on education materials the diabetes educators retrieved from the Internet. The case study data were analyzed using constant comparison within case and cross case analysis techniques described by Patton (2002) and Merriam (1998).

\section{Discussion of the Results}

Research Question 1 sought to answer how diabetes educators perceive using the Internet in their medical practice. All the diabetes educators who participated in the interviews shared a favorable view of Internet technology. Although they reported not having computer training during their undergraduate or graduate education, the educators sought knowledge and gained skill from a variety of sources. Through workshops, on-the-job training, and persistent inquiry, their comfort level in using the technology improved. Educators reported using the Internet for both professional development and patient education. They acknowledged that they were getting better in 
retrieving useful diabetes information online. Diabetes educators who enjoyed using the technology devoted more time to working online.

Research Question 2 sought to answer how diabetes educators integrate Internet technology in their medical practice. Diabetes educators integrated the Internet technology in their practice in a variety of methods. They voiced their appreciation for the availability to download patient diabetes information posted on the Internet. Educators routinely retrieved diabetes education information online to meet individual patient needs. Advances in mobile computing changed their work habits. One computer savvy educator was able to replicate her office and classroom experience at multiple worksites. She retrieved and printed-out diabetes education materials as needed at each worksite. In restructuring web-based information and enlarging the font size, another educator customized the information her patient needed. Diabetes educators reported benefiting from participating in a variety of online communication features. They exchanged information in chat rooms and on message boards or forums.

Research Question 3 sought to determine what factors influence the diabetes educator's integration of Internet technology in medical practice. All the educators participating in the study had access to computers at their worksite. One educator indicated that her diabetes education classroom had limited connectivity to the Internet.

Educators agreed that they used the computers effectively in their practice and that computer use increased their productivity. Educators who reported that they did not receive adequate computer training were successful in integrating computer and Internet technology in their practice. Educators who enjoyed using the Internet found or made time for conducting Internet searches. One educator indicated her preference for 
looking up diabetes information on the Internet rather than from a textbook. The recently posted information on the Internet may be more up-to-date than that the published material found in textbooks. Educators also indicated that they were developing expertise in using the Internet in their practice.

Research Question 4 sought to answer how diabetes educators perceive the impact of Internet technology on the diabetes educator-patient relationship. Although diabetes educators noted useful diabetes information available on the Internet, they also expressed concern with the quality of the information on some websites. Conducting online searches without guidance, patients sometimes experienced both misinformation and "missed" information. Educators viewed these challenging situations as opportunities. They were able to help clarify the information their patients brought to their attention. Educators reported that their patients visited the recommended diabetes websites for review and obtaining additional information not covered during class time.

\section{Limitations of the Study}

There are several limitations to this study. One limitation of this study is the low number of participants. Only the diabetes educators who were members of the American Association of Diabetes Educators in West Virginia were surveyed.

Educators who were not AADE members or AADE members who opted-out of the listing were not contacted to participate in the study. Diabetes educators in West Virginia may have different perspectives than diabetes educators in other states on how Internet technology could work for diabetes self-management. For example, educators working in remote settings might not find certain tasks useful because of the limited availability of specialty services in their locations. Educators in facilities with limited 
Internet access might desire an easier information retrieval system, such as preloaded diabetes education materials on a CD-ROM or DVD. Another limitation is that studies with small samples often raise the question of whether all of the main issues were identified. All the participants indicated that they are Caucasian. There is still the possibility that a larger, more heterogeneous group might have uncovered new issues. No new issues emerged by the fifth participant in the interview process.

The information collected is dependent on the questions asked and the interpretation, memory, veracity, and accuracy of the respondents. Additional information and opinions shared by educators during the interview process provided insight and clarification to their responses to research questions in the survey.

\section{Implications of the study}

The study confirmed that Internet technology has had a major effect on diabetes education and care in West Virginia. The information that patients and educators need to know has expanded exponentially. The Internet has been a significant factor in disseminating information. Diabetes self-management education is an ongoing process of facilitating the knowledge, skill, and ability necessary for diabetes self-care. Diabetes educators can play a major role in promoting aggressive metabolic control to reduce the risk of complications, particularly among the high-risk population in West Virginia. Difficulty in reaching the desired targets for blood glucose levels among people with diabetes underscores the need for effective preventive strategies. Diabetes educators can guide their patients in using Internet technology to better manage their diabetes and the complications. Achieving good diabetes control requires support for sustained behavior changes. A quality diabetes webpage can be like an additional member of a care team. It 
can provide support when educators are not available. It can help promote continuity of care for underserved people in rural West Virginia where access to care is limited.

Diabetes educators can use the Internet to maintain regular contact with their patients. Improvements in chronic disease care require diabetes educators to focus efforts beyond the routine encounters.

Diabetes educators can use innovative diabetes self-management education strategies to actively engage their patients. The interactive format of the Internet and 24-hour availability makes it an appealing mode of communication for many people. This strategy provides patients with additional opportunity to gain greater depth of knowledge and understanding about their disease process. They can retrieve the information presented during office visits and classes. They can review procedures on how to achieve specific glycemic goals. Internet technology is a useful tool for promoting active learning for patients and educators alike.

Technology is facilitating the spread, collection, and management of information among people around the world. New technologies and research make keeping up with the current body of diabetes knowledge a full-time challenge. What does this mean for diabetes educators who were born before the 1980s when a personal computer was a rarity? Diabetes educators in West Virginia are becoming more knowledgeable and skilled in the use of technology. They learn to integrate new resources into their practice. As Internet technology matures, educators must anticipate uncertainties and tolerate changes. Skills and knowledge become obsolete at an alarming pace. Web sites for professional development bring the instruction to educators on-demand 24/7, allowing them to work it into their busy schedules. King 
(2008) emphasized that staying flexible, intellectually curious, and well read promotes staying professionally viable. Diabetes information that set diabetes educators apart as highly recognized experts is becoming common knowledge today or is easily assessable on the Internet. It is the educators' practical application and clinical experience with patients that set them apart from those who only know the information.

As diabetes education experts, diabetes educators in West Virginia are becoming aware of the many sources of information available to consumers. They are gaining insights to know where patients turn for information and what they are being told, so they can tell it better. In facilitating behavioral change among their patients, educators themselves must become better consumers of online diabetes information as they help their patients identify which websites are most appropriate for a particular diabetes management task.

The Internet can enhance the educator-patient relationship. Interacting with their patients more frequently, diabetes educators in West Virginia can extend the reach of counseling with the use of the Internet. Educators can encourage their patients to communicate what they have learned online, monitor their progress, provide support, and help them become more engaged in their own diabetes management. They can customize the information found online to meet the educational needs of their patients. Creative, patient-centered educational strategies can support informed decision-making and behavioral change. The quality of the educator-patient relationship has clinically important implications for a range of valued outcomes beyond the acquisition of knowledge, particularly patients' treatment adherence and health outcomes. 
The results from this study pertain to diabetes educators in rural West Virginia. How do diabetes educators practicing in other states, particularly in rural communities, utilize Internet technology in their practice? How do their perspectives and experiences compare to those of diabetes educators in West Virginia? What can we learn from each other to meet the challenge of limited access, high transportation cost, and time constraints? Integration of Internet technology could be an economical and effective adjunct to providing education to a growing number of people with diabetes.

The implications of this study are summarized below in relation to the current technology practices among diabetes educators in West Virginia. Suggestions for best practices are:

1. Proficiency in using the Internet for diabetes education can be incorporated in the professional standards for achieving and maintaining certification in diabetes education. Continuing education opportunities in integrating the Internet in diabetes education could help educators could improve their effectiveness in integrating this technology in their practice.

2. Information educators frequently sought, such as current research, medications, products, devices, and handouts, can be organized on diabetes websites for easy access. Maintaining an updated list of useful online diabetes resources can reduce the time required for conducting online searches.

3. Guidance on using the Internet for diabetes self-care can be part of the national standards for diabetes self-management education. Directing patients to specific diabetes websites ensures that the information would be creditable, useful, and at the patients' levels of functional health literacy. 
4. Diabetes educators can use the Internet to maintain regular patient contact, monitor patient progress, and provide support.

5. Communication about diabetes information found on the Internet can help enhance the educator-patient relationship.

\section{Suggestions for Future Research}

Health professionals enter the field of diabetes education with years of experience in their own discipline. Their skills with the use of computers and Internet technology may be limited by the lack of formal training. However, none of the educators in this study actually requested training on using the Internet for information retrieval as part of their continuing education. Future research could identify training strategies most beneficial for educators on integrating computer and Internet technology in medical practice.

Retrieving useful diabetes information on the Internet can be a challenge for patients and educators alike. Future studies could focus on designing portals with a single point of access to diabetes information targeted for educators as well as for patients. What user-friendly features would be found in the "ideal” diabetes website? How can diabetes information be better organized and formatted to allow for easy retrieval? Educators can take an active role in designing user-friendly diabetes websites. In addition to requesting certain features on the diabetes websites, educators can partner with webmasters in developing interactive tutorials on how to effectively navigate the websites.

Best practices in a variety of diabetes education settings could be identified. Future studies could explore how diabetes educators are using the information they 
retrieve from the Internet in multiple work environments. Different patterns of use could be identified. How can diabetes educators customize their own diabetes websites to fit their professional needs as well as those of the patients they serve?

Comparable studies replicated in other states with both rural and urban communities could provide additional information on how diabetes educators working in more diverse environments are integrating Internet technology in their practice. How do the views and experiences of other health care professionals delivering chronic disease care and education compare with those of diabetes educators?

Six of the diabetes educators in the study reported that they did not use the Internet for diabetes information. Further studies can be conducted to determine the reasons for not using this technology. What are the factors that prevent educators from using this technology? Useful information can be also gained from studying the views and experiences of non-users.

The patients' perspectives and experiences with Internet technology in managing their diabetes require further exploration. Patient skills with using the Internet may be limited as well. What are their comfort levels in using the computer and retrieving information from the Internet? What are the best teaching methods for increasing patient proficiency in using the Internet for their diabetes care? Effective communication requires exchange of information in both directions. From the patients' perspectives, how do educators respond when patients sharing information from the Internet? How would their diabetes educators' interest in integrating the computer and Internet in diabetes education influence their patient-educator relationship? 


\section{References}

American Association of Diabetes Educators (2005). The scope of practice, standards of practice, and standards of professional performance for diabetes educators. Chicago: American Association of Diabetes Educators.

American Diabetes Association (2008). Standards of medical care in diabetes. Diabetes Care, 31, S12-S54.

Anderson, B. \& Funnell, M. (2000). The art of empowerment: Stories and strategies for diabetes educators. Alexandria, VA: American Diabetes Association.

Anderson, B., Funnell, M., Butler, P. M., Arnold, M. S., Fitzgerald J. T., \& Feste, C. C. (1995). Patient empowerment: Results of a randomized controlled trial. Diabetes Care, 18(7), 943-949.

Anderson, J., Rainey, M. R., \& Eysenbach, G. (2003). The impact of cyberhealthcare on the physician-patient relationship. Journal of Medical Systems, 27(1), 67-84.

Baker, L., Wagner, T. H., Singer, S., \& Bundorf, M. K. (2003). Use of the Internet and e-mail for health care information: Results from a national survey. Journal of American Medical Association, 289(18), 2400-2406.

Cain, M. M., Sarasohn-Kahn, J., \& Wayne, J. C. (2000). Health e-People: The online consumer experience. Retrieved September 25, 2005, from http://admin.chcf.org/documents/ihealth/HealthEPeople.pdf

Centers for Disease Control and Prevention. (2003). WISEWOMAN: collection of success stories from inception through 2002. Retrieved September 25, 2005, from http://www.cdc.gov/wisewoman/pdf/success_stories.pdf 
Centers for Disease Control and Prevention. (2008a). Behavioral Risk Factor

Surveillance System Prevalence date: Diabetes 2007. Retrieved July 31, 2008, from

http://apps.nccd.cdc.gov/brfss/display.asp?cat=DB\&yr=2007\&qkey=1363\&state $=\mathrm{WV}$

Centers for Disease Control and Prevention. (2008b). Diabetes: Disabling disease to double by 2050. Retrieved August 27, 2008, from http://www.cdc.gov/nccdphp/publications/aag/ddt.htm

Centers for Disease Control and Prevention. (2008c). National Diabetes Fact Sheet, 2007. Retrieved July 20, 2008 from http://www.cdc.gov/diabetes/pubs/pdf/ndfs_2007.pdf

Center for Policy Alternatives. (2006). Municipal wireless internet. Retrieved June 26, 2006, from http://www.stateaction.org/issues/issue.cfm/issue/MunicipalWireless.xml

Denzin, N. K. \& Lincoln, Y. S. (2003). The landscape of qualitative research: Theories and issues. Thousand Oaks, CA: Sage.

Diabetes Prevention Program Research Group. (2002). Reduction in the incidence of type 2 diabetes with lifestyle intervention or metformin. New England Journal of Medicine, 346, 393-403.

Eysenbach, G., Powell, J., Kuss, O, \& Sa, E. (2002). Empirical studies assessing the quality of health information for consumers on the world wide web: A systematic review. Journal of the American Medical Association, 287, 26912700. 
Fox, S. (2005). Health information online: Eight in ten internet users have looked for health information online, with increased interest in diet fitness, drugs, health insurance, experimental treatments, and particular doctors and hospitals. Washington, D.C.: Pew Internet \& American Life Project. Retrieved on May 26, 2005, from http://www.pewinternet.org/pdfs/PIP_Healthtopics_May05.pdf

Fox, S., Anderson, J. Q., \& Rainie, L. (2005). The Future of the Internet: In a survey, technology experts and scholars evaluate where the network is headed in the next ten years. Washington, D.C.: Pew Internet \& American Life Project. Retrieved on February 13, 2005, from http://www.pewinternet.org/pdfs/PIP_Future_of_Internet.pdf

Fox, S. \& Rainie, L. (2002). Vital decisions: How Internet users decide what information to trust when they or their loved ones are sick. Washington, D.C.: Pew Internet \& American Life Project. Retrieved on February 13, 2005, from http://www.pewinternet.org/pdfs/PIP_Vital_Decisions_May2002.pdf

Franz, M. (ed.) (2003). Core Curriculum for Diabetes Educators ( $5^{\text {th }}$ ed.). Chicago, IL: American Association of Diabetes Educators.

Funnell, M., Brown,T. L., Childs, B. P., Haas, L. B., Hosey, G. M., Jensen, B., et al. (2008). National Standards for Diabetes Self-Management Education. Diabetes Care, 31, S97-S104.

Gerber, B. S. \& Eiser, A. R. (2001). The patient-physician relationship in the 
Internet age: future prospects and the research agenda. Journal Medical Internet Research, 3(2):e15. Retrieved September 26, 2005, from http://www.jmir.org/2001/2/e15/

Glasgow, R. E. \& Bull, S. S. (2001). Making a difference with interactive technology: Considerations in using and evaluating computerized aids for diabetes self-management education. Diabetes Spectrum, 14(2), 99-106.

Harry, B., Sturges, K. M., \& Klingner, J. K. (2005). Mapping the process: An exemplar of process and challenge in grounded theory analysis. Educational Researcher, 34(2), 3-13.

Institute of Medicine. (2001). Crossing the quality chasm. Washington, DC: National Academy Press. Retrieved May 28, 2005, from http://www.nap.edu/books/0309072808/html/

Johnson, R. B. \& Onwuegbuzie, A. J. (2004). Mix methods research: A research paradigm whose time has come. Educational Researcher, 33(7), 14-26. Retrieved on July 3， 2006, from http://www.aera.net/uploadedFiles/Journals_and_Publications/Journals/Educatio nal_Researcher/Volume_33_No_7/03ERv33n7_Johnson.pdf

Kaiser Family Foundation. (2005, January 12). E-health and the elderly: How seniors use the Internet for health survey. Key findings from a national survey of older Americans. Retrieved on February 10, 2005, from http://www.kff.org/entmedia/entmedia011205pkg.cfm

King, K. (2008). The Competitive Edge ( $3^{\text {rd }}$ ed.). Lippincott Williams \& Wilkins. Lewis, D. (2001). Current computer use by diabetes educators. The Diabetes 
Educator, 27, 239-244.

Lewis, D. (1994). Concerns and characteristics affecting the adoption of computer based instruction by diabetes educators. Unpublished doctoral dissertation. West Virginia University, Morgantown.

Madden, M. \& Rainie, L. (2003). America's online pursuits: The changing picture of who's online and what they do. Washington, D.C.: Pew Internet \& American Life Project. Retrieved on February 10, 2005, from http://www.pewinternet.org/pdfs/PIP_Online_Pursuits_Final.PDF

Mazzi, C.P. \& Kidd, M. (2002). A framework for the evaluation of internetbased diabetes management. Journal of Medical Internet Research, 4(1), e1. Retrieved February 2, 2005, from http://www.jmir.org/2002/1/e1/

Merriam, S. B. (1998). Qualitative research and case study applications in education. San Francisco, CA: Jossey-Bass.

Merrill, C. W. (2002). The impact of Internet information on the doctor-patient relationship. Unpublished master's thesis. University of North Carolina, Chapel Hill, $\quad$ N.C.

Mikell, C. E. (2004, December). Information prescription: Closing the health literacy gap. Paper presented at the meeting of the Public Health Symposium conducted at the West Virginia University School of Medicine, Morgantown, West Virginia.

National Center for Chronic Disease Prevention and Health Promotion. (2008). West Virginia: State-based diabetes prevention and control programs. Retrieved on August 21, 2008, from 
http://www.wvdiabetes.org/

Patton, M. Q. (2002). Qualitative research and evaluation methods ( $3^{\text {rd }}$ ed.). Thousand Oaks, CA: Sage.

Powell, M. P., Glover, S. H., Probst, J. C., \& Laditka, S. B. (2004). South Carolina Rural Health Research Center: Assessment of barriers to the delivery of Medicare reimbursed diabetes self-management education in rural areas. Retrieved on September 25, 2005, from http://rhr.sph.sc.edu/report/SCRHRC-DIABETES_Exec_Sum.pdf

Risk, A. \& Petersen, C. (2002). Health information on the Internet. Journal of the American Medical Association, 287, 2713-2715.

Schillinger, D., Piette, J., Grumbach, K., Wang, F., Wilson, C., Daher, C., LeongGrotz, K., Castro, C., \& Bindman, A. B. (2003). Closing the loop: Physician communication with diabetic patients who have low health literacy. Archives of Internal Medicine, 163(163), 83-90.

Stoop, A. P., van’t Riet, A, \& Ber, M. (2004). Using information technology for patient education: Realizing surplus value? Patient Education and Counseling, 54, 187-195.

Tashakkori, A \& Teddlie, C. (2003). Handbook of mixed methods in social and behavioral research. Thousand Oaks, CA: Sage.

Turner, R. (2004, August 2). The high dose of tech. U.S. News and World Report. Retrieved May 4, 2005, from http://www.usnews.com/usnews/health/mostwired/articles/2wired.htm Vinicor, F. (2004). The future of diabetes: What is there besides new medicines? 
Clinical Diabetes, 22, 94-96.

Wagner, T. H., Baker, L. C., Bundorf, M. K., Singer, S. (2004). Use of the Internet for health information by the chronically ill. Preventing Chronic Disease. Retrieved February 15, 2005, from http://www.cdc.gov/pcd/issues/2004/oct/04_0004.htm.

Wakefield, D., Sheeley, B., Kraus, V., Sivitz, W., Laminasti, E., Zollo, S., et al. (n.d.). Delivering diabetes education over the Internet: Factors in patient acceptance. Retrieved on March 22, 2005, from http://collab.nlm.nih.gov/tutorialspublicationsandmaterials/telesymposiumcd/3B $\underline{-1 . p d f}$

Walker, E. (1999). Characteristics of the adult learner. The Diabetes Educator, 25(suppl. 6), 25-33.

West Virginia Department of Health and Human Resources. (n.d.). West Virginia Diabetes Strategic Plan, 2002-2007. Retrieved August 27, 2008, from http://www.wvdiabetes.org/Portals/12/Diabetes\%20Plan.pdf

West Virginia Library Commission (n.d.) 2008-2012 Library Services and Technology Act: Five Year Plan, 2008-2012, retrieved August 26, 2008 from http://www.imls.gov/pdf/5yrplans/WVplan2012.pdf

Wilson, E. V. \& Lankton, N. K. (2004). Modeling patients’ acceptance of providerdelivered e-health. Journal of the American Medical Informatics Association, 11(4), 241-248.

Yin, R. (2003). Case study research: Design and methods ( $3^{\text {rd }}$ ed.). Thousand Oaks, CA: Sage Publications. 
Zamudio, V. (2005, April). Special focus: Diabetes education is more than giving information. Endocrine Today, 3(4), 38-47. 
Appendix A

West Virginia University Internal Review Board

Of Human Subjects 


\section{WestVirginiaUniversity}

College of Human Resources and Education

January 11, 2007

\section{MEMORANDUM}

TO:

Liz Quintana

FROM:

$$
\text { Lynn Cartwright }
$$

Interim Associate Dean

RE: Human Resources \& Education H.S. \#2007-002

\section{Title: 'Exploring West Virginia Diabetes Educators' Perceptions of and Experiences with Integrating Internet Technology in their Practice"}

Your Application for Exemption for the above-captioned research project has been reviewed under the Human Subjects Policies and has been approved. Attached are the original of your cover letter with the signed stamp of approval. This must accompany your survey or questionnaire.

This exemption will remain in effect on the condition that the research is carried out exactly as described in the application.

Best wishes for the success of your research.

cc: Deans Office

Student Advising and Records

Anne Nardi, Advisor 
Appendix B

Survey Packet: Cover Letter and Survey

\section{Follow-up Letter}




\section{WestVirginiaUniversity \\ College of Human Resources and Education}

December 15, 2006

Dear Diabetes Educator,

I am Liz Quintana, a doctoral candidate in the College of Human Resources and Education, West Virginia University. Because of your membership in the American Association of Diabetes Educators, I am requesting your participation in my dissertation research on the integration of Internet technology in diabetes education. The research is conducted in partial fulfillment of the requirements for my doctorate in Technology Education.

The purpose of the study is to investigate how diabetes educators in West Virginia perceive their role as consumers of Internet technology. The research will require your participation through the completion of a survey about using the Internet in your practice as a diabetes educator. Completion of this survey will take approximately 10 minutes of your time.

Your participation in this study is completely voluntary, and you do not have to answer every question. All your responses will be kept confidential throughout the study. Your name will never appear on any report. The results of the research study may be published, but your identity will be kept anonymous. Upon conclusion of the study, all documents and recordings will be destroyed.

Please indicate on the survey if you wish to participate in a brief personal interview to further discuss how you feel about using the Internet for diabetes education. The interview would take 15-20 minutes at your worksite or a location most convenient to you. The interview may be recorded for accuracy.

We will be glad to share the results of the study with you. Be sure to indicate on the survey that you would like to receive this information.

Thank you for your contribution to this research. Please complete and return the survey in the enclosed selfaddressed stamped envelop by January 25,2007 . Feel free to contact me if you have any questions or concerns about this research and your participation in the study.

Sincerely,

Lız Quintana, MS, RD, LD, CDE

Doctoral Student, Technology Education

West Virginia University

P.O. Box 9159

Morgantown, WV 26506-9159

304-293-7246

equintana@hsc.wvu.edu
Anne Nardi, Ph.D.

Dean, College of Human Resources and Education

West Virginia University

PO Box 6122

Morgantown, WV 26506

304 293-5704

Anne.Nardi@mail.wvu.edu 


\section{Internet Use among Diabetes Educators Survey}

Please answer each question to the best of your ability. You do not have to answer all the questions. If a question is not applicable, please move on to the next question. Check $\checkmark$ the appropriate boxes and fill in the blanks for written answers

Computer Access and Use

1. Do you have access to a computer?

2. How did you acquire your computer skills?

3. How often do you use the computer?

Please complete this part by circling your response on a scale of:

$\begin{array}{cccccccc}\text { Atrongly Agree } & \text { Agree } & \text { Somewhat Agree } & \text { Not Sure } & \text { Somewhat Disagree } & \text { Disagree } & \text { Strongly Disagree } & \text { Not Applicable } \\ 1 & 2 & 3 & 4 & 5 & 6 & 7 & \text { NA }\end{array}$

Using the computer and Internet in my profession $\quad$ Strongly Agree $\quad$ Strongly Disagree

\begin{tabular}{|c|c|c|c|c|c|c|c|c|}
\hline 4. I have adequate training in using computers & 1 & 2 & 3 & 4 & 5 & 6 & 7 & NA \\
\hline 5. I use computers effectively in my practice & 1 & 2 & 3 & 4 & 5 & 6 & 7 & NA \\
\hline 6. I am comfortable using the computer & 1 & 2 & 3 & 4 & 5 & 6 & 7 & NA \\
\hline 7. Computer skills will help me as a professional & 1 & 2 & 3 & 4 & 5 & 6 & 7 & NA \\
\hline 8. Computers increase my productivity & 1 & 2 & 3 & 4 & 5 & 6 & 7 & NA \\
\hline 9. I participate in computer-based instructions & 1 & 2 & 3 & 4 & 5 & 6 & 7 & NA \\
\hline 10. The computer is a good communications tool & 1 & 2 & 3 & 4 & 5 & 6 & 7 & NA \\
\hline
\end{tabular}

11. Learning to use computers makes high demands on my time $\quad \begin{array}{lllllllll} & 1 & 3 & 4 & 5 & 6\end{array}$

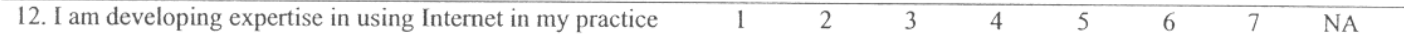

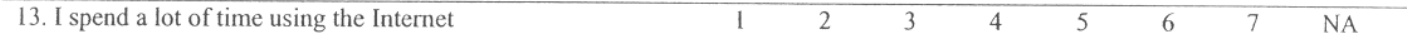

\begin{tabular}{llllllll}
\hline 14. I enjoy using the Internet & 1 & 2 & 3 & 4 & 5 & 6 & 7 \\
\hline 15. I have difficulty finding time to search for information & 1 & 2 & 3 & 4 & 5 & 6 & 7 \\
\hline
\end{tabular}
online

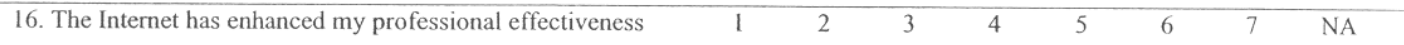

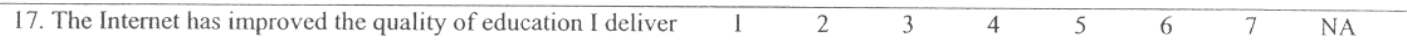

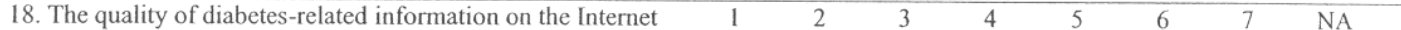
for health care professionals is high

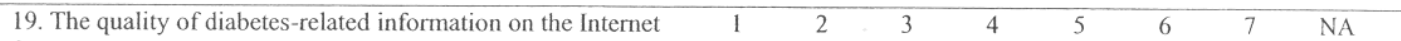
for consumers is high

20. The Internet is a useful tool

$\begin{array}{llllllll}1 & 2 & 3 & 4 & 5 & 6 & 7 & \text { NA }\end{array}$


Using the Internet in your practice as a diabetes educator

21. I surf the web for general diabetes information

22. I read diabetes-related news

Please check $\checkmark$ all that apply

\begin{tabular}{|c|c|c|c|}
\hline 23. I perform medical searches for diabetes-related problen & & 31. I receive email from patients & 口 \\
\hline 24. I search for patient handouts & 口 & 32. I email diabetes information to patients & 口 \\
\hline 25. I locate diabetes products & $\square$ & 33. I obtain continuing education credits in diabetes & 口 \\
\hline 26. I purchase diabetes educational materials and products & $\square$ & 34. I have my own professional web page & $\square$ \\
\hline 27. I obtain messages from professional Listserv & $\square$ & 35. My office has a web page for patients communication & $\square$ \\
\hline 28. I check messages on the forum or message board & $\square$ & & \\
\hline
\end{tabular}

36. Other uses (please describe)

What information on diabetes web sites have you found useful in your practice? Please check $\checkmark$ all that apply

\begin{tabular}{lccc}
\hline 37. Clinical guidelines & $\square$ & 44. Physical activity tips \\
\hline 38. Diabetes medication & $\square$ & 45. Link for additional diabetes information \\
\hline 39. Diabetes research & $\square$ & 46. Special links for health professionals \\
\hline 40. Diabetes product information & $\square$ & 47. Special links for consumers \\
\hline 41. Patient education handouts & $\square$ & 48. Support group \\
\hline 42. Nutrition facts & $\square$ & 49. Message board
\end{tabular}

43. Recipes

○

50. Other uses (please describe)

\section{Patient interest in information from the Internet}

51. Have patients ever approached you with information that

No, it's never happened

Yes, but only once or twice

Yes, it happens nearly every week 
Please complete this part by circling your response on a scale of:

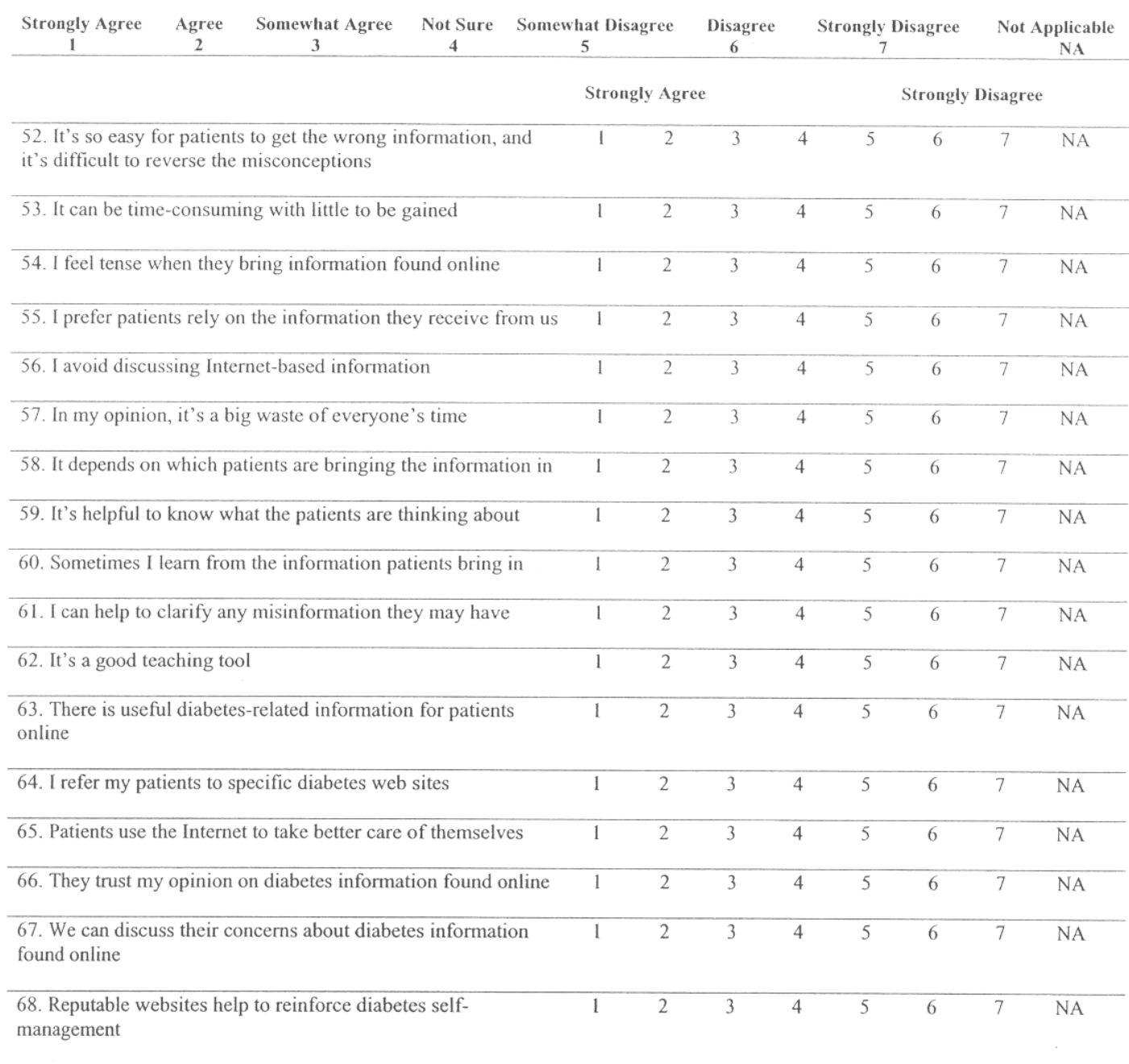

69. Please comment on your experiences with patients who have used the Internet for diabetes information.

70. Please list 2 websites that you find most useful in your work as a diabetes educator. (Name of Website or URL)

71. Please list 2 websites that you have recommended to your patients with diabetes. (Name of Website or URL)

72. Approximately how many years have you been using the Internet for diabetes information?

73. Please include any additional comments on using the Internet for diabetes information 
Demographics

Gender: Male: $\square \quad$ Female: $\square$

Race/Ethnicity:

Native American/American Indian $\square \quad$ African American $\square$

White/non-Hispanic Asian/Pacific Islander

Hispanic $\quad \square \quad$ Other, please specify

Are you a Certified Diabetes Educator?

Yes If yes, in what year were you first certified?

No $\square \quad$ If no, are you planning to take the certification exam? Yes $\square$ No $\square$ If yes, in what year?

Are you Board Certified in Advanced Diabetes Management (BC-ADM)? Yes $\square \quad$ No $\square$ If yes, in what year?

Total diabetes education experience (in years)

Average number of diabetes patients seen in a month

Are you presently providing Diabetes Education? Yes $\square$ No $\square \quad$ If yes, please specify.

Outpatient $\square \quad$ Inpatient $\square \quad$ Individual counseling $\square$ Group classes $\square$

Other methods, please describe

Your Health Profession:

Registered nurse $\quad \square \quad$ Registered dietitian $\square \quad$ Registered Pharmacist $\square$

$\begin{array}{llll}\text { Physician } & \text { Social Worker Exercise Physiologist }\end{array}$

Social worker

Other, please specify

Highest degree earned:

Bachelors $\square$ Masters $\square \quad$ Doctorate $\square$

Other, please specify

Work Site (Please check all that apply)

$\begin{array}{lllllll}\text { Outpatient } & \square & \text { Clinic } & \square & \text { Physician's office } & \square & \text { Private industry } \\ \text { Inpatient } & \square & \text { Hospital } & \square & \text { Public health } & \square & \text { Private consultant } \\ \text { Other work site, please describe } & & \end{array}$

I am willing to participate in an interview to discuss using the Internet for diabetes education. Yes $\square$ No $\square$

I am interested in receiving the results of the study upon its conclusion. $\quad$ Yes $\square$ No $\square$

If you have checked YES to one of these, please complete the following:

Name

Mailing address

Email address

Phone (day)

(evening)

Please return this completed survey in the enclosed self-addressed stamped envelop to Liz Quintana, PO Box 9159, Morgantown, WV 26506 by January 27, 2007. Thank you very much for your contribution to this study. 
February 1, 2007

Dear Diabetes Educator,

Last month a survey seeking your opinions about using the Internet in your practice as a diabetes educator was mailed to you.

If you already completed and returned the survey, please accept my sincere thanks. If not, please do so today.

I am especially grateful for your help because it is only by asking diabetes educators to share their perspectives that that we can better understand how the Internet is integrated in diabetes education.

If you did not receive a survey, or if it was misplaced, I included another one with this mailing. Please complete and return the survey in the enclosed self-addressed stamped envelop by February 8, 2007. Feel free to contact me if you have any questions or concerns about this research and your participation in the study.

Sincerely,

Liz Quintana, MS, RD, LD, CDE

Doctoral Student, Technology Education

West Virginia University

P.O. Box 9159

Morgantown, WV 26506-9159

304-293-7246

equintana@hsc.wvu.edu 
Appendix C

Research Questions: Major Concepts 
Research Questions: Major Concepts

\begin{tabular}{|c|c|c|c|c|}
\hline & Quantitative Method & Qualitative & Method & Integrative Phase \\
\hline & Survey Questions & $\begin{array}{l}\text { Interview } \\
\text { Questions } \\
\end{array}$ & Observation Guide & Expected results \\
\hline Question 1 & & & & \\
\hline $\begin{array}{l}\text { How do } \\
\text { diabetes } \\
\text { educators } \\
\text { perceive using } \\
\text { the Internet in } \\
\text { their medical } \\
\text { practice? }\end{array}$ & $\begin{array}{l}\text { I use computers } \\
\text { effectively in my } \\
\text { practice (5) } \\
\text { I am developing } \\
\text { expertise in using } \\
\text { Internet in my practice } \\
\text { (12) } \\
\text { I enjoy using the } \\
\text { Internet (14) } \\
\text { The Internet has } \\
\text { enhanced my } \\
\text { professional } \\
\text { effectiveness (16) } \\
\text { The Internet has } \\
\text { improved the quality } \\
\text { of education I deliver } \\
\text { (17) }\end{array}$ & $\begin{array}{l}\text { Would you } \\
\text { describe how you } \\
\text { feel about using the } \\
\text { Internet to obtain } \\
\text { diabetes } \\
\text { information? } \\
\text { How do you decide } \\
\text { when to use the } \\
\text { Internet for } \\
\text { diabetes education? } \\
\text { What factors } \\
\text { influences you } \\
\text { most when making } \\
\text { those decisions? }\end{array}$ & $\begin{array}{l}\text { Access to } \\
\text { computer and } \\
\text { printer } \\
\text { Access to the } \\
\text { Internet }\end{array}$ & $\begin{array}{l}\text { Diabetes educators } \\
\text { who are } \\
\text { comfortable with } \\
\text { using the Internet } \\
\text { and regard it as a } \\
\text { useful tool tend to } \\
\text { feel that it is a } \\
\text { useful tool. They } \\
\text { feel that they are } \\
\text { using it effectively } \\
\text { and developing } \\
\text { expertise in } \\
\text { integrating this } \\
\text { technology in their } \\
\text { medical practice. } \\
\text { They also enjoy } \\
\text { using the Internet. }\end{array}$ \\
\hline
\end{tabular}

useful tool (20) 


\begin{tabular}{|c|c|c|c|c|}
\hline & Quantitative Method & Qualitative & Method & \multirow{2}{*}{$\begin{array}{l}\text { Integraftive Phase } \\
\text { Expected results }\end{array}$} \\
\hline & Survey Questions & $\begin{array}{l}\text { Interview } \\
\text { Questions } \\
\end{array}$ & $\begin{array}{c}\text { Observation } \\
\text { Guide }\end{array}$ & \\
\hline Question 2 & & & & \\
\hline $\begin{array}{l}\text { How do } \\
\text { diabetes } \\
\text { educators } \\
\text { integrate } \\
\text { Internet } \\
\text { technology } \\
\text { in their } \\
\text { medical } \\
\text { practice? }\end{array}$ & $\begin{array}{l}\text { I participate in computer- } \\
\text { based instructions (9) } \\
\text { I surf the web for general } \\
\text { diabetes information (21) } \\
\text { I read diabetes-related news } \\
\text { (22) } \\
\text { I perform medical searches } \\
\text { for diabetes-related } \\
\text { problems (23) } \\
\text { I search for patient handouts } \\
\text { (24) } \\
\text { I locate diabetes products } \\
\text { (25) } \\
\text { I purchase diabetes } \\
\text { educational materials and } \\
\text { products (26) } \\
\text { I obtain messages from } \\
\text { professional listserv (27) } \\
\text { I check messages on the } \\
\text { forum or message board } \\
\text { (28) } \\
\text { I participate in diabetes- } \\
\text { related chat room (29) } \\
\text { I share web-based diabetes } \\
\text { information with colleagues } \\
\text { (30) } \\
\text { I receive email from patients } \\
\text { (31) } \\
\text { I email diabetes information } \\
\text { to patients (32) } \\
\text { I obtain continuing } \\
\text { education credits in diabetes } \\
\text { (33) } \\
\text { I have my own professional } \\
\text { web page ( } 34 \text { ) } \\
\text { My office has a web page } \\
\text { for communication with } \\
\text { patients ( } 35 \text { ) } \\
\text { Others (36) } \\
\text { Please list } 2 \text { websites that } \\
\text { you find most useful in your } \\
\text { work as a diabetes educator } \\
\text { (70) } \\
\text { What information on } \\
\text { diabetes web sites have you } \\
\text { found useful in your }\end{array}$ & $\begin{array}{l}\text { What types of } \\
\text { diabetes } \\
\text { information do } \\
\text { you usually look } \\
\text { for? How to you } \\
\text { use the } \\
\text { information? }\end{array}$ & $\begin{array}{l}\text { Availability of } \\
\text { diabetes } \\
\text { education } \\
\text { materials for } \\
\text { educators from } \\
\text { the Internet } \\
\text { Availability of } \\
\text { diabetes } \\
\text { education } \\
\text { materials from } \\
\text { the Internet for } \\
\text { patients in patient } \\
\text { waiting area and } \\
\text { education room }\end{array}$ & $\begin{array}{l}\text { Diabetes educators } \\
\text { who are } \\
\text { comfortable with } \\
\text { using the Internet } \\
\text { and regard it as a } \\
\text { useful tool surf the } \\
\text { web daily and } \\
\text { participate in one or } \\
\text { more Internet } \\
\text { communications } \\
\text { formats. They } \\
\text { participate in } \\
\text { computer-based } \\
\text { instruction and } \\
\text { obtain continuing } \\
\text { education credit. } \\
\text { They share web- } \\
\text { based diabetes } \\
\text { information and } \\
\text { education resources } \\
\text { with patients and } \\
\text { colleagues. }\end{array}$ \\
\hline
\end{tabular}


Quantitative Method Qualitative Method Integrative Phase

Survey Questions $\quad$ Interview $\quad$ Observation Guide $\quad$ Expected results

Questions

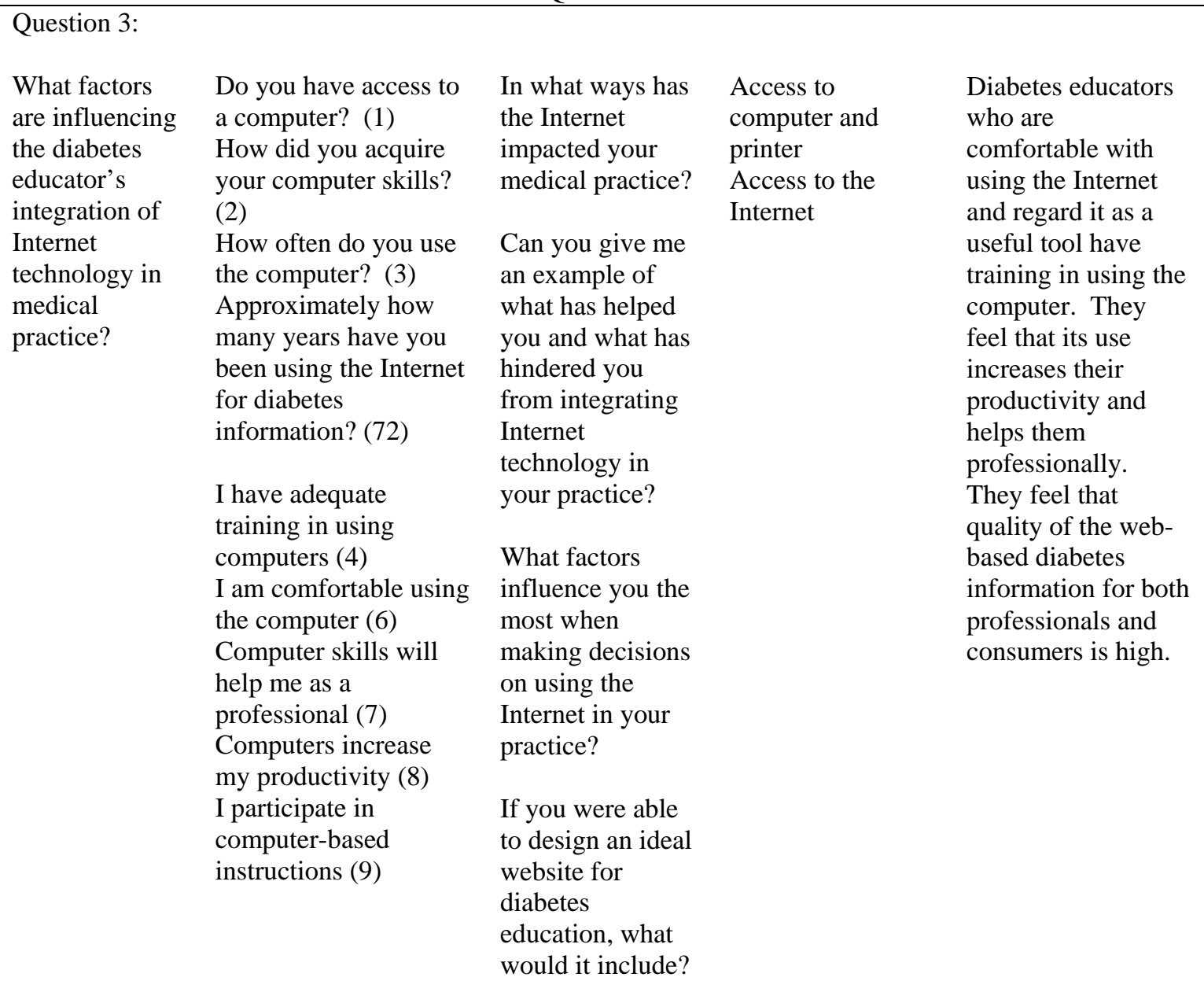


Quantitative Method Qualitative Method Integrative Phase

$\begin{array}{llll}\text { Survey Questions } \quad \text { Interview } & \text { Observation } & \text { Expected results }\end{array}$

Questions Guide

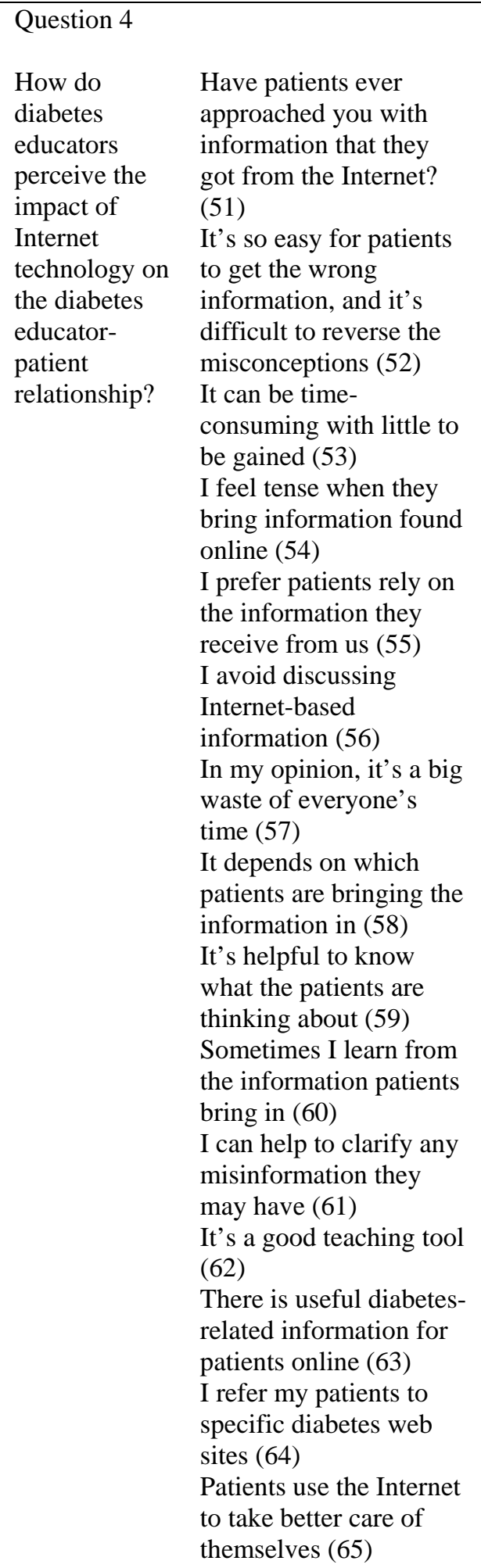

How has the

sharing of

diabetes

information from

the Internet with

your patients

influenced your

educator-patient

relationship?

If you wanted to

answer a patient's

question on the

role of cinnamon

on blood glucose,

for instance, how

would you locate

that information?

Which web sites

would you use?

Would you walk

me through that

process?

\section{Availability of diabetes \\ education \\ materials from \\ the Internet for patients in patient \\ waiting area and \\ education room}

Diabetes educators

who are comfortable

with using the

Internet may not be tense when patients

share information

from the Internet.

They may be cautious about the web-based

information their patients bring. They appreciate their patients' regarding them as authorities in diabetes education. They learn what their patients are thinking about and clarify any misinformation. They feel that the Internet is a good teaching tool for self-care and refer patients to specific websites.

Site visit:

Diabetes educators have access to the Internet and use specific websites for diabetes information for health professionals and consumers.

They use web-based patient diabetes education resources available in their medical practice. 


\begin{tabular}{|c|c|c|c|c|}
\hline & Quantitative Method & Qualitative & Method & Integrative Phase \\
\hline & Survey Questions & $\begin{array}{l}\text { Interview } \\
\text { Questions } \\
\end{array}$ & Observation Guide & Expected results \\
\hline $\begin{array}{l}\text { Question } 4 \\
\text { (continued) }\end{array}$ & & & & \\
\hline $\begin{array}{l}\text { How do diabetes } \\
\text { educators } \\
\text { perceive the } \\
\text { impact of } \\
\text { Internet } \\
\text { technology on } \\
\text { the diabetes } \\
\text { educator-patient } \\
\text { relationship? }\end{array}$ & $\begin{array}{l}\text { They trust my opinion } \\
\text { on diabetes } \\
\text { information found } \\
\text { online (66) } \\
\text { We can discuss their } \\
\text { concerns about } \\
\text { diabetes information } \\
\text { found online (67) } \\
\text { Reputable websites } \\
\text { help to reinforce } \\
\text { diabetes self- } \\
\text { management (68) }\end{array}$ & & & \\
\hline & $\begin{array}{l}\text { Please comment on } \\
\text { your experiences with } \\
\text { patients who have used } \\
\text { the Internet for } \\
\text { diabetes information } \\
\text { (69) }\end{array}$ & & & \\
\hline & $\begin{array}{l}\text { Please list } 2 \text { websites } \\
\text { that you have } \\
\text { recommended to your } \\
\text { patients with diabetes. } \\
\text { (71) }\end{array}$ & & & \\
\hline
\end{tabular}


Appendix D

Interview Questions

Worksite Observations 


\section{Interview Questions}

The following will be read to each participant immediately prior to the beginning of the interview.

Hello. I appreciate your agreeing to participate in this study.

The goal of the study is to investigate your perspectives and experience with using the Internet in your practice. The information will be used to fulfill the requirements of my dissertation, and for professional conferences and publications.

Before we start, I wish to point a few things. At any time you have a question, feel free to interrupt.

1. Your participation is entirely voluntary and you do not have to answer every question.

2. Your responses will remain anonymous and confidentiality will be maintained.

3. No attempt will be made to reveal demographic information.

4. I would like your permission to audiotape this interview. If your prefer, you may choose not to have this interview tape recorded.

5. The information will not be used for any other purposes than what is already mentioned.

6. You may request a copy of the interview.

7. The interview will take approximately 45 minutes to conduct.

Thank you very much for participating in this study. 


\section{Worksite Observations}

\section{Question 1:}

How do diabetes educators perceive using the Internet in their medical practice?

- Would you describe how you feel about using the Internet to obtain diabetes information?

- How do you decide when to use the Internet for diabetes education? What factors influences you most when making those decisions?

Question 2:

How do diabetes educators integrate Internet technology in their medical practice?

- What types of diabetes information do you usually look for? How to you use the information?

Question 3:

What factors are influencing the diabetes educator's integration of Internet technology in medical practice?

- In what ways has the Internet impacted your medical practice?

- Can you give me an example of what has helped you and what has hindered you from integrating Internet technology in your practice?

- What factors influence you the most when making decisions on using the Internet in your practice?

- If you were able to design an ideal website for diabetes education, what would it include?

Question 4:

How do diabetes educators perceive the impact of Internet technology on the diabetes educatorpatient relationship?

- How has the sharing of diabetes information from the Internet with your patients influenced your educator-patient relationship?

- If you wanted to answer a patient's question on the role of cinnamon on blood glucose, for instance, how would you locate that information? Which web sites would you use? Would you walk me through that process?

- Is there anything I have not asked about that you think I should know? 
Appendix E

SMOG Readability Calculations for AADE Reviewers 


\begin{tabular}{|lc|}
\hline $\begin{array}{l}\text { SMOG Test Table } 1 \\
\text { Words with } \\
3 \text { or more }\end{array}$ \\
syllables \\
$0-2$ & \\
$3-6$ & 4 \\
2 & 5 \\
$13-20$ & 6 \\
$21-30$ & 7 \\
$31-42$ & 8 \\
$43-56$ & 9 \\
$57-72$ & 10 \\
$73-90$ & 11 \\
$91-110$ & 12 \\
$111-132$ & 13 \\
$133-256$ & 14 \\
$157-182$ & 15 \\
$183-210$ & 16 \\
$211-240$ & 18 \\
&
\end{tabular}

SMOG Test Table 2

Number of Conversion sentences Number $29 \quad 1.03$

$28 \quad 1.07$

$27 \quad 1.1$

$26 \quad 1.15$

$25 \quad 1.2$

$24 \quad 1.25$

$23 \quad 1.3$

$22 \quad 1.36$

$21 \quad 1.43$

$20 \quad 1.5$

$19 \quad 1.58$

$18 \quad 1.67$

$17 \quad 1.76$

$16 \quad 1.87$

$15 \quad 2$

$14 \quad 2.14$

$13 \quad 2.3$

$12 \quad 2.5$

$11 \quad 2.7$

$10 \quad 3$
The SMOG TEST

Use the Smog Test to ensure that your patient education materials are written at a sixth grade level.

- Select three sets of 10 sentences from the beginning, middle, and end of your material.

- Determine how many in those 30 sentences have three or more syllables.

- DO NOT include the word Diabetes.

- Include repeated words.

- Count hyphenated words as one word.

- If a long sentence has a colon, consider each part of it a separate sentence. For abbreviated words, read them out loud to determine their non-abbreviated syllable count.

- Use the Smog Test Table 1 to find the readability grade level.

\section{SMOG ON SHORTER PASSAGES}

To determine the readability of a passage with less than 30 sentences, use this method.

- Count the total number of sentences in your material.

- Use the Conversion Table 2 to locate the conversion number in the column opposite the number of sentences in your sample.

- Count the number of words in your material that have three or more syllables. (DO NOT include the word Diabetes.)

- Multiply this word count by your conversion number. Use the resulting number as your adjusted word count to find the readability grade level in Table 1.If for example, your sample consists of 15 sentences and has 12 words or three or more syllables:

- In left-hand column of Table 2, locate the number of sentences in your material: 15 .

- Opposite 15 in the adjacent column, note your conversion number: 2.0. Multiply your word count (12) by 2 to equal 24. Use Table 1 to find the readability level of your materials.

- For a word count of 24, the grade level is eight. 


\section{SMOG READABILITY TIPS, EXAMPLES AND RESOURCES}

\section{Word Counting Rules:}

- A sentence is any group of words ending with a period, exclamation point, or question mark.

- Words with hyphens count-as-one-word.

- Proper nouns are counted.

- Read numbers out loud to decide the number of syllables.

- In long sentences with colons or semicolons followed by a list, count each part of the list with the beginning phrase of the sentence as an individual sentence.

- Count abbreviations as the whole word they represent.

\section{Samples of Different Reading Levels:}

\section{College:}

With the onset of nausea, diarrhea, or other gastrointestinal disturbances, consult your physician immediately.

\section{2th Grade:}

If you experience nausea, diarrhea or other stomach or bowel problems, call your physician immediately.

\section{8th Grade:}

If you start having nausea, loose bowel movements, or other stomach or bowel problems, call your doctor immediately.

\section{4th Grade:}

If you start having an upset stomach, loose bowel movements, or other problems, call your doctor right away.

\section{SMOG WEB RESOURCES:}

http://uuhsc.utah.edu/pated/authors/readability.html

Table by Harold C. McGraw, Office of Educational Research, Baltimore County Public Schools, Towson, Maryland Reference: Doak, C.C., Doak, L.G.\& Root, J.H. (1985). Teaching patients with low literacy skills.Philadelphia: J.B. Lippincott Co. 
Appendix F

Q4 I have adequate training in using computers 
Q4 I have adequate training in using computers

$\mathrm{r}_{\mathrm{S}}$

Q5 I use computers effectively in my practice

$.809 * *$

Q6 I am comfortable using the computer

$.725^{* *}$

Q7 Computer skills will help me as a professional

$-.042$

Q8 Computers increase my productivity

$.366^{*}$

Q9 I participate in computer-based instructions

$.641^{* *}$

Q10 Computer is a good communications tool

.064

Q11 Learning computers makes high demands on my time $e^{(\mathrm{a})}$

Q12 I am developing expertise in using Internet in my practice

Q13 I spend a lot of time using the Internet $^{(\mathrm{a})}$

Q14 I enjoy using the Internet

Q15 I have difficulty finding time to search for information online ${ }^{(a)}$

Q16 The Internet has enhanced my professional effectiveness

Q17 The Internet has improved the quality of education I deliver

Q18 The quality of diabetes-related information on the Internet for health

$.324 *$ care professionals is high

Q19 The quality of diabetes-related information on the Internet for consumers is high

Q20 The Internet is a useful tool

(a) Negative statements that were coded in reverse are italicized.

* Correlation is significant at the 0.05 level (2-tailed).

** Correlation is significant at the 0.01 level (2-tailed). 
Q4 I have adequate training in using computers (Kruskal Wallis Test)

\begin{tabular}{|c|c|c|}
\hline & $\mathrm{H}$ & $\mathrm{P}<.05$ \\
\hline Q21 I surf the web for general diabetes information & .008 & NS \\
\hline Q22 I read diabetes-related news & .417 & NS \\
\hline Q23 I perform medical searches for diabetes-related problems & 2.356 & NS \\
\hline Q24 I search for patient handouts & .233 & NS \\
\hline Q25 I locate diabetes products & .129 & NS \\
\hline Q26 I purchase diabetes educational materials and products & .000 & NS \\
\hline Q27 I obtain messages from professional Listserv & 9.623 & .002 \\
\hline Q28 I check messages on the forum or message board & 6.181 & .013 \\
\hline Q29 I participate in diabetes-related chat room & 1.411 & NS \\
\hline Q30 I share web-based diabetes information with colleagues & 1.077 & NS \\
\hline Q31 I receive email from patients & 2.436 & NS \\
\hline Q32 I email diabetes information to patients & .258 & NS \\
\hline Q33 I obtain continuing education credits in diabetes & .002 & NS \\
\hline Q34 I have my own professional web page & 1.411 & NS \\
\hline Q35 My office has a web page for communication with patients & 1.994 & NS \\
\hline
\end{tabular}


Q4 I have adequate training in using computers (Kruskal Wallis Test)

\begin{tabular}{lcr}
\hline & $\mathrm{H}$ & $\mathrm{P}<.05$ \\
\hline Q37 Clinical guidelines & 3.750 & $\mathrm{NS}$ \\
Q38 Diabetes medication & 5.465 & .019 \\
Q39 Diabetes research & 1.197 & $\mathrm{NS}$ \\
Q40 Diabetes product information & .194 & $\mathrm{NS}$ \\
Q41 Patient education handouts & .351 & NS \\
Q42 Nutrition facts & .609 & NS \\
Q43 Recipes & 1.144 & NS \\
Q44 Physical activity tips & 0.007 & NS \\
Q45 Link for additional diabetes information & 3.447 & NS \\
Q46 Special links for health professionals & 2.091 & NS \\
Q47 Special links for consumers & 4.746 & .029 \\
Q48 Support group & 1.221 & NS \\
Q49 Message board & .894 & NS \\
\hline
\end{tabular}


Q4 I have adequate training in using computers

$\mathrm{r}_{\mathrm{S}}$

Q52 It's so easy for patients to get the wrong information, and it's difficult to reverse the misconceptions ${ }^{(a)}$

Q53 It can be time-consuming with little to be gained

Q54 I feel tense when they bring information found online

Q55 I prefer patients rely on the information they receive from us

Q56 I avoid discussing Internet-based information

Q57 In my opinion, it's a big waste of everyone's time

Q58 It depends on which patients are bringing the information in

Q59 It's helpful to know what the patients are thinking about

Q60 Sometimes I learn from the information patients bring in

Q61 I can help to clarify any misinformation they may have

Q62 It's a good teaching tool

Q63 There is useful diabetes-related information for patients online

Q64 I refer my patients to specific diabetes web sites

Q65 Patients use the Internet to take better care of themselves

Q66 They trust my opinion on diabetes information found online

Q67 We can discuss their concerns about diabetes information found online

Q68 Reputable websites help to reinforce diabetes self-management

(a) Negative statements that were coded in reverse are italicized.

* Correlation is significant at the 0.05 level (2-tailed).

** Correlation is significant at the 0.01 level (2-tailed). 
Appendix G

Q5 I use computers effectively in my practice 
Q5 I use computers effectively in my practice

$r_{S}$

Q4 I have adequate training in using computers

$.809 * *$

Q6 I am comfortable using the computer

$.874^{* *}$

Q7 Computer skills will help me as a professional

Q8 Computers increase my productivity $.376 *$

Q9 I participate in computer-based instructions

Q10 Computer is a good communications tool

Q11 Learning computers makes high demands on my time ${ }^{(a)}$

Q12 I am developing expertise in using Internet in my practice

Q13 I spend a lot of time using the Internet ${ }^{(\mathrm{a})}$

$-.391 *$

Q14 I enjoy using the Internet

Q15 I have difficulty finding time to search for information online $e^{(\mathrm{a})}$

$.328^{*}$

Q16 The Internet has enhanced my professional effectiveness

Q17 The Internet has improved the quality of education I deliver

Q18 The quality of diabetes-related information on the Internet for health care professionals is high

Q19 The quality of diabetes-related information on the Internet for

consumers is high

Q20 The Internet is a useful tool

(a) Negative statements that were coded in reverse are italicized.

* Correlation is significant at the 0.05 level (2-tailed).

** Correlation is significant at the 0.01 level (2-tailed). 
Q5 I use computers effectively in my practice (Kruskal Wallis Test)

$\mathrm{H} \quad \mathrm{P}<.05$

Q21 I surf the web for general diabetes information

0.068

NS

Q22 I read diabetes-related news

0.081

NS

Q23 I perform medical searches for diabetes-related problems

4.202

.040

Q24 I search for patient handouts

1.125

NS

Q25 I locate diabetes products

0.207

NS

Q26 I purchase diabetes educational materials and products

1.337

NS

Q27 I obtain messages from professional Listserv

9.357

.002

Q28 I check messages on the forum or message board

6.170

.013

Q29 I participate in diabetes-related chat room

1.013

NS

Q30 I share web-based diabetes information with colleagues

1.046

NS

Q31 I receive email from patients

5.040

.025

Q32 I email diabetes information to patients

NS

Q33 I obtain continuing education credits in diabetes

0.332

NS

Q34 I have my own professional web page

1.013

NS

Q35 My office has a web page for communication with patients

3.583

NS 
Q5 I use computers effectively in my practice (Kruskal Wallis Test)

\begin{tabular}{lcc}
\hline & $\mathrm{H}$ & $\mathrm{P}<.05$ \\
\hline Q37 Clinical guidelines & 3.800 & $\mathrm{NS}$ \\
Q38 Diabetes medication & 4.836 & .028 \\
Q39 Diabetes research & 1.651 & $\mathrm{NS}$ \\
Q40 Diabetes product information & .721 & $\mathrm{NS}$ \\
Q41 Patient education handouts & 2.616 & $\mathrm{NS}$ \\
Q42 Nutrition facts & .116 & $\mathrm{NS}$ \\
Q43 Recipes & 2.003 & $\mathrm{NS}$ \\
Q44 Physical activity tips & 2.334 & $\mathrm{NS}$ \\
Q45 Link for additional diabetes information & 8.680 & .003 \\
Q46 Special links for health professionals & 2.231 & $\mathrm{NS}$ \\
Q47 Special links for consumers & 4.101 & .043 \\
Q48 Support group & 3.486 & $\mathrm{NS}$ \\
Q49 Message board & 3.047 & NS \\
\hline
\end{tabular}


Q5 I use computers effectively in my practice

$\mathrm{r}_{\mathrm{S}}$

Q52 It's so easy for patients to get the wrong information, and it's difficult to reverse the misconceptions ${ }^{(\mathrm{a})}$

.179

Q53 It can be time-consuming with little to be gained

Q54 I feel tense when they bring information found online

Q55 I prefer patients rely on the information they receive from us

Q56 I avoid discussing Internet-based information

Q57 In my opinion, it's a big waste of everyone's time

Q58 It depends on which patients are bringing the information in

Q59 It's helpful to know what the patients are thinking about

Q60 Sometimes I learn from the information patients bring in

Q61 I can help to clarify any misinformation they may have

Q62 It's a good teaching tool

Q63 There is useful diabetes-related information for patients online

Q64 I refer my patients to specific diabetes web sites

Q65 Patients use the Internet to take better care of themselves

Q66 They trust my opinion on diabetes information found online

Q67 We can discuss their concerns about diabetes information found online

(a) Negative statements that were coded in reverse are italicized.

* Correlation is significant at the 0.05 level (2-tailed).

** Correlation is significant at the 0.01 level (2-tailed). 


\section{Appendix $\mathrm{H}$}

Q18 The quality of diabetes-related information on the Internet for health are professionals is high

Q19 The quality of diabetes-related information on the Internet for consumers is high 
Q18 The quality of diabetes-related information on the Internet for health care professionals is high

$\mathrm{r}_{\mathrm{S}}$

Q4 I have adequate training in using computers

Q5 I use computers effectively in my practice

Q6 I am comfortable using the computer .168

Q7 Computer skills will help me as a professional .203

Q8 Computers increase my productivity

Q9 I participate in computer-based instructions .252

Q10 Computer is a good communications tool .302

Q11 Learning computers makes high demands on my time $e^{(\mathrm{a})}$ .238

Q12 I am developing expertise in using Internet in my practice .218

Q13 I spend a lot of time using the Internet ${ }^{(\mathrm{a})}$

Q14 I enjoy using the Internet

Q15 I have difficulty finding time to search for information online $e^{(a)}$

Q16 The Internet has enhanced my professional effectiveness $.327^{*}$

Q17 The Internet has improved the quality of education I deliver $.338^{*}$

Q19 The quality of diabetes-related information on the Internet for $.558 * *$ consumers is high

Q20 The Internet is a useful tool

(a) Negative statements that were coded in reverse are italicized.

* Correlation is significant at the 0.05 level (2-tailed).

** Correlation is significant at the 0.01 level (2-tailed). 
Q19 The quality of diabetes-related information on the Internet for consumers is high

$\mathrm{r}_{\mathrm{S}}$

Q4 I have adequate training in using computers

Q5 I use computers effectively in my practice

Q6 I am comfortable using the computer .068

Q7 Computer skills will help me as a professional .092

Q8 Computers increase my productivity

Q9 I participate in computer-based instructions .295

Q10 Computer is a good communications tool

Q11 Learning computers makes high demands on my time ${ }^{(\mathrm{a})} \quad-.142$

Q12 I am developing expertise in using Internet in my practice

Q13 I spend a lot of time using the Internet ${ }^{(\mathrm{a})}$

Q14 I enjoy using the Internet .168

Q15 I have difficulty finding time to search for information online $e^{(a)}$

Q16 The Internet has enhanced my professional effectiveness .186

Q17 The Internet has improved the quality of education I deliver

Q18 The quality of diabetes-related information on the Internet for health care professionals is high

Q20 The Internet is a useful tool

(a) Negative statements that were coded in reverse are italicized.

* Correlation is significant at the 0.05 level (2-tailed).

** Correlation is significant at the 0.01 level (2-tailed). 
Appendix I

Q8 Computers increase my productivity 
Q8 Computers increase my productivity

$\Gamma_{\mathrm{S}}$

Q4 I have adequate training in using computers

Q5 I use computers effectively in my practice

Q6 I am comfortable using the computer

Q7 Computer skills will help me as a professional

$.566 * *$

Q9 I participate in computer-based instructions

Q10 Computer is a good communications tool

Q11 Learning computers makes high demands on my time $e^{(\mathrm{a})}$

Q12 I am developing expertise in using Internet in my practice

Q13 I spend a lot of time using the Internet ${ }^{(\mathrm{a})}$

Q14 I enjoy using the Internet

Q15 I have difficulty finding time to search for information online ${ }^{(\mathrm{a})}$

Q16 The Internet has enhanced my professional effectiveness

Q17 The Internet has improved the quality of education I deliver

Q18 The quality of diabetes-related information on the Internet for health care professionals is high

Q19 The quality of diabetes-related information on the Internet for consumers is high

Q20 The Internet is a useful tool

(a) Negative statements that were coded in reverse are italicized.

* Correlation is significant at the 0.05 level (2-tailed).

** Correlation is significant at the 0.01 level (2-tailed). 
Appendix J

Q11 Learning computers makes high demands on my time Q13 I spend a lot of time using the Internet

Q15 I have difficulty finding time to search for information online 
Q11 Learning computers makes high demands on my time ${ }^{(\mathrm{a})}$

$\mathrm{r}_{\mathrm{S}}$

Q4 I have adequate training in using computers

Q5 I use computers effectively in my practice

Q6 I am comfortable using the computer

Q7 Computer skills will help me as a professional

Q8 Computers increase my productivity

Q9 I participate in computer-based instructions

Q10 Computer is a good communications tool

Q12 I am developing expertise in using Internet in my practice

Q13 I spend a lot of time using the Internet ${ }^{(a)}$

Q14 I enjoy using the Internet

Q15 I have difficulty finding time to search for information online ${ }^{(a)}$

Q16 The Internet has enhanced my professional effectiveness

Q17 The Internet has improved the quality of education I deliver

Q18 The quality of diabetes-related information on the Internet for health care professionals is high

Q19 The quality of diabetes-related information on the Internet for consumers is high

Q20 The Internet is a useful tool

(a) Negative statements that were coded in reverse are italicized.

* Correlation is significant at the 0.05 level (2-tailed).

** Correlation is significant at the 0.01 level (2-tailed). 
Q13 I spend a lot of time using the Internet ${ }^{(\mathrm{a})}$

$r^{\mathrm{s}}$

Q4 I have adequate training in using computers

Q5 I use computers effectively in my practice

$-.391 *$

Q6 I am comfortable using the computer

Q7 Computer skills will help me as a professional

$-.072$

Q8 Computers increase my productivity

Q9 I participate in computer-based instructions

Q10 Computer is a good communications tool

Q11 Learning computers makes high demands on my time ${ }^{(\mathrm{a})}$

Q12 I am developing expertise in using Internet in my practice

$-.550 * *$

Q14 I enjoy using the Internet

$-.485 * *$

Q15 I have difficulty finding time to search for information online $e^{(a)}$

$-.588 * *$

Q16 The Internet has enhanced my professional effectiveness

$-.628 * *$

Q17 The Internet has improved the quality of education I deliver

Q18 The quality of diabetes-related information on the Internet for health care professionals is high

Q19 The quality of diabetes-related information on the Internet for $-.066$ consumers is high

Q20 The Internet is a useful tool

(a) Negative statements that were coded in reverse are italicized.

* Correlation is significant at the 0.05 level (2-tailed).

** Correlation is significant at the 0.01 level (2-tailed). 
Q15 I have difficulty finding time to search for information online ${ }^{(a)}$

$\mathrm{r}_{\mathrm{S}}$

Q4 I have adequate training in using computers

Q5 I use computers effectively in my practice

Q6 I am comfortable using the computer

Q7 Computer skills will help me as a professional

Q8 Computers increase my productivity

Q9 I participate in computer-based instructions

Q10 Computer is a good communications tool

Q11 Learning computers makes high demands on my time ${ }^{(\mathrm{a})}$

Q12 I am developing expertise in using Internet in my practice

Q13 I spend a lot of time using the Internet ${ }^{(\mathrm{a})}$

Q14 I enjoy using the Internet

Q16 The Internet has enhanced my professional effectiveness

Q17 The Internet has improved the quality of education I deliver

Q18 The quality of diabetes-related information on the Internet for health care professionals is high

Q19 The quality of diabetes-related information on the Internet for consumers is high

(a) Negative statements that were coded in reverse are italicized.

* Correlation is significant at the 0.05 level (2-tailed).

** Correlation is significant at the 0.01 level (2-tailed). 


\title{
CURRICLUM VITA
}

\author{
Graduate School \\ West Virginia University.
}

\begin{abstract}
Name: $\quad$ Elizabeth Quintana
Address: $\quad 1417$ Dogwood Avenue, Morgantown, WV 26505

E-mail: liz_quintana7246@yahoo.com
\end{abstract}

State University College

Plattsburgh, New York

Bachelor of Science in Home Economics May 1970

Texas Tech University

Lubbock, Texas

Master of Science in Nutrition, August 1972

West Virginia University

Morgantown, West Virginia

Doctor of Education, December 2008 